\title{
Food for deliberation \\ Philosophical reflections on responsible innovation in the business context
}

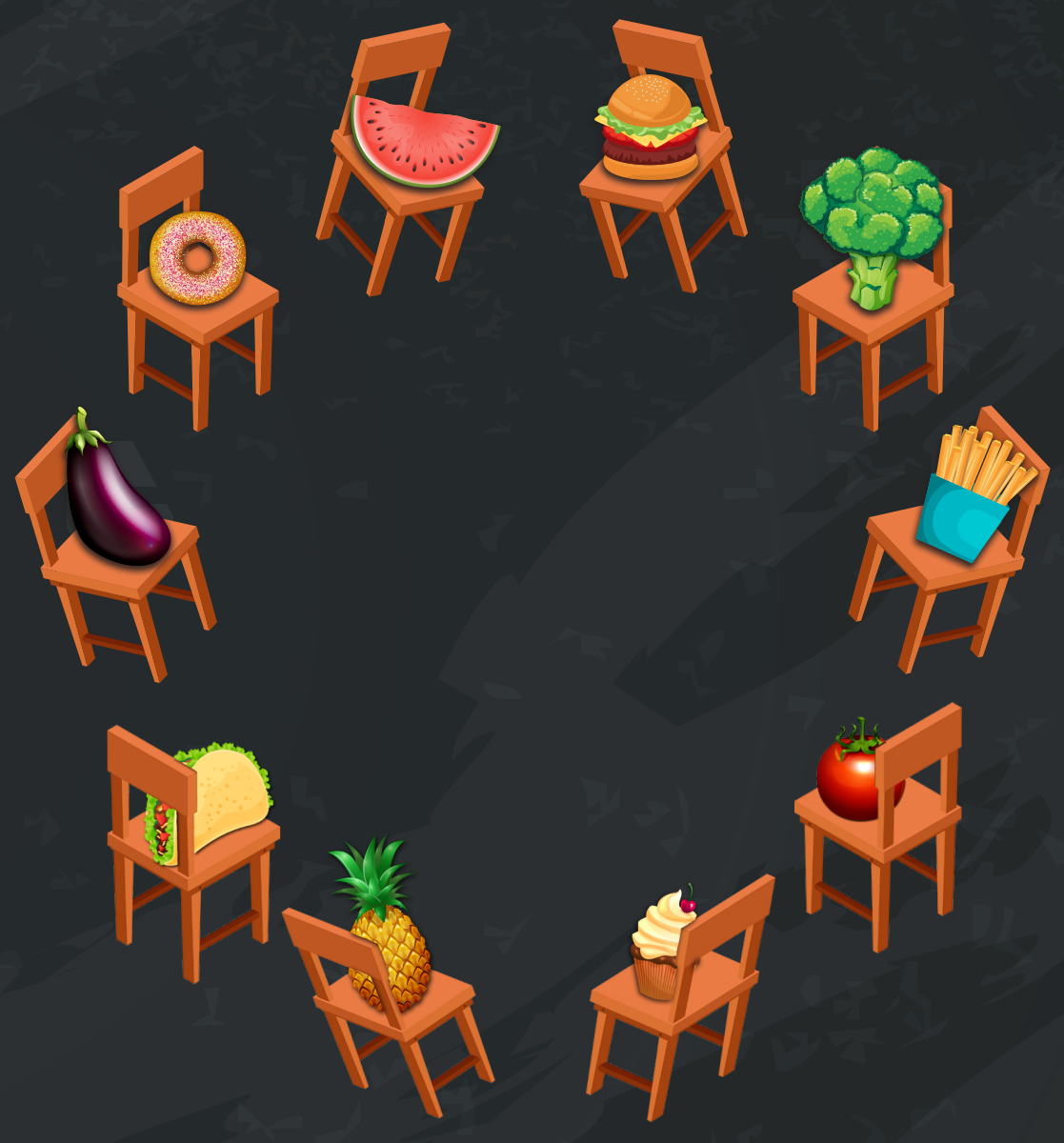

Teunis Brand 



\section{Propositions}

1. A good dialogue between companies and stakeholders about societal issues does not preclude conflict nor considerations of self-interest.

(this thesis)

2. Innovation of food products and services should contribute to the engagement of people with their social and natural environment. (this thesis)

3. Basic moral beliefs do not need rational justification to be rationally held.

4. The academic focus on publishing in top journals is more problematic for the social sciences compared to the natural sciences.

5. The difficulty of overseeing a deadline of four years negatively affects the productivity of PhDs.

6. The proverb "he who increases knowledge increases sorrow" is applicable to the eater's knowledge about the nutritional composition of food.

7. Working with our hands, and the creativity and intelligence needed for it, require revaluation in our society.

Propositions belonging to the thesis, entitled

Food for deliberation: philosophical reflections on responsible innovation in the business context

Teunis Brand

Wageningen, 10 maart 2020 



\section{Food for deliberation}

Philosophical reflections on responsible innovation in the business context

Teunis Brand 


\section{Thesis committee}

\section{Promotors}

Prof. Dr M.F. Verweij

Professor of Philosophy

Wageningen University \& Research

Dr V. Blok

Associate Professor Sustainable Entrepreneurship, Business Ethics and Responsible Innovation

Wageningen University \& Research

\section{Other members}

Prof. Dr P.M. Macnaghten, Wageningen University \& Research

Prof. Dr T.E. Swierstra, Maastricht University

Prof. Dr R.J.M. Jeurissen, Nyenrode Business University, Breukelen

Dr E.H.W.J. Cuppen, Delft University of Technology

This research was conducted under the auspices of the Wageningen School of Social Sciences (WASS). 


\section{Food for deliberation \\ Philosophical reflections on responsible innovation in the business context}

\section{Teunis Brand}

\section{Thesis}

submitted in fulfilment of the requirements for the degree of doctor at Wageningen University by the authority of the Rector Magnificus, Prof. Dr A.P.J. Mol, in the presence of the Thesis Committee appointed by the Academic Board to be defended in public on Tuesday 10 March 2020 at 4 p.m. in the Aula. 
Teunis Brand

Food for deliberation

Philosophical reflections on responsible innovation in the business context 180 pages

$\mathrm{PhD}$ Thesis, Wageningen University, Wageningen, the Netherlands (2020) With references, with summaries in English and Dutch.

ISBN: 978-94-6395-247-7

DOI : https://doi.org/10.18174/509524 


\section{TABLE OF CONTENTS}

$\begin{array}{lll}\text { Chapter } 1 & \text { Introduction }\end{array}$

Chapter 2 Responsible innovation in business

Chapter 3 Stakeholder dialogue as agonistic deliberation

51

Chapter 4 Tensions in stakeholder interaction

Chapter $5 \quad$ Commodity or focal thing?

Chapter $6 \quad$ Conclusions and discussion

References

Summary

Samenvatting

Acknowledgements

WASS completed training and supervision plan

178

Colophon 



\section{CHAPTER 1}

\section{INTRODUCTION}




\section{CHAPTER 1 INTRODUCTION}

On the $21^{\text {st }}$ of April 2016, a public debate was organized to discuss a front-of-pack health label in The Netherlands, called 'Het Vinkje'. This label was issued by the foundation Ik Kies Bewust, which had as goal to inform consumers about healthy choices and to stimulate healthy food product innovation. On the same day as the public debate, a group of food professionals and activists published a very critical article about the label, in which they wrote the following lines:

“...the public interest clashes very strongly with business interests in this case. The motives behind it [the label] are impure, it serves a different goal. (...) Health is our greatest good. This good is not safe in the hands of a sophisticated corporate lobby, which aims to maximize profits."

With this quote, we have arrived at the heart of the problems that are central to this thesis. This quote signals something about the perception that people have concerning the relation between commercial goals and public interests like public health. In this case, the writers of the opinion piece consider there to be a rather strong conflict between the two. It can be difficult for companies to engage in dialogue with such critical stakeholders about issues that affect public interests like health (given that the stakeholders themselves are willing to have a discussion at all). One of the questions that will be central in this thesis is how we should deal with tensions between commercial objectives and public interests in the interaction between companies and their stakeholders.

The research project of which this $\mathrm{PhD}$ thesis is a part, is called 'Motivations, drivers, and barriers for responsible innovation in the Dutch food sector: the influence of a healthy food logo on the innovation agenda for healthy food'. The label that we used as a case was 'Het Vinkje', which I referred to above. The Dutch Choices Foundation (Stichting Ik Kies Bewust) that issued the label was involved in the research project as co-funder and project partner. Within this project, it was my role to reflect from a normative-ethical perspective on the meaning and challenges of responsible innovation in the context of business in general, and the food industry in particular.

The focus on deliberation in the main part of this thesis has to do with its centrality in the existing research on responsible innovation (RI). RI shortly means that social and ethical aspects of innovation are taken into account in the innovation process. Researchers within this field have argued that this can only be properly done by opening up the innovation process to a wide set of stakeholders and to members of the public (Brand \& Blok, 2019; Burget, Bardone, \& Pedaste, 2017; 
Owen, Macnaghten, \& Stilgoe, 2012). Yet, even though stakeholder and public deliberation is considered to be a central element of RI, it appeared to me that there was relatively little critical reflection on this element, especially concerning the challenges that come with it in the business context. In my view, and as I will argue in this thesis, the challenges that come with deliberation in the business context require to reconsider it as central ideal of RI. The series of stakeholder dialogues organized by the Dutch Choices Foundation made it possible to do some qualitative empirical research about how deliberation works in practice.

Chapter 2, 3, and 4 of this thesis are all aimed at achieving a better understanding of the challenges that come along with stakeholder engagement and dialogue within the business context. Chapter 2 connects the research on RI to theories of business ethics. For chapter 3 and 4, I decided to approach the issue of stakeholder engagement and dialogue from the literature on business ethics and Corporate Social Responsibility (CSR). The reason is that stakeholder engagement can be used not only when reflecting on the social and ethical aspects of innovation, but basically for all different kinds of activities of companies that have a societal impact.

Chapter 5 has a special place in this thesis. In this chapter, I reflect from the perspective of the philosophy of technology of Albert Borgmann on the place of engagement with food (innovation) in a life well-lived. Although this is a rather different topic compared to the other chapters in this thesis, there were good reasons to take this route. First, despite the fact that the research project is specifically about RI in the food industry, chapter 2 to 4 provide little specific attention to this domain of literature and to food (apart from providing the context of research in the case-study of chapter 4). Yet, I wanted to include also some reflections on the ethical aspects of food (innovation) in this thesis. Second, research on RI focuses very much on what it means to govern an innovation process responsibly. This results in general guidelines for innovation processes which are meant to be suitable for different contexts or sectors. Although this procedural approach has its value, it should - in my view - be complemented by substantive ethical and philosophical reflection. This requires to take into account the nature and context of specific kinds of innovations. Third and last, I wanted to reflect critically on the assumption which seems to be widely accepted in the field of RI, namely that we need technological innovation to address the problems and challenges of our time (von Schomberg and Blok 2018; Blok and Lemmens 2015). To me, this assumption is far from self-evident. For example, should we take for granted that we need technological innovation to make food healthier? In order to answer the question what responsible food innovations are, we need to have some idea about what place food has in a good life, and what the role of technology in our relation 
to food should be. Philosophy of technology is an appropriate place to look for answers to these questions. Especially the philosophy of Albert Borgmann was helpful in this regard, because he explicitly reflected on the relation between technology and the good life, and also illustrated his view often with examples about food, cooking, and sharing meals.

The remainder of this introductory chapter is organized as follows. I will introduce the main theories and concepts I make use of in the different chapters, and explain how they relate to the topics of this thesis. I will start by introducing the concept of RI. After that, different theories of business ethics are introduced, in which I focus especially on the role of stakeholder engagement within those theories. Lastly, I provide a very brief introduction to the philosophy of technology of Albert Borgmann, which can be taken as a stepping stone for chapter 5. This introductory chapter closes with a brief overview of the chapters that form the body of this thesis.

\subsection{Responsible Innovation and the centrality of deliberation}

The field of Responsible Innovation (RI) is a relative new field of research, which combines earlier approaches to the governance of research and innovation (de Saille, 2015). The overall goal of RI is to take into account the social and ethical aspects of innovation from the start of innovation processes, and hence to move beyond the focus on economic benefits. Its main concern and starting point is the question what we want science and innovation to bring into the world (Owen, et al., 2013, p. 34). In this way, RI is not only meant to anticipate unintended consequences and risks of emerging technologies, but also to be proactive: concerned with reflecting on the desirable direction of innovation (Ribeiro et al., 2017). Many authors on RI stress the limitations of a reactive approach to the governance of innovation which is dominant in many regulations (e.g. Lee \& Petts, 2013). Regulation is often about what should not happen: it puts risks, restrictions and prohibitions at the centre. In the RI literature, different reasons are given for the limits of a top-down regulatory approaches to the governance of innovation (Owen et al., 2013; von Schomberg, 2013). First, rules and regulation are rooted in knowledge that is obtained by past experience, and thus is insufficient to be directive for new developments or products of which the effects are unknown. Second, a natural response to risk and uncertainty is to take precautionary measures, but strict precautionary measures can impede innovation. Third, as a consequence of the former limitations, the regulatory approach to the governance of innovation often fails to direct innovation towards socially desirable ends. It can only set limits on certain undesirable outcomes of innovation. The proactive approach to RI becomes visible in the prospective use of 
the concept of responsibility (to take responsibility to do something), over against a retrospective use (responsibility as accountability and liability). As Grinbaum and Groves put it, "the responsibility associated with innovation [is] necessarily responsibility for the future it helps to create" (2013, p. 119). In taking a proactive and prospective approach to responsibility, RI aims to go beyond constraining and limiting innovation towards caring for and directing it.

Inextricably connected to this proactive orientation is the question how the direction of innovation is to be determined. Many authors in RI argue that this question has to be answered through some form of stakeholder and public engagement in the innovation process (van Lente, Swierstra, \& Joly, 2017). The 'framework for responsible innovation' as developed by Stilgoe, Owen, and Macnaghten embodies this commitment to the 'democratization' of innovation (Stilgoe et al., 2013; Owen et al., 2013; Owen, 2014; Owen et al., 2012). Democratization of innovation implies that innovation processes should be organized more inclusively, so that a broad set of stakeholders can have a say about the social and ethical aspects that need to be taken into account. In this vain, Owen and colleagues argue that RI "has a primary purpose to democratically open up and realise new areas of public value for science and innovation", and thus "suggests a need for substantive processes of inclusive reflection and deliberative democracy" (Owen et al., 2012, pp. 754, 755).

The shift in the division of responsibilities from governments and individual innovators towards innovators in cooperation with stakeholders and society as proposed in the RI framework entails not only democratization, but also a moralization of the innovation process. ${ }^{1}$ It entails moralization because innovators are assigned more responsibility for the social and ethical aspects of innovation than in the traditional division of moral labour. According to Ribeiro et al. (2017, p. 84), this reflects "an existing yet growing plea for a much more explicit acknowledgement of the inherently value-laden nature of science and technology". RI implies that innovators cannot simply shift the responsibility for the social and ethical aspects of technology to the users of their products or to the government, but that they should anticipate moral concerns and accommodate them into the design of products (van den Hoven, 2013).

The distinction between moralization and democratization is not made in the literature on RI itself. Sometimes, a related distinction is made between product and process approaches (Koops, 2015; cf. Ruggiu, 2015). The product approach consists of a normative framework that aims to incorporate values and norms into

1 The distinction between moralization and democratization is comparable with the distinction between moralization and politicization made by Dubbink and Van de Ven (2012) and Dubbink and Van Liedekerke (2014). 
technologies. This approach can be seen as an attempt to moralize technology. An example of this approach is Value Sensitive Design (van den Hoven, 2013). The process approach does not define values in advance, but prescribes an innovation process that is procedurally responsible. In the process approach, it is assumed that increased responsibility for social and ethical aspects of innovation implies a democratization of the innovation process, in the form of deliberative and participatory governance mechanisms. The framework of RI developed by Owen, Stilgoe, and Macnaghten (Owen, Stilgoe, et al., 2013; Stilgoe et al., 2013) is the predominant example of this approach.

As there is not one uniform approach to RI, some authors put more emphasis on what I call moralization (such as van den Hoven, 2013), while others put more emphasis on democratization (Stilgoe, Owen, and Macnaghten 2013; von Schomberg 2013). Although moralization does not necessarily entail democratization and vice versa, most often the different approaches to RI show a mix of both. For example, deliberation with stakeholders can be a means to integrate ethical and societal values into innovations. Hence, Timmermans and Blok (2018) conclude that the "the active involvement of societal actors and stakeholders" is central to most approaches of RI.

\subsection{Deliberation in theories of business ethics}

Since the aim of this thesis is to reflect on RI in the context of business, it makes sense to make the connection to the field of business ethics. Very generally, scholars in this field reflect on the kind of responsibilities companies have, and do research on how companies exercise these responsibilities in practice. The field of business ethics therefore has a normative and a descriptive component. ${ }^{2}$ In this thesis, the focus is on normative theories of business ethics, and specifically on the place of stakeholder engagement within these theories. In what follows, I introduce two normative approaches to business ethics which give a central place to deliberation: stakeholder theory and political CSR. After that, I shortly discuss some criticism that has been raised against these views, especially concerning the role of deliberation.

\footnotetext{
2 The descriptive work of most often carried out under the header of Corporate Social Responsibility (CSR), while the term business ethics is more often used for normative-ethical reflection on the behaviour of people in business (Norman, 2013a). This distinction, however, is not strict.
} 


\section{Stakeholder theory}

The general question for stakeholder theory is in whose interests a firm should be managed. Stakeholder theory is often presented as an alternative to shareholder theory (Freeman, 2002). According to shareholder theory, managers have a fiduciary duty to act in the interest of their shareholders, which are considered to be the owners of the firm (Friedman, 1970; Jensen \& Meckling, 1976). ${ }^{3}$ This means that the relation between managers and shareholders is one of agent and principal: the shareholder (principal) entrusts the care for the firm to the manager (agent). According to shareholder theorists, one of the main reasons to give this special place to shareholders is that they are the bearers of residual risk, since their remuneration is not specified in a contract (which is the case with other stakeholders, like employees or debt-financers). Stakeholder theorists, however, argue that the special place of shareholders is unjustified. In their view, it is the duty of management to act in the interests of all stakeholders of a firm.

If managers should act in the interests of all stakeholders, the question arises who counts as stakeholder. Stakeholders have been broadly understood as "any group or individual that can affect or be affected by the realization of an organization's purpose" (Freeman, Harrison, Wicks, Parmar, \& de Colle, 2010, p. 26). If we take this broad definition, not only employees and financers, but also customers and competitors count as stakeholders. Clearly, these different groups do not only have different, but also conflicting interests. Whose interests should be given priority in corporate decision-making? The broad definition of Freeman is not of much help in answering this question. Different authors have developed different answers, for example by distinguishing between normative and derivative stakeholders (Phillips, 1997, 2003a, 2003b) or by distinguishing between the legitimacy and urgency of their claims (Mitchell, Agle, \& Wood, 1997). Even though these distinctions are helpful, the issue how to balance the interests of different stakeholders is thereby not settled. Probably this question cannot be answered by theorizing, but only in practice and in the actual interaction with different stakeholders.

Stakeholder theory has received quite some criticism over the years, which often circles around similar themes. One of these themes is its vagueness. It is often not clear what the concrete implications of stakeholder theory are: how should companies balance different interests, what does it mean that different interests should be balanced, and what are the implications of stakeholder theory for

\footnotetext{
${ }^{3}$ In this regard, it is relevant to notice that the conception of shareholders as owners of a corporation is misleading (Ciepley, 2013). Shareholders own their shares, and they have certain rights vis-à-vis corporations, but they do not own (a part of) a corporation. 
corporate governance (Orts \& Strudler, 2009). In response to this criticism, stakeholder theorists have argued that stakeholder theory should be seen as an approach to doing business, and as a way of thinking, but not as a rigorous theory (Freeman et al., 2010; see also Norman, 2013a). Freeman, for example, has even argued that stakeholder theory is compatible with shareholder theory. Underlying this view is the claim that "there is no conflict between serving all your stakeholders and providing excellent returns for shareholders" (George, 2003; quoted in Freeman et al., 2010, p. 27). The claim that behaving ethically (by addressing stakeholder interests) is not in conflict with economic value creation is a recurrent one in stakeholder theory (Freeman, 1994; Noland \& Phillips, 2010). Without denying that economic value creation and ethical behaviour can go together, I think it is important to recognize that there can be tensions between these two. Especially situations in which such tensions arise, are interesting for business ethicists, for moral dilemmas often have to do with conflicting values and interests. This is also what we will see throughout this thesis: all chapters about deliberation deal with tensions between different values and interests.

\section{Political Corporate Social Responsibility}

Political CSR asks the question how firms should behave as political actors (Néron, 2010; Scherer \& Palazzo, 2007, 2011; Scherer, Rasche, Palazzo, \& Spicer, 2016; Whelan, 2012). Changes in the context in which companies operate requires this shift in attention, or so political CSR scholars argue. The keyword in these changes is globalization. Today, many corporations operate in a lot of different countries at the same time, which creates a lot of challenges. How should they deal with differences in regulation? How should they operate in countries in which nation states are weak or in which there is a lot of corruption? What kind of responsibilities do those multinationals have towards weak or poor nation states? And how should they relate to the political sphere in general (also vis-à-vis developed countries), given their size and corresponding influence and power? Given the change in context, political CSR scholars argue that corporations are not merely economic actors but also political actors, since they "co-create their institutional environment" (Scherer et al., 2016, p. 274). This happens, for example, when corporations assist in the provision of public goods, or when they contribute to collective decision-making about public goods.

According to the theory of Political CSR, corporations have a special responsibility to engage in political activities in contexts "where public authorities are unable or unwilling to fulfil this role” (Scherer et al., 2016, p. 274). Yet, that does not mean that corporations can do what they consider to be best. Their political activities requires a form of political legitimacy (Palazzo \& Scherer, 2006). Political 
CSR scholars build on the theory of deliberative democracy in their conceptualization of democratic legitimacy. The ideal of deliberative democracy has the following three characteristics: (1) it is talk-centred, (2) consensus-oriented, and (3) aims at participation of those affected by policies. ${ }^{4}$ With regard to the first element, the type of talk that deliberative democrats foster is deliberation, a mode of communication in which participants mutually justify their positions, and are mutually responsive to each other's views (Thompson, 2008). ${ }^{5}$ The orientation towards consensus is inherently connected to the first element, since it is the preferred outcome of a deliberative process (Cohen, 1997). This inherent connection has to do with the nature of deliberation: it presupposes that, in principle, people can change their mind, and hence that there is a possibility of consensual agreement. As a matter of fact, consensus will not always be achieved, and in most instances other ways of reaching agreement (such as through voting) will be necessary as a complement to deliberation. However, a crucial feature of deliberation is its potentially transformative character, implying that views and preferences are endogenous to the process of deliberation. With regard to the participative element, a classic formulation of deliberative legitimacy is formulated as follows: "outcomes are legitimate to the extent they receive reflective assent through participation in authentic deliberation by all those subject to the decision in question" (Dryzek, 2002, p. 651, emphasis added). Thus, most deliberative democrats embrace a certain participatory ideal, to give a voice to those who are affected by a decision. ${ }^{6}$

\footnotetext{
${ }^{4}$ All these element can be found, in varying degrees, in the major works on deliberative democracy (e.g. Cohen, 1997; Dryzek, 2002; Gutmann \& Thompson, 1997; Habermas, 1998). However, none of these elements is uncontested. There is a lot of discussion about what kinds of talk can be allowed within deliberation, whether deliberation should have consensus as a goal (or whether compromise is also appropriate), and whether deliberative democracy can have a place within electoral-representative democracy.

${ }^{5}$ Note that I do not specify what counts as mutual justification. Among deliberative democrats, there is disagreement whether only reasonable arguments (that appeal to the common good) count as justification (Cohen, 1997), or whether self-interest (Mansbridge, 2006; Mansbridge et al., 2010), rhetoric, stories, and testimonies (Dryzek, 2002) can also have a place within deliberation.

${ }^{6}$ Although the ideal of citizen participation is widely shared among deliberative democrats, I have to notice again that this ideal is not uncontested. First of all because it runs against practical limitations. As Walzer has noted: 'Deliberation is not an activity for the demos (...) 100 million of them, or even 1 million or 100,000, cannot plausibly "reason together." ( Walzer, 1999, p. 68; see also Dryzek, 2001). More fundamentally, Rummens (2012) has argued that there is a necessary connection between democracy and representation. 
According to political CSR scholars, companies should embrace the ideal of deliberative democracy, implying that they have to engage in deliberation with stakeholders and society about their political activities, in order to build legitimacy for those activities. The idea is that, in this way, deliberation functions as a kind of democratic control on corporations.

\section{Criticism on deliberative approaches to business ethics}

Both stakeholder theory and political CSR argue that it is important to engage in deliberation with stakeholders. It can be said that political CSR goes further than stakeholder theory, because it aims to broaden the dialogue to a societal or political level. Hence, in this view, not only persons or groups with a direct stake in a company should be involved, but also those indirectly affected by companies' activities (such as citizens and citizen groups).

Different authors have asked the question whether it is desirable that companies receive a bigger political role by engaging them in deliberative processes. For example, Dubbink and Van de Ven (2012) have argued that political CSR does not take the backside of the politicization of the market sufficiently into account. This backside consists in serious risks that companies abuse their power by using deliberation for lobbying purposes, or by influencing public policies in ways that do not serve the public interest. In liberalism, these risks provide reasons to conceptualize the market as apolitical, and hence to clearly distinguish the political and economic sphere (Dubbink \& Van Liedekerke, 2014; Mäkinen \& Kasanen, 2016).

A second kind of criticism is that deliberation in the market conflicts with the competitive nature of the market (Heath, 2006; Sabadoz \& Singer, 2017). Competition and the orientation to profit, so this criticism goes, make companies illsuited to engage in deliberation. The reason is that deliberation requires to set aside one's self-interest, to refrain as much as possible from the use of power and from bargaining, and instead to exchange reasons and arguments. This all is in tensions with the idea that the market is largely based on bargaining (Sabadoz \& Singer, 2017) and that operating in the market entails a permission to pursue one's particular interests (Heath, 2019).

A third line of criticism is brought forward by Hussain and Moriarty (2018). Their argument goes as follows: if we accept that certain corporate activities (especially those that influence the public sphere) require democratic legitimacy, it does not follow that corporations should themselves take part in deliberation. In their view, corporations cannot be functionary and supervising authority at the same time. If they are indeed functionaries (meaning that they are accountable to those subject to their activities), they should be democratically controlled by those subject 
to their activities, but not (partly) by themselves. From this view it would follow that, even when the activities of companies require democratic legitimacy, companies themselves are not the proper organizations to take part in deliberation.

Altogether, there are various kinds of criticism on the idea that companies should take part in deliberative processes. While some critics focus more on the practical difficulties of having genuine deliberation with companies, others raise more fundamental problems. Of course, the extent to which deliberation with companies is problematic will also depend on the kind of deliberative processes that companies engage in. At least, those who argue for the importance of deliberation between companies and their stakeholders will have to deal with this criticism. In this thesis, I will further explore what the problems of deliberation in the business context are, and how these problems affect the interaction between stakeholders. Although we should not abandon the whole idea of deliberation in the business context, I will argue that we need to recognize its limits and conceptualize it in way that accounts for its potential problems.

\subsection{Borgmann's philosophy of technology}

As said before, the focus on deliberation originated due to its centrality in the literature on RI. RI, however, is more than deliberation. This concept can be used to reflect from different angles on the ethical and social aspects of innovation. One of the angles is the innovation process, and another angle is to assess more specifically specific products or groups of products. In chapter 5 of this thesis, I take the latter angle. In a way, this chapter can be seen as both zooming in and zooming out. It zooms in on food, since food receives little attention in the other chapters. It zooms out, because it does not deal with specific innovations, but with more general patterns of the role of technology in our dealing with food.

For chapter 5, I make extensive use of Albert Borgmann's philosophy of technology, and use it to understand and analyse different ways in which people can relate to food (Borgmann, 1988, 1993). In this introductory section, I want to introduce Borgmann's philosophy in a somewhat broader way, and give some special attention to the relation of his philosophy to other approaches in the philosophy of technology. The application to food will be reserved for the fifth chapter.

Among philosophers of technology, Borgmann has developed his own distinct position. This position could probably best be clarified by using the typology he has developed himself to describe the different strands in the philosophy of technology. 
This typology distinguishes three approaches: the substantive ${ }^{7}$, the instrumentalist, and the pluralist view (Borgmann, 1988, p. 9). In the substantive view, technology is conceived as an independent and autonomous force, which develops itself over time and dominates other societal forces. The philosophy of technology of Jacques Ellul is, according to Borgmann, a clear example of the substantive view, but also Martin Heidegger conception of technology falls within the scope of the first type (Ellul, 2011; Heidegger, 2013). Both Heidegger and Ellul consider technology to be the most characteristic and dominant force in today's societies. Although Borgmann would probably agree with this, he considers the substantive view to be problematic for two main reasons. First, it is deterministic, and hence leaves no room for human freedom vis-à-vis technology, and consequently also not for the possibility to reform technology (a possibility in which Borgmann does believe). Second, the substantive approach explains everything with technology, but leaves technology itself unexplained. ${ }^{8}$

The instrumentalist view of technology is probably the most common-sense view of technology. It considers technology to be a value-neutral instrument: specific technologies are not good or bad in themselves, but can be used for good and bad ends. This approach can therefore also be considered to be anthropocentric: human beings determine the use of technology. Because of the emphasis in this view on human responsibility and freedom, it can be conceived of as the opposite of the substantive approach. Borgmann acknowledges that there are grains of truth in the instrumentalist view as well. However, his problem with this view is that it does not problematize the distinction between value-neutral means and ends. According to Borgmann, this distinction is typical for modern technology. The instrumentalist view therefore obscures that modern technology has a specific pattern.

The pluralist approach occupies a middle position between the substantive and instrumentalist view. Central in this approach is the recognition that technology and human beings co-shape each other, and analyses of how this process of co-shaping works. Philosophers of technology who take this approach often study the effects of

\footnotetext{
${ }^{7}$ In his typology of approaches to philosophy of technology, Borgmann uses the term substantive in a specific way, namely to designate essentialist and deterministic approaches. In this thesis, I sometimes use the word substantive to distinguish between procedural and substantive approaches to RI. Where procedural approaches focus on the innovation processes, substantive approaches aim to evaluate the content of innovations themselves from a normative point of view. My use of the term should therefore be distinguished from Borgmann's use.

${ }^{8}$ Borgmann mentions this second criticism especially in relation to Ellul's approach. I am not sure whether it is also a possible criticism on Heidegger, since Borgmann's own philosophy is much closer to Heidegger's compared to Ellul's.
} 
specific technologies on human behaviour and their environment. The move to the analysis of the impact of specific technologies has been called the 'empirical turn' in the philosophy of technology (Achterhuis, 2001). Two well-known philosophers of technology that Borgmann would qualify as pluralists are Don Ihde (e.g. 1979) and Peter-Paul Verbeek (e.g. 2005). Both stress the manifold ways in which technology mediates and influences the relation between people and reality (see also Keulartz, Schermer, Korthals, \& Swierstra, 2004). Although Borgmann's own philosophy is also influenced by the empirical turn (given the attention he gives to specific technologies and to empirical research about technology), his criticism on the pluralist approach is comparable to his criticism on the instrumentalist approach. He argues that the pluralist approach, by focusing on individual technologies and their complexities and ambiguities, loses sight of the bigger picture, namely the typical pattern that modern technology exhibits.

Borgmann himself tries to take into account the strong elements of each view, while avoiding their weaknesses. In my view, his position is best seen as a combination of the substantive and the pluralist view. With the substantive approach, he shares the search for the essence of modern technology. At the same time, Borgmann preferably talks about the paradigm or pattern instead of the essence of modern technology, as these terms allow him to make room for exceptions. He shares the attention to empirical research with the pluralist view. In his view, findings from the social sciences can and should inform the claims of the philosopher of technology.

The pattern by which Borgmann characterizes modern technology is called the 'device paradigm'. This pattern entails that modern technology (and specifically technological devices) tends to make commodities available in an instantaneous, ubiquitous, safe, and easy way. In making commodities available, the means (the devices) are concealed as much as possible, in such a way that the consumer of the commodities does not have to bother about the technological means. Henceforth, there is a split between means and ends: the means are the domain of the technological expert, and the ends the domain of the consumer. Borgmann also calls these two domains the background and the foreground of technology. To give an example: a CD player is designed to play music. How this exactly works is incomprehensible and inaccessible for ordinary consumers. It is also not necessary to know this in order to be able to use this device.

The device paradigm stands in contrast with focal things and practices. Contrary to devices, dealing with focal things requires engagement and skill. For example, making music is a focal practice, and in this practice the music is the focal thing. In focal things and practices, there is no gap between means and ends, experts and lay people. Ordinary persons can learn to make music, even though this requires 
practice. In making music, the language of means and ends seems even out of place: making music by yourself is not simply the means towards enjoying music, but the process of making it is also valuable in itself. ${ }^{9}$

According to Borgmann, modern technology has big benefits, but also has its problems. The benefits are quite clear: technology has strongly contributed to the increase in welfare, exemplified by developments in medicine, food production, comfort in houses, transportation, and so on. Borgmann, however, pays a lot of attention to the negative side of modern technology. He is especially critical on the disburdening side of the device paradigm. He argues that disburdenment leads to disengagement, and consequently to lack of skill, superficiality, loss of meaning, and eventually to loss in happiness. Although these are quite strong claims, Borgmann tries to support them with empirical evidence. So, if Borgmann is right that engagement and exercise of skill are crucial for living a good life, we have good reasons to be concerned about the effects of technology. Yet, Borgmann does not argue that technology should be abandoned. It has to be decentred, in order to make room for focal things and practices, through which people can exercise skill and have a meaningful relationship with things.

What does Borgmann's philosophy imply for how we deal with food? We might ask to what extent our way of dealing with food is characterized by the device paradigm. Another question is to what extent engagement is important in our relation to food. Beyond that, it is important to reflect on the implications of Borgmann's ideas for food innovation: should it foster engagement, and if so, how? These questions will be addressed in the last chapter.

\subsection{Overview of the chapters}

Chapter 2 - Central to RI is the idea that innovation processes should be opened-up to stakeholders and the wider public. More specifically, innovators have to engage in deliberation with stakeholders and members of the public about innovation. Although RI scholars assume that the centrality of deliberative engagement is just as important for innovation in the business context compared to other contexts (like research and innovation in universities and research institutes), this assumption has received little critical reflection. For this reason, the question I raise in chapter 2 is whether the ideal of deliberative engagement is an appropriate ideal for application in the context of the competitive market. Based on existing literature, I identify three tensions between the ideal of deliberative engagement and the competitive market:

\footnotetext{
${ }^{9}$ Much more can be said about focal things and practices. For a more in-depth discussion of these concepts, see Borgmann (1988, pp. 196-210), Haworth (2000), and Brittan (2000).
} 
when companies engage in deliberation with stakeholders and the wider public about their innovation strategy, this might result in conflicts with their (1) innovative capacity, (2) competitive advantage, and their (3) corporate governance structures. I argue that these tensions are persistent, because underlying them is a basic tension between exit - the mechanism of the market - and voice - the political mechanism (Hirschman, 1970). In order to see how theories of business ethics deal with this tension, I scrutinize different theories of business ethics and the place they give to deliberative engagement. However, also in these theories, these tensions receive quite little attention. The chapter closes with a discussion of how RI scholars should deal with the tension between the ideal of deliberative engagement and the way in which the competitive market works. In my view, it means that RI scholars should modify the ideal of deliberative engagement so that it fits better to the business context, or they should recommend changes in the institutional conditions of the market that would make deliberation more suitable.

Chapter 3 -This chapter critically assesses the ideals of deliberative engagement itself. I address it from a normative point of view: what should the goal of stakeholder dialogue be, and to what extent is there a place for conflict and selfinterest in a dialogue? The focal point for the analysis is the interaction between companies and non-governmental organizations (NGOs), because the latter typically represent and defend societal values. In the literature on stakeholder dialogue, it is often assumed that consensus is the proper aim and the preferred outcome of dialogue. Since self-interested considerations (about reputation, profit, and so on) hinder the achievement of consensus, their presence in a dialogue is considered to be a stumbling block that has to be removed. In this chapter, I criticize this view. I argue that companies cannot be expected to set aside their commercial interests in a dialogue, because it is constitutive for the functioning of the market that companies are allowed to pursue their particular interests. Furthermore, a focus on consensus can also be problematic for NGOs, because it is their societal role to address problems associated with the behaviour of companies, and to challenge or criticize them. I present agonistic deliberation as an alternative to a consensus-oriented stakeholder dialogue. In this kind of deliberation, conflict and self-interest have (up to a certain point) a legitimate place.

Chapter 4 - If deliberation between companies and their societal stakeholders comes with conflict and tensions, the question is how this affects the actual interaction between stakeholders. For chapter 3, I conducted a case-study of a series of stakeholder dialogues between food companies and their stakeholders. The topic under discussion was a front-of-pack health label, meant to inform consumers about healthier choices and to stimulate healthy product innovation. In my analysis, I focused specifically on the relation between commercial considerations and socio- 
ethical considerations. Based on literature and common sense, one can expect that there will arise tensions between these two. One the one hand, making food products healthier might not always go together with increasing sales. On the other hand, the efforts of food companies for enhancing public health might be met with distrust from consumers and other stakeholders, suspecting that the motives behind it are merely commercially driven. And indeed, both aspects are confirmed in the case-study. In order to see how this tension affects the interaction, I analysed the responses by companies to this tension. Three responses were found. First, companies employ a frame which describes the critics (who accused the companies of being motivated mainly by commercial considerations) as idealists who only criticize but do not accomplish anything, while they denoted themselves as pragmatic and constructive. Second, the companies stress their motivations for public health, seemingly in an effort to correct for the picture that they are only interested in making profit. Third, they call upon the government to take more responsibility for public health, in order to create a level playing field among companies and assist them in making food products healthier. I show that the way in which these responses were communicated were defensive, and did not really address the tension itself.

Chapter 5 - In this chapter, I reflect critically on food innovation. In a way, this chapter takes up one of the central questions of RI, namely what science and innovation should bring into the world (Owen, Stilgoe, et al., 2013). Applied to food, one may ask the question at what kind of ends food innovation should be focused. Should it focus on health, convenience, taste, or on other goals? In this chapter, I argue that, before the question about the proper ends of food innovation can be answered, reflection is needed about the place of food in a life well-lived, and about the way in which technology mediates the relation between people, food, and the good life. The body of chapter 5 is devoted to these questions, which I discuss by making use of the philosophy of Albert Borgmann. I discuss to what extent our relationship to food is characterized by the device paradigm, which can be described as the employment of technological devices to facilitate disburdenment and the availability of consumable commodities. The alternative to the device paradigm, as Borgmann argues, is a life of engagement with focal things. Food can be such a focal thing, as I argue in this chapter. That, however, stands in a critical relation to food innovation, as food innovation often has disengagement as a result (for example when food innovation is aimed at convenience). At the end of the chapter, I draw some implications for how food innovation could facilitate engagement and how it could foster a holistic (instead of a reductionistic) understanding of food. 
The chapters of this thesis deal with different topics. Most of them concentrate on deliberation, and one is specifically about food. Together, I hope that they provide food for deliberation. 



\title{
CHAPTER 2
}

\section{RESPONSIBLE INNOVATION IN BUSINESS: \\ A CRITICAL REFLECTION ON DELIBERATIVE ENGAGEMENT AS A CENTRAL GOVERNANCE MECHANISM}

\begin{abstract}
Published as:
Brand, T., and V. Blok (2019), Responsible innovation in business: a critical reflection on deliberative engagement as a central governance mechanism, Journal of Responsible Innovation, 6(1), 4-24.
\end{abstract}

Co-author: Vincent Blok 


\section{CHAPTER 2 RESPONSIBLE INNOVATION IN BUSINESS: A CRITICAL REFLECTION ON DELIBERATIVE ENGAGEMENT AS A CENTRAL GOVERNANCE MECHANISM}

\subsection{Introduction}

One salient characteristic of modern-day societies is their rapid change through market-driven innovation. Moreover, in our days, the word innovation carries a positive connotation along with it, exemplified by our exclusively laudable use of the adjective 'innovative'. ${ }^{1}$ In the literature on the economics of innovation, innovation is-whether implicit or explicit-assumed to be an unqualified good that should be fostered (Godin, 2015). A simple counter-example may challenge this assumption; for instance, consider the destructive effects of many 'innovative' financial products that were developed before the financial crisis of 2007-2008. Such, and many other examples, make clear the importance of reflecting on the meaning of responsible innovation.

Research on 'Responsible Innovation' (RI) is centred around the question of whether and how it is possible to direct technology and innovation towards socially desirable ends (e.g. Owen, Bessant, \& Heintz, 2013). ${ }^{2}$ One of the central tenets of RI is a commitment to the democratization of innovation, and consequently to deliberative forms of governance such as stakeholder and public engagement (Stilgoe et al., 2013). In this chapter, we examine to what extent deliberative engagement with stakeholders and the wider public is suitable as an approach to RI in business. First, we show that deliberative engagement is a central characteristic of RI, including in approaches to RI in business. We then discuss several tensions that arise when the ideal of inclusive and deliberative governance is applied to innovation processes within companies. Next, we discuss the place of deliberative engagement in theories of business ethics, namely in the market failures approach, stakeholder theory, and political corporate social responsibility (CSR). The question is to what extent these theories address and are able to overcome the tensions we

\footnotetext{
${ }^{1}$ We understand innovation in a broad way, including innovations in process and in products, and including innovations that are incremental and more radical. Since we discuss $\mathrm{RI}$ in the business context, the focus lies on commercial innovation (which is what we refer to with 'market-driven' innovation).

2 Throughout this chapter, we only use the term RI, except when we refer to or quote articles that use the term RRI (Responsible Research and Innovation). We use RI because research plays no significant role in this chapter.
} 
have identified. In the discussion section, we outline possible directions that scholars could take with regard to the place of deliberative engagement within a framework for RI in business. This comes down to a choice between maintaining or modifying the ideal of deliberative engagement with stakeholders and the wider public. The implications of this choice for a framework for RI in business are briefly examined.

\subsection{Deliberative engagement as a central governance mechanism in RI}

\section{The shift in the division of moral labour and deliberative engagement}

The emerging field of research under the heading 'Responsible Innovation' (RI) addresses the question of how innovation is to be governed responsibly (Koops, Oosterlaken, Romijn, Swierstra, \& van den Hoven, 2015; Owen, Bessant, et al., 2013). RI scholars contend that the social and ethical-hence non-economicaspects of innovation should receive more attention within the innovation process. The social and ethical aspects of innovation refers to the ways in which innovations affect safety, health, privacy, the environment, and related values. RI is broadly defined as "a collective commitment of care for the future through responsive stewardship of science and innovation in the present" (Owen, Stilgoe, et al., 2013, p. 36). Although RI as a concept is quite new, it connects several existing approaches to the governance of science, technology, and public policy (Rip, 2014; Stilgoe et al., 2013). The overall aim of RI is to shift the attention in the governance of innovation from the output side to the input side (Hartley, Pearce, \& Taylor, 2017). The approach that focuses on the output side can be considered as reactive: the social and ethical aspects of new technologies are discussed only after their development. RI is meant to be proactive, by developing mechanisms to govern responsibly from the very start of the innovation process (Ribeiro et al., 2017).

The application of the framework of RI involves a shift in the division of moral labour in society (Rip, 2014). In the 'traditional' division of moral labour, judgments about the desirability of innovations are left to consumers, or broadly to 'the market'. The government has a responsibility to intervene in the case that innovations have an impact on a societal level (when there are excessive risks or unwanted effects), for example through regulation or precautionary measures. Proponents of RI argue that a shift is needed in the responsibility for the impacts of innovations (whether environmental, social, or ethical) from governments to the innovators themselves, or to the innovators together with other societal actors. RI implies that innovators should anticipate moral concerns and integrate them into the design of products (van den Hoven, 2013). According to Ribeiro, Smith, and Millar 
(2017, p. 84), RI reflects "an existing yet growing plea for a much more explicit acknowledgement of the inherently value-laden nature of science and technology".

The call for a shift in the division of moral labour in RI raises the question how to determine the socially and ethically desirable direction of innovation. Although many different approaches to RI can be identified, they tend to view this question as one that has to be answered through some form of stakeholder and/or public engagement throughout the innovation process. For example, in their recent review of definitions and conceptual dimension of Responsible Research and Innovation (RRI), Burget, Bardone, and Pedaste (2017, p. 15) conclude that "RRI is essentially an attempt to govern research and innovation in order to include all the stakeholders and the public in the early stages of research and development". Underlying the call for participatory governance mechanisms is a commitment to the democratization of innovation processes. Owen, Macnaghten, and Stilgoe argue that RI "has a primary purpose to democratically open up and realise new areas of public value for science and innovation", and thus "suggests a need for substantive processes of inclusive reflection and deliberative democracy" (Owen et al., 2012, pp. 754, 755).

The RI literature makes a close connection between deliberation and inclusion (e.g. Wickson \& Carew, 2014; see also Lubberink, Blok, van Ophem, \& Omta, 2017b). Owen et al. (2013) describe the commitment to be deliberative as "inclusively opening up visions, purposes, questions, and dilemmas to broad, collective deliberation through processes of dialogue, engagement, and debate, inviting and listening to wider perspectives from publics and diverse stakeholders" (Owen, Stilgoe, et al., 2013, p. 38). One of the important elements of this commitment is that not only those actors who have a direct stake or interest in the innovation process should have a voice, but also members from the wider public, whose stake might be much more indirect. It is held that when diverse stakeholders and lay people are involved in the innovation process, innovators can learn about the social desirability of an innovation and become responsive to societal values and needs.

With the term 'deliberative engagement', we refer to the general commitment within RI to organize innovation processes inclusively and democratically. We call it deliberative engagement because the aim of RI is not merely to consult stakeholders and the public, but to engage and involve them within and throughout innovation processes. We call it deliberative engagement because deliberation is the proposed means of engagement. There is a reflective element in deliberation, which means that "deliberators are amenable to changing their judgements, preferences, and views during the course of their interactions" (Dryzek, 2002, p. 1). This reflective element distinguishes deliberation from other 
kinds of communication. Thus, deliberative engagement in RI can be defined as the reflective communication of innovators and researchers with stakeholders and the wider public about the social and ethical aspects of innovation (processes). ${ }^{3} \mathrm{We}$ contend that deliberative engagement is a central governance mechanism of RI, meaning that it is one of -if not the-most important ways in which social and ethical aspects should be addressed in innovation processes.

\section{$R I$ and the business context}

RI started as an approach to the governance of research and innovation in the context of science. However, there is a growing emphasis on RI in business. Most publications about RI in business apply existing approaches to RI-including the centrality of stakeholder engagement and deliberation-to the business context. Several authors have made the connection between RI and CSR. Iatridis and Schroeder (2016) show how corporate responsibility tools can be used to achieve the goals of RI in the context of business. Stakeholder engagement is one of these tools. A similar strategy is employed by Van de Poel et al. (2017), who develop a conceptual model of for RI in industry based on the dimensions of anticipation, inclusiveness, reflexivity, and responsiveness developed by Stilgoe, Owen, and Macnaghten (2013). Van de Poel et al. (2017) mention stakeholder engagement strategies, stakeholder dialogues and public dialogues as tools related to the dimension of inclusion. Voegtlin and Scherer (2015) argue that political CSR can function as a governance framework for RI in the context of international business. This currently highly debated stream within CSR emphasizes the importance of deliberation of multinational corporations with stakeholders and society, because of the growing political role of these corporations. Other articles about RI in business have investigated the motivations of companies to innovate responsibly (Garst, Blok, Jansen, \& Omta, 2017), the differences and similarities of RI with theories about social and sustainable entrepreneurship (Lubberink et al., 2017b), the relation of RI to open innovation (Long \& Blok, 2017), and the drivers and barriers of implementing RI in small and medium-sized enterprises (Auer \& Jarmai, 2018).

Although these articles assume the centrality of deliberative engagement with stakeholders and society in their approach to RI in the business context, the question whether deliberative engagement is suitable for application in this context is never systematically addressed. Yet, as the next section shows, some authors have

\footnotetext{
${ }^{3}$ We recognize that our definition of deliberation is very broad. When studying specific forms of deliberation, specification and operationalization of the concept is needed. A good overview of different types of deliberation can be found in Fung (2003). A very interesting operationalization of deliberation is developed by Steenbergen et al. (2003). 
touched more explicitly on the tensions that deliberative engagement might create when applied within companies (Noorman, Swierstra, \& Zandbergen, 2017; Lubberink, Blok, van Ophem, \& Omta, 2017a; Blok, Hoffmans, \& Wubben, 2015; Blok \& Lemmens, 2015).

\subsection{Critical issues around deliberative engagement in the context of business}

We discuss three tensions that arise when the ideal of deliberative engagement is applied to innovation in business. In identifying tensions between different pairs of elements, we do not mean to say that these elements are necessary mutually exclusive, only that they do not go smoothly together. In other words, trying to realize each of the different pairs of elements together will result in conflicts and dilemmas. We identify tensions between deliberative engagement and innovative capacity, knowledge sharing and competitive advantage, and inclusive governance and current corporate governance structures. The first two tensions are already to some extent discussed in the RI literature, while (to the best of our knowledge) the third tension has not received attention until now.

\section{Tension between deliberative engagement and innovative capacity}

We have shown that the framework for RI prescribes democratization of the innovation process. This means, ideally, that innovation processes are organized in an inclusive and deliberative way, so that social and ethical values can be taken into account from the outset. Practically, it means that companies would have to engage in dialogue with a variety of actors, such as consumers, suppliers, and nongovernmental organizations (NGOs), in order to receive feedback on their innovation processes and to shape it accordingly. Doing this can have both positive and negative effects on the innovative capacity of companies. On the positive side, it could be that companies learn from stakeholders and become more sensitive to what they deem desirable. However, requirements for deliberative stakeholder and public engagement can also have negative effects on innovative capacity, depending on how strict the requirements are. For example, it is argued that RI requires not only involvement of direct stakeholders, but also with the wider public. It is not hard to imagine that setting up mechanisms for such forms of engagement about the innovation strategy will require significant time and resources, while there might not be direct benefits for a company. Evidence for this can be found in a case-study of a small scale technological project in which Noorman, Swierstra, and Zandbergen (2017) failed to introduce methods of upstream stakeholder deliberation. According to the authors, the organization they studied had 'reasonable reasons' to reject their 
proposals. These reasons were related to the fluidity of the relations between the organization and its stakeholders, time pressure and resource constraints. This indicates that the central characteristic of RI-inclusive and deliberative engagement with stakeholders and society — can be tension with the ability of companies to exploit their innovations commercially within a competitive market. Competition incentivizes companies to constantly innovate their product portfolio in order to stay ahead of competitors. It is widely accepted that—at least up to a certain level—a competitive market fosters innovation (Aghion, Bloom, Blundell, Griffith, \& Howitt, 2005). Extensive forms of deliberative engagement may slow down the competitive process, in turn potentially reducing the innovative capacity of companies. It is thus possible that companies that do not comply with the RI requirements of deliberative engagement are more able to reap the financial benefits from their innovations compared to those that do comply. Whether the overall effect of deliberative engagement on innovative capacity is positive or negative is an empirical question, however, which we cannot answer in this chapter. We can at least expect a certain tension between the two. Furthermore, it also depends on the requirements put upon companies: the more demanding these requirements are, the more likely they may be to have a negative effect.

The fact, or at least perception, that this tension exists does not as such constitute a normative argument against the imposition of requirements for deliberative engagement on companies. One could argue that RI is morally preferable, because it is meant to direct innovation towards socially and ethically desirable ends, while the commercial exploitation of innovation is focused mainly on profit-making and on the mere satisfaction of individual consumer wants. Even if that is true, however, it remains the case that companies operating in competitive markets are under intense pressure to exploit their innovations in a profitable way in order to maintain their existence. One can hardly expect companies to voluntarily comply with requirements that significantly reduce their ability to profit from the commercial exploitation of innovation. Therefore, companies seem to have a reasonable justification when they do not voluntarily comply with requirements that significantly reduce their innovative capacity.

\section{Tension between knowledge sharing and competitive advantage}

The framework of RI emphasizes the importance of transparency towards stakeholders and societal actors throughout the innovation process. Yet transparency can be in tension with the requirement of information asymmetries in commercial innovation (Blok \& Lemmens, 2015). In the literature on entrepreneurship and innovation, information asymmetries are regarded as one of the most important 
sources of market opportunities (Kirzner, 1973; Shane \& Venkataraman, 2000; Davis, 2001; Dean \& McMullen, 2007; Barbaroux, 2014). In a perfectly competitive market where every participant has complete information, there are no opportunities for entrepreneurial profits. The very fact that information is in reality unequally distributed among market actors, makes the profitable exploitation of information possible. The innovative capabilities of companies often rest on their ability to acquire new knowledge and put it to use (Cohen and Levinthal 1990). Knowledge leakage to other companies can lead to a loss of competitive advantage. Hence, asking companies to be transparent about their innovation (process) puts pressure on their ability to achieve competitive advantage from their innovations (Blok et al., 2015).

The various regulations of intellectual property embody the tension between knowledge sharing and knowledge protection. For example, patents are meant to protect knowledge while at the same time contributing to knowledge sharing. Before a patent is granted, a company must protect its knowledge to make sure that nobody will 'steal' the idea. During that process, the company will be less willing to be transparent as compared to when a patent is already granted. Another example of the tension between knowledge sharing and protection can be found in the process of attracting investors. On the one hand, it is necessary to disclose information to a certain degree in order to attract investors, but on the other hand "inventors may be reluctant to fully disclose private information to potential investors because they fear opportunistic behaviours and imitation" (Barbaroux, 2014, p. 12). These examples indicate a tension between the ideal of transparency in RI and the practice of knowledge protection in commercial innovation. In pointing to this tension, we do not claim that transparency necessarily has a negative effect on companies' competitive advantage. Similar to the first tension, whether transparency has an overall positive or negative effect competitive advantage is an empirical question, and depends for a large degree on what exactly transparency requires. In the current literature on RI, it is not yet clear how much and for which elements of the innovation process transparency is required.

The strategic benefits of knowledge sharing are emphasized within the 'open innovation' paradigm. Open innovation entails the idea that firms also use external knowledge and ideas to develop their innovations, for example by entering into collaborative Research and Development (R\&D) agreements with other organizations (Chesbrough, 2003). There are several linkages between open innovation and RI (Long \& Blok, 2017). However, it has been argued that also within the open innovation paradigm, there is a tension between knowledge sharing and competitive advantage. This has been called the open innovation paradox (Bogers, 2011; see also Davis, 2001). According to this paradox, despite any 
strategic benefits that knowledge sharing can have, companies often remain reluctant to share information due to the risk that competitors may use such information in a way that stifles their own innovation process. Moreover, Long and Blok (2017, p. 8) note that, "whilst OI [open innovation] involves a degree of transparency, this may not be to the degree necessary to satisfy RI requirements". In their view, the requirements of transparency in RI are higher compared to the requirements in the open innovation paradigm. So, if there is already a tension between knowledge sharing and competitive advantage within open innovation, this tension is likely to be stronger in relation to RI. For this reason, Lubberink et al. (2017a, p. 200) raise the question of whether the ideal of democratic governance is realistic for companies, because "it will jeopardize the information asymmetries on which their market opportunities depend”.

\section{Tension between inclusive governance and current corporate governance structures}

RI requires innovators to take responsibility for their products beyond their narrowly defined role responsibilities. The aim of RI is that innovators also take responsibility for the impact of their products on society as a whole. Grinbaum and Groves refer to this as a political responsibility:

The innovator, as bearer of a political responsibility specific to his or her social role, has to ask herself about the wider social and political significance of what she intends to accomplish, and what her actions may accomplish despite her intentions (Grinbaum \& Groves, 2013, p. 133).

This broader political responsibility, however, should not be used to blame individuals for the unintended consequences of innovation. Since innovation is a complex and uncertain process in which many different actors participate, "there is a collective responsibility both for the right impacts and negative consequences, whether these impacts are intentional or not" (R. von Schomberg, 2013, p. 60, emphasis added). The responsibility for the wider impact of innovation is thus shared with a multiplicity of actors. That is why RI also stresses the importance of inclusive governance mechanisms for innovation processes, in which the responsibility for innovation is distributed across and shared among different actors.

The ideal of inclusive governance conflicts with contemporary corporate governance structures in many countries. Currently, the final decision-making authority about the (innovation) strategy within a company lies with the board or the investors (cf. Blok et al., 2015). In most corporations, the board of directors has the highest authority, although it is accountable to the shareholders. Shareholders have certain voting rights, but these rights are only related to major strategic 
decisions such as the appointment of new directors (Heath, 2011). In general, those with decision-making authority will only give permission for investments if a positive financial return is expected. Furthermore, innovation programmes always involve financial risk. One of the most important reasons to restrict the final decision-making authority to the board, the owners, or the investors, is that they are responsible for the return on investment (the board), or bear the financial risks of investment (owners and investors). It is for this reason that shareholders are called 'residual claimants' or the bearers of 'residual risk': a company should meet its contractual obligations towards other stakeholders before the shareholders receive their gain (Maitland, 1994; Heath, 2006; Boatright, 2006). Since the claims of shareholders on the company cannot be specified by contract, many have argued that managers have an exclusive fiduciary duty towards shareholders, that is, a duty to act on behalf of the shareholders and to serve their interests. Whether or not one agrees with this view, the primacy of shareholders is currently embedded in corporate law of many countries (Heath, 2011).

In current corporate governance structures, commercial considerations are likely to dominate decision-making processes, which simply has to do with the fact that those with decision-making authority are those with financial interests. This stands in contrast to the very aim of RI, which is to move the governance of innovation beyond mere economic considerations. The goal of RI is to incorporate social and ethical aspects into decision-making processes by opening up the governance of innovation to a wide range of actors. We suggest that significant changes in corporate governance are required if this goal is to be achieved in a structural way. One may object by arguing that boards and investors have a social responsibility to take social and ethical aspects into account, and hence that it is not necessary to change corporate governance structures in order to achieve the goals of RI in the current context. However, as Moriarty (2014) has argued, individuals often display a self-serving bias and tend to uphold beliefs that are biased towards their own interests. Consequently, he argues that if one supports the objective that companies should take multiple stakeholder interests into account, one should also support more democratic forms of corporate governance. Translating this to RI: proponents of RI who believe that companies should take broader social and ethical aspects into account in their innovation processes should probably also support corporate governance structures that give a voice to a wider set of stakeholders.

\subsection{Deliberative engagement in theories of business ethics}

If the introduction or the enhancement of deliberative engagement in the business context creates tensions, we can expect this topic to be discussed within business 
ethics. This section discusses the place of deliberative engagement within several theories of business ethics. Three prominent, although very different theories will be used for this purpose: the market failures approach to business ethics (which can be seen as an elaborate version of the shareholder approach), stakeholder theory, and political CSR. We have chosen these theories, because they are highly discussed within business ethics, and because they represent three distinct perspectives on the social and ethical responsibility of business. ${ }^{4}$ If an effective framework for RI in business is to be developed, it would be prudent to integrate it with one of these theories. As we will see, these theories vary considerably in their ability to accommodate the RI framework. We first discuss the market failures approach, which has the least similarities with RI. We close with political CSR, which has the most similarities with RI. In discussing the place of deliberative engagement in these theories, we focus on to what extent they (are able to) address the tensions identified in the previous section.

\section{Deliberative engagement and the market failures approach}

The market failures approach to business ethics, developed by Heath (2006, 2007, 2014), can be seen as an elaborate version of the shareholder approach. Heath asks what legitimizes the centrality of the profit motive in business. He asserts that profit is by no means an end in itself, but a means that "generates the competition necessary to push prices toward the levels at which markets clear" (Heath, 2006, p. 541) with the end of producing efficient outcomes. Put differently, the mechanism of the competitive market creates an efficient allocation of goods and services and thus enhances general welfare. However, numerous 'market failures' result from the fact that the conditions of perfect competition do not hold in practice. Most economic policies and regulations can be interpreted as aiming to correct market failures. For example, pollution taxes can be seen as means to 'internalize' the costs arising from the absence of a market for a clean environment. Likewise, forms of consumer protection try to mitigate the adverse effects of asymmetric information. After arguing that the rationale of most government regulation is to correct market failures - and to thereby enhance the efficiency of markets, Heath next argues that

\footnotetext{
${ }^{4}$ Hasnas (1998) distinguishes three normative theories of business ethics: shareholder theory, stakeholder theory, and social contracts theory. The market failures approach can be seen as an elaborate version of shareholder theory. This approach is recently much more discussed, also in relation to corporate political activities and corporate governance (Norman, 2011; Singer, 2018; Norman, 2015; Néron, 2016). We have chosen political CSR instead of the social contracts approach because the prominence of the former in current debates, and because of the similarities with RI.
} 
the government is limited in correcting market failures: regulation is costly and ensuring compliance might require undesirable forms of force. Market failures can never be entirely corrected by means of regulation. Following this assertion, Heath argues that companies have a moral obligation to refrain from exploiting market failures, which means that they should "behave as though market conditions were perfectly competitive, even though they may in fact not be" (Heath, 2014, p. 37). 'Efficiency imperatives' that follow from this approach include: minimizing negative externalities, competing only through price and quality, reducing information asymmetries between firm and consumers, not opposing regulation aimed at correcting market imperfections, and not engaging in opportunistic behaviour toward customers or other firms (Heath, 2014, p. 37). Heath further states that the imperatives derived from the ideal of efficient markets provide "a framework for thinking about all of the issues that are traditionally classified under the heading of "corporate social responsibility"” (Heath, 2014, p. 174).

Although the main purpose of the market in this approach is to promote efficiency, efficiency considerations do not trump considerations of justice on a societal level. According to Heath, there is a division of moral labour in our institutions: markets are designed to promote efficiency, while matters of justice are left to the welfare state. The 'limited' morality of the market with its focus on efficiency is therefore justified against the background of a state that takes care for justice. Here we see a strong difference between the market failures approach and RI. As we have shown, proponents of RI problematize a strict division of moral labour in which markets take only economic considerations into account and governments address social and ethical considerations. The aim of RI is to justify innovation beyond macro-economic benefits (von Schomberg, 2013).

How does the market failures approach address the different tensions identified above? We discuss the first two tensions and their relation to the different theories of business ethics together, because-despite their differences - they both relate to the fact that deliberation and transparency about innovation processes can be detrimental for a company's innovation strategy. Heath does not explicitly discuss the role of stakeholder and public engagement, but he clearly does not see them as morally required. Of course, engagement can be used by companies for strategic reasons, for example in order to obtain knowledge from stakeholders. However, from the perspective of this approach, to oblige companies to engage in deliberation with stakeholders and society would be at odds with how innovation in a competitive market works. Markets are efficient and companies are innovative because companies compete for the favour of customers, and not because they deliberate with them. In Heath's approach, the proper place of deliberation is in politics, not the market. With regard to transparency, it is interesting that one of the 
imperatives of the market failures approach is for companies to reduce information asymmetries between themselves and their customers. This seems to be in tension with the requirement of information asymmetries for innovation (e.g. Barbaroux, 2014). However, Heath prescribes this imperative in the context of the general obligation not to exploit market failures. That implies that companies should reduce information asymmetries in the case that these asymmetries misinform customers and thus lead to choices that customers would regret if they had more knowledge. The imperative does not imply that firms should be transparent towards stakeholders about their innovation process as such, provided that they operate within the limits of the law and that they do not aim to use the information asymmetries at the expense of customers.

With regard to the tension between inclusive governance and current corporate governance structures, Heath clearly opts for a model in which only the owners (shareholders) exercise control over the firm (Heath, 2011). Although nonowner stakeholders do not exercise control over the firm, Heath holds that the shareholder model of corporate governance in the aggregate serves the interests of all stakeholders the best. He argues that managers have an exclusive fiduciary duty towards shareholders, that is, a duty to act on behalf of them and to serve their interests. ${ }^{5}$ The reason for this is that shareholders are bearers of residual risk, contrary to stakeholders whose claims are specified by contract (Maitland, 1994; Heath, 2006; Boatright, 2006). Since the residual risk will even be greater with regard to innovation, from the perspective of the market failures approach innovation does not present a special case for corporate governance.

\section{Deliberative engagement and stakeholder theory}

In a very general sense, stakeholder theory holds that organizations are responsible to their stakeholders, that is, to "those groups and individuals who can affect or be affected by their actions" (Freeman et al., 2010, p. 9). Given the variety of existing approaches to stakeholder theory, it can be questioned whether it can really be considered as one coherent theory (Freeman, 2002; Norman, 2013b). However, it is possible to derive some general normative guidelines from it (Hasnas, 2013). In the first place, stakeholder theory requires that the fruits of organizational success should be distributed among all legitimate stakeholders, and not only among shareholders. Secondly, all relevant stakeholders should have the opportunity to give input in the organizational decision-making process (Hasnas, 2013; Boatright, 2006; cf. Phillips, Freeman, \& Wicks, 2003). To be able to apply these guidelines in

\footnotetext{
${ }^{5}$ That does not mean that, from this view, managers do not have any duties towards other stakeholders. They do, but these duties do not have the fiduciary form. 
practice, it is necessary to define who counts as a legitimate stakeholder. Phillips (2003a) makes the distinction between normative and derivative stakeholders. Normative stakeholders are those stakeholders to whom the company owes a moral obligation to take their interests into account. Standard examples of normative stakeholders are employees, shareholders, and customers. He argues that an organization has a moral obligation to give its normative stakeholders a voice about how the organization is run (Phillips, 2003b). Derivative stakeholders are those stakeholders whose interests should be taken into account in managerial decision making, but only because they can affect the interests of normative stakeholders. Examples of a derivative stakeholder are competitors and the media.

In general, stakeholder theory places much emphasis on stakeholder engagement and dialogue (Crane \& Livesey, 2003; Johnson-Cramer, Berman, \& Post, 2003). This links up with the emphasis on inclusive deliberation in RI. However, there are two noticeable differences. First, stakeholder theorists often emphasize balancing stakeholder interests, for which communication is required. Yet balancing interests seems to have more similarities with negotiation than with deliberation. Negotiation is about finding a balance or compromise among different private interests. Deliberation (at least in the classic sense) is meant to go beyond private interests, towards arriving at a shared understanding about public issues, and making argumentatively agreed-on decisions about the common good (Mansbridge et al., 2010). Second, while stakeholder theorists focus mainly on taking the interests of direct stakeholders into account, RI aims to open up innovation processes to an even broader set of actors, including members of the public.

To what extent is stakeholder theory able to address the tensions identified above? With regard to the first two tensions, it seems that stakeholder theorists recognize that strong requirements of deliberation and transparency can be difficult to achieve for commercial organizations. For example, Noland and Phillips criticize theories that call for a radical democratization of the firm, which would overburden it and reduce its capability to realize value for all stakeholders (Noland \& Phillips, 2010). Although stakeholder theory stresses the importance of embedding stakeholder engagement in the overall strategy of a company, it does not prescribe the specific form of stakeholder engagement. Hence, it leaves room for companies to shape stakeholder engagement in such a way that it does not significantly harm their competitive strategy. For example, a firm can engage with stakeholders in order to gain knowledge about their values, interests, and preferences as input to the innovation process, without involving them throughout the entire process and without sharing confidential information that could be used by competitors. Yet this flexibility does not completely eliminate the tension. It remains a challenge—also for stakeholder theory-to find a balance between stakeholder engagement and 
transparency about innovation on the one hand, and protecting the competitive position of the company on the other.

At first sight, stakeholder theory seems well-equipped to address the third tension, namely, that between inclusive governance and current corporate governance structures. After all, stakeholder theory is often described as an alternative to shareholder theory, with the aim of giving all stakeholders a say about how a company is run-and not merely shareholders (Freeman, 2002). Moriarty (2014) notes that in earlier writings, stakeholder theorists supported giving stakeholders formal and binding control over a corporation, by involving them in the board of directors. However, more recently, theorists have abandoned this idea, noting that stakeholder theory "does not mean that representatives of these groups [the key stakeholders, TB] must sit on governing boards of the firm" (Freeman et al., 2010, p. 9). According to Moriarty this is a mistake. He argues that "stakeholder theory's distributive goal of balancing stakeholders' interests is more likely to be achieved in a stakeholder democracy than under current corporate governance arrangement" (Moriarty, 2014, p. 832). Stakeholder democracy means that the boards of directors consists of representatives of different stakeholder groups, who elect their own candidates. Stakeholder theorists may find this implication of their theory too radical; however, in many current corporate governance structures, shareholder interests will have more influence in decision-making processes than the interests of other stakeholders. In that case, the tension between inclusive stakeholder governance and shareholder governance is likely to persist.

\section{Deliberative engagement and political CSR}

Within political CSR, it has been argued in that corporations have a political role, that is, they have to take responsibility for public goods, especially when nation states are failing to provide those goods (Palazzo \& Scherer, 2006; Scherer \& Palazzo, 2007; Matten \& Crane, 2005). When corporations assume a political role, their political activities require some form of (democratic) legitimation. Scherer and Palazzo argue that the theory of deliberative democracy provides a model to legitimize corporate activities that address public issues. Deliberative democracy assumes that "the legitimacy of a political decision rests on the discursive quality of the decision-making process" (Scherer \& Palazzo, 2007, p. 1107). This means that corporate political activities can be legitimized if corporations engage in discursive processes of public will-formation, in a way that places the public interest at the centre. By emphasizing the public impact of corporate activities, political CSR also aims to go beyond merely taking the interests of direct stakeholders into account. For that reason, Scherer and Palazzo emphasize that corporations have to cooperate 
with and build consensus among civil society actors such as NGOs about certain public issues in which they are involved.

There are many connections between political CSR and the emphasis on deliberation within RI. Since innovations shape our societies to a great degree, they can be regarded as relevant objects of public concern and deliberation. Therefore, from the perspective of political CSR, innovation processes themselves should in a sense be politicized and subjected to democratic control. This comes down to the application of deliberative democratic principles to innovation processes, in which outcomes are legitimate "to the extent they receive reflective assent through participation in authentic deliberation by all those subject to the decision in question" (Dryzek, 2001, p. 651; see also Wong, 2016). Like RI, political CSR provides a framework that stresses the need for public engagement, inclusive deliberation, transparency, and accountability (Voegtlin \& Scherer, 2015). In such a view, RI in the business context depends on the quality of deliberative engagement with stakeholders and the wider public about the purposes, values, and impacts that a company should pursue or try to avoid with its innovations.

To what extent does political CSR address the identified tensions? Again, we discuss the first two tensions together. The response to these tensions from the perspective of political CSR is quite comparable with that of stakeholder theory: the demands of deliberation for companies should not be too high. Although deliberation is crucial in gaining legitimacy, Scherer and Palazzo note that "it is not necessary to solve every single coordination problem through an unlimited democratic discourse" (Scherer \& Palazzo, 2007, p. 1111). As economic actors, businesses have a 'license to operate'. Only as political actors should they be subjected to democratic control. In relation to RI, the question is to what extent innovation counts as economic or political activity. Does the fact that innovations shape our societies make innovation political? And if this is the case, should the introduction of innovations with a high potential impact be subjected to requirements of democratic deliberation and transparency? Several authors see RI as a way to politicize research and innovation (Hartley et al., 2017; Grinbaum \& Groves, 2013). Politicization is understood as “a means to recognise and open up political questions to a broader range of voices and ensure that the role of values is visible. (...) It opens up decisions about the public good to public scrutiny through deliberation and accountability" (Hartley et al., 2017, p. 362). The question is to what extent the idea that innovation is a political activity holds for every kind of innovation, whether human enhancement technologies or a new type of solar panels. Furthermore, the question is also whether politicization is desirable for every kind of innovation process. And more important for this chapter, whether it holds for every context, whether science or business. Until now, these questions have not 
been explicitly addressed in the RI literature. Nor do we claim to answer them here. Yet, the similarities between RI and political CSR on the issue of politicization are noticeable.

Within political CSR, there is little attention for the implications of a politicized role of companies for corporate governance (Whelan, 2012). The focus lies on the role of multi-stakeholder initiatives (Mena \& Palazzo, 2012). In a notable exception, Scherer, Baumann-Pauly, and Schneider (2013) hold that the democratic deficit that is created when corporations engage in political activities can be compensated for by democratic governance mechanisms within organizations. The aim of such mechanisms is to integrate stakeholders into organizational decision making. What does this mean concretely? The authors provide the case of multinational corporation Lafarge, which formed stakeholder panels entrusted with the task to discuss issues of sustainability and biodiversity and to provide policy recommendations to the board. The question is whether the appointment of stakeholder panels goes far enough for achieving substantial democratization. It has been argued that "if these 'Political' CSR writings are to be meaningfully associated with 'deliberative democracy' (...) then they need to go beyond indirect and/or 'board external' forms of accountability” (Whelan, 2012, p. 719). Without formal governance structures, participatory equality will be difficult to achieve. Therefore, Whelan (2012) proposes a 'political' model of corporate governance, which extends the voting rights over the board of directors to core stakeholders (employees, customers, suppliers, and shareholders) and civil society representatives. Until now, this proposal has not been taken up by political CSR scholars. The appointment of stakeholder panels assigned the task of reflecting on and giving advice about the social and ethical aspects of innovation seems to be an easier way to achieve inclusive governance. However, the question remains whether this will be enough for realizing inclusive governance.

\subsection{Discussion: the place of deliberative engagement in a framework for RI in business}

We have identified three tensions that attend the application of the framework of RI to business. We have also scrutinized three theories of business ethics, and the extent to which these theories incorporate deliberative engagement. Two of these, stakeholder theory and especially political CSR, share with RI the commitment to deliberative stakeholder engagement. However, also within these theories, the problematic relation between transparent, inclusive and deliberative governance on the one hand, and innovative capacity, competitive advantage and current corporate governance structures on the other hand, persists. This gives rise to the question 
how RI should proceed with a framework for the business context. We discuss this question by first pointing to the underlying tension between the ideal of deliberative engagement and the way in which the market works: the tension between voice and exit. After that, we discuss two directions in which RI scholars can proceed: proposing more radical changes in the business context in order to realize the ideal of inclusive and deliberative governance and modifying the ideal. Our focus is primarily on the second direction, in which the ideal is critically reconsidered. It should be noted that our description is not meant to be exhaustive, and that there are also in-between positions possible.

\section{The underlying tension between voice and exit}

The three tensions we discuss above relate, in our view, to the more basic tension between voice and exit. In his seminal Exit, Voice, and Loyalty, Hirschman (1970) worked out these mechanisms as different responses to decline in the quality of good or other provisions. Exit is the mechanism that characterizes the economic sphere. When the quality of a product declines, the usual response of a consumer will be to stop buying the product and shift to a different one. Voice is the mechanism that characterizes the political sphere. When the quality of policy declines, the proper response for citizens is to raise their voice and express their concern, and not (in the first place) to move to another polity. Of course, exit plays a role in the political sphere as does voice in the market. People can express their dissatisfaction with the vision of a political party by voting for a different party, which is a form of exit. Likewise, consumers can write a letter to a company instead of simply buying another product. Yet one can say that exit is what qualifies the market mechanism. To put it more strongly: markets are efficient precisely because they are built on exit. If companies had to deliberate extensively with a wide set of stakeholders, and to build consensus or negotiate compromises among them about what kind of product to bring on the market (like governments have to do in policymaking), conventional wisdom implies that markets would be neither efficient nor innovative.

RI tries to make innovation processes more responsive to voice, by engaging stakeholders and publics in innovation processes. When this governance approach is applied to innovation within companies, however, it is applied in a context that is designed to be mainly responsive to exit. For this reason, the introduction of mechanisms of voice creates tensions. Since the market operates mainly on the basis of exit, a certain tension between voice and exit is likely to be persistent.

A related concern is that the responsiveness of companies to exit (e.g. declining sales) is largely based on strategic considerations. This could be in conflict with the ideal of responsiveness to social and ethical considerations. For example, 
when companies use voice as a mechanism, one can expect that instrumental motives (to improve their business case) will always be present (Garst et al., 2017). The dominance of strategic considerations could undermine taking social and ethical aspects seriously. Furthermore, it is even possible that organizations institutionalize voice in order to make it ineffective (Hirschman, 1970, p. 124). An example of this would be that companies give stakeholders and members of the wider public a limited voice, with the intention of silencing criticism instead of being genuinely responsive to societal concerns (cf. Burchell \& Cook, 2013a). A more significant conflict regarding the ideal of responsiveness in RI is hardly conceivable.

By pointing to the underlying tension between voice and exit, we do not mean to argue that RI in the business context is impossible, but that an RI framework designed for this context should take this tension seriously. For that reason, we discuss two directions in which this tension is taken more seriously.

\section{Maintaining the ideal of deliberative engagement}

The first direction that we consider is maintaining the ideal of deliberative engagement with stakeholders and society when attempting to bring RI into the context of innovation in business. RI scholars electing this approach might study best practices that live up to this ideal and how such practices mitigate the tensions identified above. It is our impression that most of the research about RI in the business context follows more or less this direction: several tools and methods are developed to enhance the ideal of inclusive and deliberative innovation processes within companies. However, the risk of focussing only on best practices, tools, and methods is that the ideal will only be implemented within firms that already have a disposition towards innovating in a responsible way and thus are willing to adopt those measures. Therefore, we think that if one wants to maintain the ideal of deliberative and inclusive governance, it should be complemented with reflection on its implications for innovation on a broader governance level. We have indicated that there is a tension between the ideal of RI and the way in which a competitive market operates. The question then is what kind of socio-economic model fits better with RI. On a more concrete level, the question is what RI implies for the structure of innovation processes and for corporate governance. For example, regulations for intellectual property might have to be changed in a way that makes innovations more transparent and open to different users. Furthermore, in order to include a broad set of stakeholders in the innovation process, the dominance of shareholder interests or generally financial interests in corporate decision-making processes has to be broken. How exactly this can be achieved is open to discussion. Yet if RI is to be meaningfully applied as a general governance mechanism of innovation in a 
commercial context, these issues have to be addressed.

\section{Modifying the ideal of deliberative engagement}

Another possible direction for RI in business is not to take the ideal of inclusive and deliberative governance for granted, but to think about what market actors can achieve given the context in which they operate. A possible way to do this is to reconceptualize deliberative engagement in a way that is more suitable to a commercial context. Noorman, Swierstra, and Zandbergen (2017) examine this direction. In their case-study, they find a lack of commitment and accountability to stakeholders other than shareholders, and a limited inclusion of these other stakeholders in decision-making processes. They acknowledge that the company they studied had good reasons for not applying the ideal of RI, reasons which very much relate to the tension between inclusive deliberation and innovative capacity. Accordingly, they argue that the deliberative ideals of RI need to be adapted in order to make it applicable in the business context. One way of proceeding in this direction is to apply different (i.e. less strict) standards for transparency and inclusion in the case of innovation in a commercial context. Another element to account for is the conflict that could exist between the commercial interests of companies and public goods such as health and sustainability. This possible conflict could easily be translated into a conflict among stakeholders, for example between companies and NGOs. Since companies need a business case for their innovations, and stakeholders such as NGOs have the societal role to address public issues, this conflict is likely to be persistent. What does this imply for deliberation among these actors? It seems that we cannot expect these actors to always aim at consensus, nor to set considerations of self-interest (i.e. profit, reputation) completely aside. In order to be able to manage the tensions we identify, an account of deliberation is needed that explicitly takes conflict and self-interest into account (Blok, 2014a; cf. Mansbridge et al., 2010). Such accounts of deliberation are currently scarce within RI (van Oudheusden, 2014).

What would modifying the ideal of deliberative engagement imply for a general governance framework for RI in business? The currently dominant approach to RI in the literature can be characterized as procedural, because RI is defined by process requirements, of which deliberative engagement with stakeholders and society is the key (Pellé, 2016). One could argue that a purely procedural approach is not suitable for business, and hence that the business context requires an approach that is more focused on outcomes (Pellé 2016). A framework for RI with a focus on outcomes will focus on assessing to what extent innovations match with particular societal values and norms. In this respect, an approach to RI for business can benefit from the literature on sustainable entrepreneurship (Lubberink et al., 2017a). 
Several authors have argued that sustainable entrepreneurship can be interpreted as an entrepreneurial activity that aims to solve market failures that lead to environmental degradation (Cohen and Winn 2007; Dean and McMullen 2007). An approach to RI inspired by the idea of sustainable entrepreneurship would focus on assessing the outcomes of corporate innovation activities (namely, to what extent they solve market failures), and not on the deliberative process in the first place. Such an approach would not first and foremost require companies to deliberate with stakeholders and society about their innovation process, nor to be completely transparent about it. Of course, for companies that want to innovate responsibly, there can nevertheless be good reasons to engage with stakeholders about their innovation programme. Companies may do so if they lack knowledge, or in order to gain support from stakeholders. An outcome-oriented approach does in no way prohibit companies from doing so. In fact, processes of stakeholder engagement can be very important. However, in an outcome-oriented approach to RI, such processes are seen as instrumental to the substantive goal of RI (to take social and ethical values into account, or to solve market failures), instead of being identified as such with RI.

Further research and debate will have to address the question of whether an approach that gives up the centrality of certain process requirements such as inclusion and deliberation can still be called RI. However, the choice between an outcome-oriented or procedural approach will not be a matter of either-or. It is more likely that a balance has to be found between process and outcome requirements. Currently, the balance in the RI literature clearly tilts to the side of process requirements. Reconsidering the ideal for a view of RI in business might lead to a stronger focus on outcomes.

\subsection{Conclusion}

The main aim of this chapter was to critically reflect on the question of whether deliberative engagement is a suitable governance mechanism for RI in business. Our conclusion is that there remain tensions between the ideal of opening-up innovation processes to deliberative engagement and the way in which competitive markets currently operate. These tensions also appear (albeit in different ways) in theories of business ethics. We have identified two directions (proposing more radical changes in the business context in order to realize the ideal of inclusive and deliberative governance and modifying the ideal itself) that scholars working on RI in business can take in a way that explicitly recognizes these tensions. In this description, we have refrained from taking a position on which direction is preferable. Our aim is to urge scholars in the field of RI to take into account the tensions that come with 
applying RI to business. The different directions can be worked out in a consistent way. The former can be seen as a more idealistic, long term approach, and the latter as pragmatic and focused on realizing RI on the short term. 



\section{CHAPTER 3}

\section{STAKEHOLDER DIALOGUE AS AGONISTIC DELIBERATION: EXPLORING THE ROLE OF CONFLICT AND SELF-INTEREST IN BUSINESS-NGO INTERACTION}

Published as:

Brand, T., V. Blok, and M.F. Verweij (2019), Stakeholder dialogue as agonistic deliberation: exploring the role of conflict and self-interest in business-NGO interaction, Business Ethics Quarterly, 30(1), 3-30.

Co-authors: Vincent Blok and Marcel Verweij 


\section{CHAPTER 3 STAKEHOLDER DiALOGUE AS AGONISTIC DELIBERA- TION: EXPLORING THE ROLE OF CONFLICT AND SELF-INTEREST IN BUSINESS-NGO INTERACTION}

"For one thing, with pluralist market society spawning a never-ending series of social conflicts in fairly rapid succession, it differs from other types of socio-political arrangements in one important respect: it cannot pretend to establish any permanent order and harmony; all it can aspire to accomplish is to "muddle through" from one conflict to the next." (Hirschman, 1994, p. 213)

\subsection{Introduction}

In the literature on Corporate Social Responsibility (CSR), increasing attention is paid to the role that stakeholder dialogue plays in addressing and solving complex CSR-related issues. Dialogue is an indispensable aspect of the interaction between companies and nongovernmental organizations (NGOs), especially with regard to collaboration and partnership formation (Roloff, 2008; Seitanidi \& Crane, 2009; Burchell \& Cook, 2013b; Selsky \& Parker, 2005; Van Tulder, Seitanidi, Crane, \& Brammer, 2016). The idea is that addressing complex societal issues-such as sustainability, human rights, or public health-requires dialogue and collaboration between multiple actors. The aim of this chapter is to get a better understanding of the norms that should govern stakeholder dialogues about complex societal issues. Generally, stakeholder dialogue is described as a practice by which companies shift from a one-way communication strategy towards a more responsive, two-way communication with their stakeholders (Crane \& Livesey, 2003). Although there is often a broad set of stakeholders involved in such dialogues (companies, NGOs, governments, citizens, etc.), the focal point of our analysis is the interaction between companies and NGOs, specifically. ${ }^{1}$

Two elements stand out in the literature on stakeholder dialogue, namely, that participants should have a consensual orientation and that they should set strategic considerations aside (e.g. Baur \& Palazzo, 2011; Foster \& Jonker, 2005; García-

\footnotetext{
${ }^{1}$ Strictly speaking, not companies and NGOs engage in dialogue, but their employees or representatives. However, for reasons of convenience, we will 'non-strictly' speak as if companies and NGOs engage in dialogue.
} 
Marzá, 2005; Unerman \& Bennett, 2004). We will argue that both elements are problematic when it comes to the interaction between companies and NGOs, especially when there are frictions between the commercial interests of companies and a societal issue. Our core arguments are that an orientation towards consensus is in tension with the function of NGOs to voice social criticism, and that the expectation to set aside strategic considerations is in tension with the idea of a competitive market in which companies are allowed to exhibit a certain partiality towards their own (commercial) interests. For these reasons, we believe that an alternative approach to dialogue is needed in which conflict and self-interest have a legitimate and, up to a certain point, desirable place.

Our analysis proceeds as follows. In the first section, we elaborate on the currently prominent conceptualization of stakeholder dialogue in the CSR literature and show that it strongly relies on Habermas's concept of communicative action. Following this, we discuss the problems of conceptualizing stakeholder dialogue in terms of communicative action. The last section provides an alternative way of conceptualizing stakeholder dialogue that we call agonistic deliberation, which incorporates the concept of agonism from the political philosophy of Chantal Mouffe (Mouffe, 1999, 2005), and builds on the concept of deliberative negotiation developed by Jane Mansbridge and others (Mansbridge, 2009; Mansbridge et al., 2010; Warren \& Mansbridge, 2013). Our alternative stresses the importance of a struggle between companies and NGOs, and, at the same time, upholds mutual justification as a central deliberative norm.

\subsection{The current conceptualizations of stakeholder dialogue}

What are the central characteristics of a good stakeholder dialogue as presented in the CSR literature? This question implies that we are not so much concerned with a descriptive view of stakeholder dialogue (what it actually looks like in practice), but with a normative view or an ideal. ${ }^{2}$ The ideal indicates where companies and

\footnotetext{
${ }^{2}$ We recognize that there is a lot of literature adopting an instrumental approach to stakeholder engagement and dialogue, which generally assesses the extent to which stakeholder relations contribute to firm performance (Berman, Wicks, Kotha, \& Jones, 1999; Choi \& Wang, 2009; e.g. Jones, 1995). There are basically two reasons why we do not discuss this approach in this chapter. First and foremost, our concern is with approaches that present a distinctively normative perspective on stakeholder dialogue. An instrumental approach to stakeholder engagement and dialogue cannot answer the question what kind of norms and ideals should guide the interaction between companies and NGOs. Whether and how stakeholder dialogue affects firm performance is not our main interest (although it is relevant to have knowledge about this relation). Second, studies in this field often focus only 54
} 
stakeholders should be aiming in their communication with one another. Although we recognize that there is not one homogeneous view of stakeholder dialogue, we identify what seems to be the dominant normative view. After discussing the literature on stakeholder dialogue, we show how this view relates to the concepts of communicative and strategic action.

Before turning to the characteristics of the ideal stakeholder dialogue in the literature on CSR, we want to clarify what we mean by 'stakeholder dialogue' in general and what kind of stakeholder dialogues we focus on in this chapter. We understand stakeholder dialogue broadly as the two-way communication between companies and their stakeholders (Crane \& Livesey, 2003). More specifically, to count as stakeholder dialogue, it should be an organized or planned event in which participants deliberately engage and should stand apart from regular day-to-day communicative interaction. Furthermore, it should be a dialogue that concerns policies and activities at an organizational level. Although the topics in such dialogues and the participating stakeholders can both be widely diverging, we narrowed down for a specific focus. First, with regard to topics, our focus is on the way in which the activities of companies affect societal values. Examples of such values are public health, human rights, and sustainability. Second, with regard to participants, the analysis in this chapter is restricted to interaction between companies and NGOs. The choice for NGOs is motivated by the consideration that these organizations typically represent and promote societal values (Baur \& Palazzo, 2011; Martens, 2002), and because they play an increasingly important role in CSR (Arenas, Lozano, \& Albareda, 2009).

\section{Characteristics of the ideal stakeholder dialogue in the CSR literature}

In the CSR literature, the ideal stakeholder dialogue is described as a dialogue in which the participants have a consensual attitude in regards to building a shared view about a societal issue (e.g. Baur \& Palazzo, 2011; Foster \& Jonker, 2005; Golob \& Podnar, 2014; Kaptein \& Van Tulder, 2003). Furthermore, commercial interests have, ideally, no influence on the process and the outcome, because the dominance, or maybe even the presence, of strategic considerations distorts the process of building a shared understanding (e.g. Crane \& Livesey, 2003; Unerman \& Bennett, 2004). As Noland and Phillips (2010, p. 40) put it, in a communicative approach to dialogue, communication is "uncorrupted by power differences and strategic motivations" with the aim of "agreement for the sake of agreement." When we refer to strategic considerations, we mean to refer to considerations that have to do

on whether stakeholders interact or not, but not how they interact, while we are interested mainly in the latter. 
with private interests as opposed to public interests. For example, having a good reputation is a private interest of a company or an NGO, but not a public interest. Contrariwise, the availability of healthy food is a public interest, namely, an interest of us all (although it is also in each person's private interest).

One of the central characteristics of the ideal dialogue as sketched out in the literature is that it aims to achieve consensus among participants. Although several authors make explicit use of this concept (Patzer, Voegtlin, \& Scherer, 2018; Golob \& Podnar, 2014; García-Marzá, 2005; Foster \& Jonker, 2005), it is often not clear what they exactly mean by it. Other authors do not explicitly use the concept consensus, but emphasize that dialogue should lead to a 'shared understanding' between stakeholders, which seems to imply some form of consensus (JohnsonCramer et al., 2003). Many authors make use of Habermas' theory of communicative action and his theory of deliberative democracy, in which the importance of finding consensus is also emphasized (Roloff, 2008; Scherer \& Palazzo, 2007; Palazzo \& Scherer, 2006; Foster \& Jonker, 2005; van Huijstee \& Glasbergen, 2008; Unerman \& Bennett, 2004). We find that the importance of finding consensus within stakeholder dialogue is often assumed, but receives little explicit attention.

Since we want to address the question of whether a consensus orientation is desirable in stakeholder dialogues between companies and NGOs, it is important to be clear on how we understand consensus. As we see it, a consensus is an agreement in the sense that actors hold the same belief about something (whether initially or as a result of dialogue), and know that the others have the same belief. We agree with Habermas that a genuine consensus is based on reasons and is not the result of coercion (Habermas, 1990, 1996). Now, of course, people can agree and disagree about a lot of different things. A useful distinction can be made between (dis)agreements concerning facts, values, and actions (Rescher, 1993). ${ }^{3}$ For example, a person can hold the following beliefs: that sugar intake is the main cause of obesity, that public health is a prime value, and that food companies should reduce sugar levels in drinks. The first is a factual claim, the second relates to values, and the third relates to action. When engaging in a discussion, agreement and disagreement can appear at different levels. It could be that there is consensus about what to do, without there being consensus about the other levels. Hence, there are stronger and weaker forms of consensus. For example, there is a strong consensus between a food company and an NGO when they both adopt public health as a core value, have the same beliefs about the causes of obesity, and also share beliefs about

\footnotetext{
${ }^{3}$ Taste (or subjective preference) is a fourth element where people can (dis)agree about. However, it does not make sense to convince others of a certain taste, unless one of the other elements is at play.
} 
how obesity should be addressed. Yet it is possible that, though they reach consensus about how obesity should be addressed, they do not have the same beliefs regarding the causes of obesity nor have they adopted the same values. This would be a weak consensus (by which we do not mean to imply that such a consensus is necessarily unstable). ${ }^{4}$ Yet it is important to notice that, since it is a consensus about action, both parties genuinely, and on the basis of reasons, believe that what they agree on is the right thing to do.

A consensus should be distinguished from a compromise. A compromise is an agreement which reflects a "settlement of differences by mutual concessions" (Benjamin, 1990, p. 5). To give an example, suppose that an NGO requests a company to stop child marketing, while the company wants to continue child marketing. After ample discussion, they agree to abandon child marketing on a limited set of unhealthy products, even though the NGO would prefer the company abandon child marketing altogether. Although they mutually agree to work out this course of action, it is not a consensus, because both had to give in, to some extent, on the course of action they initially preferred, and because at least one of the participants is not internally convinced, on the basis of reasons that this is the right thing to do. ${ }^{5}$

How can consensus be achieved? What does it require from participants? In the literature, different criteria for good stakeholder dialogue are discussed. Although not all authors explicitly mention consensus as the desired outcome, the following criteria that could enhance the achievement of consensus are mentioned in the literature. In the first place, participants in a dialogue should be willing to change their minds (Burchell \& Cook, 2006; Crane \& Livesey, 2003). Furthermore, the communication should be symmetrical, in the sense that the different parties have equal opportunity to present their points of view (Crane \& Livesey, 2003; Foster \& Jonker, 2005). In order to make sure that a dialogue does not favor a particular view, it is important that a diversity of voices can be heard (Payne \& Calton, 2002). Participants should also never be forced to adopt a certain position, but they should be allowed to develop their own position on the basis sound arguments (Roloff, 2008; Unerman \& Bennett, 2004). The problem is that even if all these requirements are fulfilled, consensus-whether in its stronger or weaker form-will not always be achieved. The difficulty to achieve consensus, especially

\footnotetext{
${ }^{4}$ There are also other forms of weaker and stronger forms of consensus. For example, it could be that people have the same beliefs, but for different reasons. This is what Rawls (1987) calls an 'overlapping consensus'. This form of consensus can also be called 'weaker' compared to a consensus in which people have the same reasons for having a belief.

${ }^{5}$ It may be noted that agreement is used for both consensus and compromise. In what follows in this chapter, we will use agreement only when it could include both.
} 
under conditions of pluralism, is often acknowledged (Baur \& Palazzo, 2011; Mena \& Palazzo, 2012). At the same time, it is maintained that an orientation towards consensus is crucial. For example, Mena and Palazzo (2012) consider a consensual orientation as one of the criteria for evaluating the input legitimacy of multistakeholder initiatives. Similarly, Baur and Palazzo hold that even though it may be difficult to achieve consensus as final outcome, NGOs and companies must at least show "the principle willingness to achieve a shared position" (Baur \& Palazzo, 2011 , p. 693, our emphasis). So, even though it is recognized in the literature that consensus will often not be achieved in practice, it is presented as something to strive for.

The ideal stakeholder dialogue, with its focus on consensus, is often contrasted with a dialogue in which participants are merely trying to defend and pursue their own interests. Van Huijstee and Glasbergen (2008, p. 300) refer to this as the strategic management perspective of dialogue in which "companies are motivated to engage with stakeholders to manage risk . . . and to gain competitive advantage." When dialogue is used for merely strategic purposes, it can become a form of manipulation or propaganda (Bendell, 2003; Golob \& Podnar, 2014). It is called an 'instrumental dialogue' because it is merely seen as a means to achieve the private ends of an individual or organization (Crane \& Livesey, 2003). In that case, the dialogue is not really open for different views, but is "centred on communicating self-interest and aligning the other's interest to one's own" (Crane \& Livesey, 2003, p. 47). We are, thus, presented with a dichotomy. At one end of the spectrum lies the ideal dialogue in which participants aim at a rationally motivated consensus. At the other end lies a dialogue in which actors treat each other strategically.

\section{Stakeholder dialogue and Habermas's philosophy}

Many readers will recognize in the CSR literature about stakeholder dialogue an indebtedness to the philosophy of Jürgen Habermas, both in content and in terminology. Indeed, many business ethics scholars who study the interaction between companies and its stakeholders, make use of Habermas's work. For example, from the perspective of stakeholder theory, Phillips (1997) has argued that Habermas's discourse ethics provides an appropriate procedure for determining the obligations that companies have towards their stakeholders. Other approaches within business ethics use the philosophy of Habermas as well to defend the importance of deliberation in the business context, appealing to his theory of discourse ethics (Gilbert \& Rasche, 2007; Rasche \& Esser, 2006; Reynolds \& Yuthas, 2008; Unerman $\&$ Bennett, 2004; Zakhem, 2008) or to his theory of deliberative democracy (Palazzo 
\& Scherer, 2006; Scherer \& Palazzo, 2007; Scherer et al., 2016). Despite the difference between these approaches, they all hold that CSR activities should be validated within processes of deliberation with stakeholders and society.

A fundamental distinction in Habermas's work, underlying both his discourse ethics and his theory of deliberative democracy, is the distinction between communicative and strategic action. A brief discussion of the distinction between communicative and strategic action will increase our understanding of the conceptualization of stakeholder dialogue in the CSR literature. Habermas's conception of communicative rationality is most extensively worked out in The Theory of Communicative Action (Habermas, 1985, 1987). He speaks of communicative action "when actors are prepared to harmonize their plans of action through internal means, committing themselves to pursuing their goals only on the condition of an agreement . . about definitions of the situation and prospective outcomes" (Habermas, 1990, p. 134). Crucial in this definition is that actors pursue their goals on the basis of a shared definition of the situation. That means that actors, when confronted with a certain action problem, communicatively arrive at a consensus about what is at stake and what should be done about it. In communicative action, an action problem will be dealt with on the basis of this consensus. When Habermas writes that actors are prepared to harmonize their plans of action through internal means, he means that actors convince each other about the interpretation of the situation on the basis of arguments in a way that each can freely accept: "In discourse what is called the force of the better argument is wholly unforced. Here convictions change internally via a process of rationally motivated attitude change" (Habermas, 1990, p. 160). Communicative action, therefore, is a form of communication that aims to achieve a consensus based on rational argumentation.

Habermas contrasts communicative action with strategic action, by which actors influence each other through external means:

If the actors are interested solely in the success, i.e., the consequences or outcomes of their actions, they will try to reach their objectives by influencing their opponent's definition of the situation, and thus his decisions or motives, through external means by using weapons or goods, threats or enticements. Such actors treat each other strategically. (Habermas, 1990, p. 133)

According to Habermas, the use of external means connects strategic action to coercion (cf. Johnson, 1991). In that way, it is the opposite of communicative action. A person who changes his action plan in response to a threat or a promise might not be internally convinced of the alternative, but is forced (however weak 
the force may be) to adopt it. Actors that act strategically try to influence one another, in order to achieve their own interests.

Despite the strong distinction that Habermas draws between communicative and strategic action, he does recognize that strategic action, as well as mixed forms of strategic action and communicative action, might legitimately appear in the real world. Firstly, Habermas recognizes that interaction in a market economy is largely (although not entirely) based on strategic action, which he does not consider to be problematic as such (Habermas, 1996). Hence, his conception of communicative action is not meant to replace all forms of strategic action. Secondly, his model of deliberative democracy also includes the balancing of interests and compromise formation (Habermas, 1998). At the same time, Habermas maintains that the procedures for a fair compromise must presuppose the discourse principle, which "is supposed to secure an uncoerced consensus" (Habermas, 1996, p. 166). The normative force of an orientation towards consensus, therefore, plays a crucial role throughout Habermas's philosophy (Markell, 1997). ${ }^{6}$

The distinction between communicative and strategic action resembles the distinction between the ideal dialogue and the instrumental dialogue, which we identified in the CSR literature. These two types of stakeholder dialogue are presented as the two ends of a spectrum, and they define each other negatively. For example, Patzer et al. (2018, p. 342) hold that “a main precondition is that stakeholder engagement should be based on a communicative rationale and the main objective should be to reach consensus, rather than fulfill strategic intentions." Likewise, Foster and Jonker (2005, pp. 55, 54) claim that Habermas's concept of communicative action "is the only sort of action that can be said to allow a constructive dialogue and reasonable action," while strategic action is about "egoistic success." In a strategic or an instrumental dialogue, participants do not seek agreement as something worthy in itself, but try to influence others to advance their own ends. In this opposition, strategic considerations or considerations of selfinterest have a rather negative connotation. A dialogue in which they play an important role is characterized as corrupted or distorted. Hence, our conclusion that communicative action functions (whether explicitly or implicitly) as a regulative ideal for stakeholder dialogue. In other words: for many authors in this field,

\footnotetext{
${ }^{6}$ This article is also not meant as an interpretation of Habermas, nor is it a critique of his philosophy. That would require a much different approach, delving much deeper into his work. The distinction between communicative action and strategic action is used heuristically, to better understand the CSR literature about stakeholder dialogue. Our main interest is to reflect on whether a consensual orientation is desirable or not in the interaction between companies and NGOs, and not whether the view we develop conflicts with or could be brought in alignment with Habermas' philosophy.
} 
communicative action provides the standards in terms of which the quality of a stakeholder dialogue should be assessed.

\subsection{Problems of the current conceptualization of stakeholder dialogue}

We want to raise the question of whether communicative action (especially the orientation towards consensus) is a proper ideal for stakeholder dialogue between companies and NGOs. Do we actually want those actors to aim at consensus? Why or why not? And can we expect them to ignore strategic considerations? This section outlines several problems with conceptualizing stakeholder dialogue in terms of communicative action. First, we recall some criticism that has been brought forward in the literature. This criticism mainly focuses on the fact that communicative action cannot be achieved in practice, because its standards are too high. Second, we outline what we consider to be a more fundamental problem, namely, that a focus on consensus can be problematic also as a regulative ideal for stakeholder dialogue between companies and NGOs.

Criticism on conceptualizing stakeholder dialogue in terms of communicative action

The ideal of stakeholder dialogue based on communicative action has been criticized in several articles, mainly by highlighting that communicative action cannot be realized in practice. Høvring, Andersen, and Nielsen (2018, p. 643) have argued that the complexity of the practice of stakeholder dialogue receives too little attention and, thus, that there is "an overall tension between an idealization of CSR dialogue versus a realistic execution." They also argue that in the practice of stakeholder dialogue, there remains a tension between the commercial and the societal responsibilities of a company. Burchell and Cook (2013b) show that the key motivations for companies to engage in dialogue with NGOs are reputation management and maintenance of their license to operate. These motives concern the private interests of the company instead of a public interest. Moreover, they note that some companies use dialogue with NGOs to silence criticism, while continuing business as usual. This is a form of co-optation, which means that an actor is able to "bring the interests of a challenging group into alignment with its own goals" (Trumpy, 2008, p. 480; see also Baur \& Schmitz, 2012). Another risk occurs when participants are pushed to reach a consensus: the risk of creating a false consensus (van de Kerkhof, 2006). In that case, a consensus-oriented dialogue may turn out to serve the interests of the most powerful actors (Brown \& Dillard, 2013; Dawkins, 2015). Moog et al. (2015) show in their case study of the Forest Stewardship Council that it became dominated by commercial concerns, regardless of the fact 
that the governance structure of this multi-stakeholder initiative was explicitly designed to include different voices. They argue that this relates directly to the limited resources NGOs have compared to multinational corporations.

It is questionable whether this criticism necessitates the rejection of communicative action as a regulative ideal for stakeholder dialogue. The fact that an ideal is far from realized in practice does not, as such, provide a good reason to reject it. Many, if not all, adherents of consensus-oriented stakeholder dialogue recognize that the ideal is often not achieved in real life. One could say that an ideal is always counterfactual: it is the very function of an ideal to be aspired to, even though its complete realization may not be possible. Therefore, communicative action could probably function for stakeholder dialogue as a regulative ideal "that provide[s] standards at which to aim, not criteria that if not met disallow the process" (Warren \& Mansbridge, 2013, p. 90). Some authors, however, have also argued that a consensus-oriented dialogue might not be a proper ideal. Høvring et al. (2018) have argued that conflict and dissensus can also be a source for social change. Blok (2014b) has noted that the emphasis on harmony and alignment in the literature on partnership formation neglects the fact that there can be fundamental differences (in views and interests) between stakeholders (see also Blok, 2019, 2014a). Sabadoz and Singer argue that the business context, as such, is hostile to consensual deliberation, because "the purpose of the market is precisely to orient behavior with minimal concern for moral consensus” (2017, p. 195). ${ }^{7}$ This criticism on a consensus orientation in stakeholder dialogue does not only apply to business-NGO relations, but also to other stakeholder relations. We want to address the question of why, specifically for companies and NGOS, consensus can be a problematic regulative ideal.

\section{The market as adversarial and nonideal institution}

Companies operate within the institutional context of the market. At its core, this means that the exchange of goods and services is mediated by prices, which are established through a process of supply and demand. The virtue of the price mechanism is that it helps to bring supply and demand together in an efficient way,

\footnotetext{
${ }^{7}$ The article by Sabadox and Singer (2017) discusses the general question whether markets are an appropriate context for (consensual) deliberation (and their answer is negative). Although we agree with much of their argument, our approach is different. Our question is: given the fact that companies and NGOs do engage in dialogue, what norms should and should not guide their communicative interaction? In a way, this chapter picks up their suggestion that different contexts might require different deliberative standards (Sabadoz \& Singer, 2017, pp. 201-202).
} 
at least compared to a system of central planning. Instead of carrying out specific orders, demand and supply are brought together by letting companies compete for the favor of customers. The element of competition is characteristic for what Heath calls adversarial institutions, which he defines as institutions "whose social function is discharged, not by having participating individuals intend the desired outcome, but . . . letting the desired outcome arise as a (typically unintended) consequence of the agonistic interaction that results" (Heath, 2019, p. 350). The idea is that, while the purpose of markets is to realize overall efficiency and market-clearing prices, corporate managers do not directly intend that goal, but indirectly contribute to it by aiming at the proper functioning of their particular company, often understood in terms of the pursuit of profit. Heath notes that seeing the market as an adversarial institution implies that companies are allowed to exhibit a certain partiality, which permits the pursuit of profit. This permission is indirectly justified by the overall beneficial effects that the pursuit of profit and competition have on the functioning of the price mechanism.

As an adversarial institution, the market is also a nonideal institution. Companies are allowed to exhibit a certain partiality through the pursuit of profit in order to obtain the overall benefits of competition. This permission implies that, to a certain degree, companies are allowed to impose harm on others: lowering one's prices might harm competitors, and dismissing employees in order to secure the survival of a company is also in tension with some strong moral intuitions (cf. Applbaum, 1999; Heath, 2019). It is important to acknowledge that there is a risk in the permission to pursue profits: companies may take this as license for the unconstrained pursuit of their commercial interests at the expense of everything else. If only a few actors in the market think and act like this, the very element of competition might create a perverse incentive for other companies to do the same (given that firms can reap financial benefits from acting this way, at least in the short term).

The permission to pursue profits does not imply that companies should maximize profits. Companies can have-and probably should have-very different reasons for doing what they do, and one of their main motivations might be to contribute to society by delivering high quality products (although they will need to do this in a profitable way). The point is that the market morality at least permits the pursuit of profit, and the idea of markets as adversarial institutions aims to justify this permission. Furthermore, the permission to pursue profits does not exempts companies from their social responsibilities. Although most business ethicists accept that the pursuit of profit is legitimate, they maintain that companies have social responsibilities besides their economic objectives, whether these are grounded in their responsibilities towards stakeholders (e.g. Freeman et al., 2010), in their duty 
to refrain from profiting from market failures (Heath, 2014) or in the political nature of corporations (e.g. Scherer \& Palazzo, 2007). Yet all these theories have to account for the fact that the social responsibility of companies is limited due to the competitive nature of the market and the permission to pursue profits (Dubbink, 2004).

As a nonideal institution, the market exhibits some structural problems, for which it stands in need of correction. A common correction is government policies that countervail market failures and promote competition. Self-regulation and CSR can also contribute to correcting market failures and the neglect of public values (cf. Norman, 2011). A third form of correction comes from civil society: citizens and NGOs that try to hold companies accountable for what they are doing, or work together with companies in order to improve their performance in relation to societal issues (cf. Crouch, 2011). In order to shed more light on the role of NGOs, we now turn to a short discussion of their societal role.

\section{Advocacy NGOs as response to a nonideal world}

Advocacy NGOs (also called watchdog or social movement NGOs) are non-profit organizations that promote a specific societal value (Martens, 2002; see also Baur \& Palazzo, 2011; Baur \& Schmitz, 2012; Yaziji \& Doh, 2009)..$^{8}$ We conceive of societal values as those values that are regarded by a substantial part of society as objects of worth and regard, for which they need the attention of different societal actors. ${ }^{9}$ If there were no societal problems that threatened those values, or if companies and other societal actors were to already recognize and address these problems, many NGOs would probably not exist. These organizations are, so to say, a response to the fact that we live in a nonideal world. By implication, they do not accept the status quo, but aim to change practices that relate to their mission and engage in social criticism. ${ }^{10}$ Of course, that NGOs are supposed to defend and promote societal values does not mean that everyone agrees with their mission and actions: what counts as societally valuable can always be contested. Furthermore, NGOs can also

\footnotetext{
${ }^{8}$ Our analysis is restricted to advocacy NGOs, in contrast to 'service NGOs' that deliver certain goods or services to their members. See Yaziji and Doh (2009) for difference between these types.

${ }^{9}$ By talking about a 'substantial part of society', we want to avoid the pitfall that only those values about which there is consensus, or which are held at least by a majority of society, are regarded as societal values. In our definition, societal values can be contested and need not be held by a majority.

${ }^{10}$ There might be NGOs who actually try to retain the status quo, but only if the status quo is challenged by some negative force. In that case, they still want to change something, namely to stop the negative trend. 
be used as a vehicle for group interests. However, without saying that NGOs always genuinely serve the public interest, they are, at least, the type of organization that we can expect to do so. They have (or should have) a social purpose, and people support or become a member of those organizations on the basis of their social purpose (Hussain \& Moriarty, 2018). Whether they serve this social purpose properly can always be subjected to critical scrutiny.

The strategies that NGOs adopt to pursue their mission can be very different. An important distinction has been made between radical and moderate, or reformative activist, groups (e.g. den Hond \& de Bakker, 2007; Mena \& Waeger, 2014). Reformative groups are understood as more willing to cooperate with companies as compared to radical groups. Yet, despite their differences in tactics, the goal of both types of NGOs is similar, namely, to change current practices to protect the values they defend. Specifically, in addressing corporate behavior, their goal is to improve "firm practices with respect to social, environmental, or ethical CR [corporate responsibility] issues" (Mena \& Waeger, 2014, p. 1096).

\section{Why dialogue between companies and NGOs requires nonideal normative principles}

Although this short exercise about the market as a nonideal institution and the societal function of NGOs may be somewhat oversimplified, it aims to make clear that there is an adversarial element in the relation between companies and NGOs. Companies operate within the fallible institution of the competitive market, which requires correction and social criticism. NGOs play an important corrective role and voice social criticism and, therefore, it does not come as a surprise that many CSR scholars insist that companies should engage in dialogue with NGOs. We argue, however, that the insistence on the importance of consensus in such dialogues is problematic, and that nonideal normative principles are necessary to guide the interaction between companies and NGOs. We contend that an orientation towards consensus as regulative ideal can be problematic for two reasons. First, an orientation towards consensus requires a certain impartiality, namely, the ability to set aside one's particular interests in relation to a societal issue. This can be very difficult for companies, especially when their strategic interests are in tension with addressing a societal problem. Put differently, an orientation towards consensus can be in tension with the permission that companies have (and which is constitutive for the functioning of the market) to pursue the particular interests of their company. Second, consensus implies the convergence of beliefs, as we noted before. In certain cases, this can be undesirable given the role that NGOs have as agents of social criticism. This is so mainly because their identity might be dependent on specific views about societal values, but also because they are, in many cases, financially supported by donors and members because of their activism and critical attitude. 
Hence, an orientation towards consensus from their side can be conflicting with their role of challenging companies to pay more attention to certain societal values.

That a consensus orientation can be problematic as regulative ideal, indicates that it is not necessarily so. We contend that problems with a consensus orientation arise especially when a convergence in beliefs jeopardizes the core activities or views of one or more of the parties in a dialogue. For companies, this situation crops up when their production processes or products themselves contribute to societal problems or are the subject of societal debate. For example, there are tensions between the activities of beverage companies and public health, because the (excessive) consumption of sugar-sweetened beverages contributes to problems like obesity (cf. Iivonen, 2018). The same holds for transport companies and the emission of fossil fuels. This does not mean that such companies do not have to change their processes of products. Yet even though they might recognize the problematic relation of their activities to a social problem, and even though they might be willing to change, they cannot simply set their current commercial interests aside, nor is it likely that they are always able to meet the ideals of NGOs. Striving after consensus with a public health or environmental NGO threatens the identity of such companies more directly compared to companies whose activities are contingently related to a societal problem.

For NGOs, the problems of a consensus orientation are similar. For them, aiming at consensus in a dialogue with companies whose activities are strongly at odds with their mission constitutes a threat to their identity. Of course, it could be that also in these cases, a consensus arises at certain points. But arguing that NGOs should always strive after it, or marking a consensual orientation as criterion for their legitimacy, is a different thing (cf. Baur \& Palazzo, 2011). Contrariwise, we suggest that a certain cautiousness to achieve consensus with companies (whose interests and activities are in conflict with their mission) is a more appropriate mark for their legitimacy. Hence, we argue that in such cases, it is better to give up the regulative ideal of consensus and instead adopt nonideal normative principles.

\subsection{Agonistic deliberation: incorporating self-interest and conflict within stakeholder dialogue}

Based on our analysis, we propose an alternative view of stakeholder dialogue. This alternative is not meant to replace, but to complement other forms of stakeholder dialogue. We call our alternative agonistic deliberation, because the dialogue between companies and NGOs will often be a form of deliberation between adversaries. In what follows, we first discuss the sources of inspiration for our 
approach, and in what way our approach differs from these sources. After that, we describe what agonistic deliberation entails.

\section{Sources of inspiration: agonistic pluralism and deliberative negotiation}

Our approach to stakeholder dialogue is inspired by two main sources: (1) Chantal Mouffe's agonistic pluralism and (2) the idea of deliberative negotiation developed by Jane Mansbridge (among others). From Mouffe $(1999,2005)$ we borrow the concept of agonism, which we translate to the relation between companies and NGOs. The work of Mansbridge is used as inspiration for how to incorporate issues of conflict and self-interest within deliberation (Mansbridge, 2009; Mansbridge et al., 2010; Warren \& Mansbridge, 2013). In what follows, we shortly describe those two approaches and which elements we adopt for our own conceptualization of stakeholder dialogue.

Mouffe's approach to political philosophy—agonistic pluralism-criticizes the theory of deliberative democracy, with its emphasis on seeking rational consensus. According to Mouffe, politics always has an inherently conflictual, or antagonistic, dimension. In this view, the aim of democracy is not to eradicate conflict (since that would be impossible), but to domesticate it (Mouffe, 1999). Mouffe explains how this domestication of conflict could work by drawing a distinction between an antagonist and an adversary. The first is an enemy: someone who is to be destroyed. The second is an opponent, "somebody whose ideas we combat but whose right to defend those ideas we do not put in question" (Mouffe, 2000b, p. 102). The essence of agonistic pluralism consists of accepting that there are unbridgeable differences between ideologies (pluralism) and the conception of politics as a struggle between adversaries (agonism).

This approach to political philosophy has been used by several authors to understand the relation between companies and their stakeholders. For example, by using Mouffe's philosophy, Burchell and Cook "seek to re-emphasise the importance of conflict and challenge within analysis of CSR and stakeholder dialogue” (2013a, p. 742). They argue that the relations between companies and NGOs are best interpreted as agonistic: there is a struggle between those actors about the meaning and content of the social responsibilities of companies. Another approach to stakeholder engagement based on Mouffe's agonistic pluralism was developed by Dawkins (2015). In his view, the problem with most approaches to stakeholder engagement is that they fail to pay sufficient attention to the (often unequal) power relations between stakeholders. He argues that there is a "clear need for countervailing voice" (2015, p. 11) to counter (corporate) hegemony. The aim of his agonistic approach to stakeholder engagement is to make a 'fair fight' between 
stakeholders possible, where dissensus and conflict are not seen as something negative.

Agonistic pluralism provides a promising alternative to the idealized conception of consensual deliberation, by seriously taking into account conflict and issues of power. However, we think that this approach suffers from a significant problem, which relates to the fact that Mouffe sees the agonistic struggle between adversaries as a struggle for hegemonic power (Mouffe, 2005; see also Rummens, 2009). According to Dawkins (2015) and Burchell and Cook (2013a), the struggle between companies and their stakeholders can also be interpreted as a hegemonic power struggle. Although this can be true from an empirical point of view, it would be very problematic from a normative point of view. In our view, striving for hegemonic power is at odds with the very idea of agonism. Agonism implies respect for one's opponent and for the rules of the game. This conflicts with seeking hegemony, which means that one view or group dominates over others (cf. Knops, 2007; Erman, 2009; Rummens, 2009). Hence, we would argue that adopting an agonistic attitude means that actors abstain from seeking hegemonic power. To illustrate this point, consider a criminal trial procedure. This is an institution in which a prosecutor and defense lawyer are adversaries: they represent and defend opposing views and interests (see also Applbaum, 1999; Heath, 2019). However, if one of the parties would seek and achieve hegemonic control over the other, the very institution - which is meant to represent both sides-would be dissolved. This also holds in the context of business-NGO interactions: companies and NGOs both fulfill valuable roles, and it is undesirable that one group would ever come to dominate the other. So, even though we adopt the idea of agonism from Mouffe's philosophy, this should rather be interpreted as a rejection of the legitimacy of a struggle for hegemony between companies and NGOs.

The work of Mansbridge- our second source of inspiration —is located within deliberative democracy. In her work, she has analyzed how conflict and self-interest can have a legitimate place within deliberation (Mansbridge et al., 2010). Many deliberative democrats draw, in one way or another, on the distinction between communicative and strategic action. The first is connected with arguing, consensus, and the public good; the second with bargaining, conflict, and private interests (Elster, 2000). By drawing on this distinction and, of course, by emphasizing that deliberative democracy should rely on the first part, Mansbridge argues that deliberative democrats discard the legitimacy of conflicts over self-interest within deliberation (Mansbridge, 2006). As an alternative to this dichotomy, she and others have developed a typology of agreement seeking procedures, where agreement includes both consensus and compromise (Warren \& Mansbridge, 2013). In between pure deliberation and pure bargaining, a place is given to 'deliberative 
negotiation.' Deliberative negotiation is a process in which actors "make and respond to claims, arguments, and proposals with the aim of reaching mutually acceptable binding decisions . . . based on processes of mutual justification, respect, and reciprocal fairness" (Warren \& Mansbridge, 2013, p. 92). Deliberative negotiation differs from pure deliberation in at least the following ways: it allows for (conflicts of) self-interest as legitimate part of the process, and it accepts compromise (besides consensus) as a legitimate outcome. Other goals, like clarifying conflict and increasing mutual understanding, also fall within the scope of deliberative negotiation.

We think that the notion of deliberative negotiation can be fruitfully applied to business-NGO interaction. Although the meaning of agonistic deliberation is quite close to this notion, we choose the adjective agonistic in order to stress the adversarial element in the relation between companies and NGOs. Furthermore, we wanted to avoid the word negotiation because it suggests that a conflict between parties can be reduced to differences in private interests. In the case of conflict between companies and NGOs about societal issues - characterized by their public nature-this would be problematic, even though it affects private interests. We define agonistic deliberation as an approach to dialogue between adversarial stakeholders in which enduring conflict in views and interests is legitimate and to some extent desirable, yet in which participants are willing to mutually justify and accommodate their views on how to address a societal issue. On the one hand, this approach recognizes the differences between actors and the possibility of enduring conflict. On the other hand, it retains a certain ideal as to how participants should treat each other. By noting that agonistic deliberation is an approach to dialogue between adversarial stakeholders, we leave room for other types of dialogue. As we noted before, this adversarial element is especially present when there are strong tensions between the core activities of companies and the missions of NGOs. Our approach to dialogue is specifically tied to those situations in which there is such an adversarial element in the relation between stakeholders.

\section{Conflict in agonistic deliberation}

A distinguishing element of agonistic deliberation is that it recognizes the possibility of enduring conflict between companies and NGOs. Conflict and contestation between those actors can be necessary and desirable for at least three reasons. First, it plays a role in creating awareness of societal problems, mobilizing support for change, and urging actors to take responsibility. The need of partisanship and conflict for mobilization is strongly emphasized by Mouffe (e.g. 2005). In some cases, citizens may come to realize the urgency of a certain issue only after NGOs have publicly criticized a company's problematic activities. And companies may 
sometimes only resort to action after having been criticized in such a campaign. Second, conflict and contestation will be necessary because new situations will always create new problems and challenges that call for new responses. For this reason, agreements between companies and NGOs are likely to be tentative, and existing ways of addressing a problem might become out of date. Third, conflict might be necessary in order to fight power imbalances (Dawkins, 2015). When companies use their power to defend their interests in a way that conflicts with public interests, it is the role of NGOs to make this visible and to contest this use of power. For that matter, we must recognize that NGOs can misuse their power, too. For example, when an NGO has achieved an influential position, it can be in their interest to retain the status quo, without really contributing to societal change. For that reason, it is also important to critically examine the activities of NGOs and hold them accountable for these activities. This critical role can be fulfilled by citizens and other NGOs.

NGOs have different means for creating awareness, calling for new responses, and fighting power imbalances. Campaigning, especially through the media, is the most well-known way to do so. The question might be raised as to whether dialogue is a proper venue for conflict. Why not campaign when there is conflict and only engage in dialogue when there is a possibility of consensus? Does it make sense to engage in dialogue when there is no prospect of consensus? We would like to turn this question around: Would it make sense to refrain from engaging in dialogue for the mere reason that actors are hesitant to aim at consensus? If that would be the case, companies will only deliberate with NGOs whose views are (potentially) close to theirs, with the risk that NGOs that criticize their activities will not be taken seriously. In addition, consensus, or something close to it, is not the only valuable outcome of dialogue. Dialogue is also relevant and important when there is and will remain a certain conflict: even without a prospect of consensus, dialogue might help to clarify the conflict, increase mutual respect, and create awareness a societal problem (Warren \& Mansbridge, 2013). Furthermore, as shown by empirical research, campaigning and engaging in dialogue are not mutually exclusive strategies. Burchell and Cook (2013b) report that NGOs sometimes engage in dialogue with the same companies whose activities they are campaigning against, even though these companies want them to stop their campaigns.

When companies and NGOs deliberate, the tensions between them will likely be persistent, since we can expect that both parties will continue to have different views about how societal issues should, ideally, be addressed. Parties will often have to accept that compromises are inevitable if they want to reach an agreement. As Mouffe notes, compromises "should be seen as temporary respites in an ongoing 
confrontation" (Mouffe, 2000a, p. 16). In such agreements, the threat of exit is always present, both from the side of companies and NGOs (Sabadoz \& Singer, 2017; cf. Hirschman, 1970). There is always a risk that one of the parties will withdraw from an cooperative agreement, if they consider their interests harmed or their views not taken into account. This happened, for example, with the Forest Stewardship Council, from which several NGOs withdrew (Moog et al., 2015). The purport of agonistic deliberation is to recognize this possibility, which is one of the reasons why we do not want to preclude the legitimacy of conflict within deliberation.

\section{Self-interest in agonistic deliberation}

We have shown that authors who conceptualize a good stakeholder dialogue in terms of communicative action do not consider self-interest to have a legitimate place in it. Yet both companies and NGOs have certain interests that deeply influence their functioning. We contend that it would be better to explicitly put these interests on the table within a dialogue, especially when they are in tension with addressing a societal issue. The commercial interests of companies are related to their responsibilities towards owners, employees, suppliers, etc. These interests are a legitimate and essential part of business. Concealing them for the sake of reaching agreement with NGOs is not likely to result in stable agreements. Moreover, hiding self-interested motives behind well-sounding arguments could lead to (mutual) distrust.

Companies must also understand that it is in the interest of NGOs to retain a certain independence from companies. A reputation of independence is necessary for the identity of an NGO and its ability to raise funds. If an NGO is seen as making agreements too easily with companies, it risks losing its legitimacy in the eyes of the public. Consequently, in an agreement between companies and NGOs on how to address a societal issue, the interests of both parties in an agreement must be sufficiently taken into account. We, therefore, hold that self-interest has a legitimate place within stakeholder dialogue, because it is informative of and has influence on the positions of participants.

Clearly, self-interest is relevant as information within a dialogue (Mansbridge, 2006). But, could it also count as justification for adopting a certain position? Is it sufficient to argue that we are against a proposal, because it does not match our interests? We hold that this is not sufficient for a justification of one's view. Still, there is a difference between companies and NGOs and the role that self-interest plays in determining their position. As we said before, the functioning of a competitive market relies on the permission to pursue self-interest within certain limits (Heath, 2007, 2019). In order to have the benefits of the competitive market, 
companies are allowed to adopt a certain partiality in their actions, namely, to pursue what is in the interest of their constituencies-whether those are only the shareholders or a broader (but still limited) set of stakeholders. Hence, it would be inconsistent to expect companies to adopt a completely impartial point of view in a dialogue about societal issues.

The case for NGOs is different. Because of the partiality that companies exhibit and the consequent risk that they take societal issues into account too infrequently, NGOs represent those societal issues in order to correct them. NGOs must be able to justify their activities with reference to the societal values they support, because supporting those values is their core function. Admittedly, NGOs also exhibit a kind of partiality, since they only defend a very particular subset of all relevant societal values. Yet that makes it even more important for them to justify why these particular values are important and require the attention of other societal actors. That does not mean that strategic considerations are irrelevant for NGOs. They have to raise money and gain public support in order to be able to carry out their mission. Still, because the core function of advocacy NGOs is to serve societal values, we can expect that their strategic considerations are instrumental to the societal goals they pursue. At the same time, there can be tensions between considerations that relate to raising money or gaining public support and their overall mission. For example, NGOs might have to focus on different topics than they would prefer to, because they failed to raise money for the topics they deemed most important. When this is the case, it might also influence their input within a dialogue. So, even though it remains crucial for NGOs to be able to justify their views and activities with reference to the societal values they support, we cannot simply declare it invalid if they make use of strategic considerations within a dialogue.

What to do, it might be asked, if there is a strong conflict between public interests and the private interests of an actor within deliberation? Should not public interests always trump private interests? Are private interests not, in the end, irrelevant when it comes to taking a normative position? We do not think so. Of course, there are clear cases of such conflict where public interests should prevail. Consider the interests that a food company might have in hiding information about the negative health effects of certain additives. Their interests provide them with no (sufficient) reason to hide the information. But the case already becomes more complicated when we think about unhealthy products that make up a significant part of the portfolio of some food companies. Should they abandon such products for the sake of public health? By giving this example we do not mean to say that such companies should not change anything. We only seek to make the point that we cannot simply say that public interests always trump private interests. Conflicts 
between these two can be genuine ethical conflicts, for which they should be a topic of discussion within deliberation.

\section{Compromise in agonistic deliberation}

If consensus is neither a probable nor a desirable outcome of a dialogue between a company and an NGO, what outcome could fit with agonistic deliberation? We think that compromise is also a viable outcome of dialogue, and that many collaborations between companies and NGOs, in fact, are based on compromises. Warren and Mansbridge (2013, p. 97) define a compromise as "an agreement in which all sides sacrifice something of value (i.e., make concessions) to improve on the status quo from the perspective of each." When an agreement is characterized as compromise, both parties in the agreement can retain their independence and can also maintain a critical distance from the views of the other. For NGOs that want to maintain such critical distance from companies, aiming at a workable compromise in dialogue and collaboration fits better to their role as challenger and social critic.

Many authors indicate that collaboration between companies and NGOs requires that participants reach agreement on the division of responsibilities (Roloff, 2008; Rondinelli \& London, 2003; e.g. Van Tulder et al., 2016). In our view, such an agreement is more likely to be a compromise rather than a consensus. Seitanidi and Crane (2009, p. 422), for example, mention explicitly that partners in a collaboration can overcome crises "by not avoiding conflict but rather accept disagreements as functional which permits retaining the organisation's identity intact." We, therefore, think that agonistic deliberation could better explain what is going on in actual dialogues and collaborations between companies and NGOs compared to a view based on pure communicative action. The necessary element of cooperation is that both parties are willing to accept the terms of collaboration and are willing to carry out their tasks, even though they might have different reasons for doing so. If the interests in and commitment to cooperation are strong enough, it would not require a complete convergence of views on the matter.

In general, it is more likely that NGOs that adopt a reformative stance are willing to engage in dialogue with companies about their social responsibility compared to radical NGOs. Yet even when a moderate NGO enters a dialogue with a company in order to cooperate on behalf of a societal issue, they will-in most cases, and to a certain degree- have to make concessions for the sake of pragmatic improvement. Although it may sound contradictory, one could even make the argument that radical NGOs consider consensus as more important compared to reformative ones. As Mena and Waeger argue, "radicals only evaluate proactive firms positively if they address CR [corporate responsibility] issues in ways radicals consider entirely satisfactory" (Mena \& Waeger, 2014, p. 1096). In other words, 
radical groups will approach companies positively and constructively only if there is a possibility of convergence in views-a consensus. However, since they do not believe in such a possibility (or only in some exceptional cases), they do not engage in a consensual dialogue or consider cooperating with companies. "In contrast, reformative activist groups emphasize the importance of achieving workable solutions . . . even if they do not immediately address CR issues comprehensively" (Mena \& Waeger, 2014, p. 1096). Hence, while reformative groups recognize that they would not easily achieve consensus with companies, they do not take this as a reason not to engage in dialogue with them, because they consider a compromise as sufficient ground for dialogue and cooperation.

\section{The deliberative aspect of agonistic deliberation}

We have argued for the legitimacy of conflict and self-interest in deliberation. However, as Hirschman has noted, conflict can function both as glue and as solvent: it can be something that binds us together, but also something that tears us apart (Hirschman, 1994). In order to avoid a situation in which conflict within stakeholder dialogue becomes a solvent, certain deliberative norms need to be respected. The same holds in relation to self-interest: its presence can only be legitimized within deliberative boundaries. By employing the distinction between antagonists and adversaries, we already presupposed certain deliberative norms. Unlike antagonists, adversaries recognize the legitimacy of their opponents, even though they pursue different ends (Mouffe, 2000b, 2005). This recognition of the other as having the right to have a different view is necessary to make the management of dissensus possible. Hence, the interaction between adversaries is guided by certain mutually accepted rules, such as abstaining from violent behavior. As soon as one starts to use violence against one's opponent, that turns him into an antagonist. $^{11}$

Beyond recognizing the legitimacy of one's opponent, our definition of agonistic deliberation states that participants should be willing to mutually justify and accommodate their views. Hence, mutual justification and accommodation is the central deliberative norm that should guide agonistic deliberation. It implies that participants in a dialogue, even though they are in conflict without a prospect of

\footnotetext{
${ }^{11}$ We recognize the difficulty of how to define violence. Campaigns of NGOs can seriously damage companies (for example successful appeals to consumers to boycott a company or product), although we would not immediately classify every campaign that results in damage as violence. See also Baur and Palazzo (2011, pp. 590-591) on the criterion of 'civil behavior' for the legitimacy of NGOs. For a general and very informative study about the ethics of adversarial relations in public and professional life, see Applbaum (1999). 
resolution, should be willing to give and respond to reasons. It also implies that participants should be willing to explore differences and agreements (without saying that they should reach agreement). The exploration of differences can lead to better mutual understanding, so that participants know from each other where they disagree and why. This principle is very much in line with recent work in deliberative democracy. For example, Thompson (2008, p. 504) notes that mutual justification is "the most important distinguishing characteristic of deliberation." This norm is not the same as aiming at consensus. Mutual justification is very well possible without consensus as aim or as outcome. A dialogue based on this norm might also result in a mutual clarification of positions, in increased mutual understanding, or in one or more of the participants changing his or her mind. Rescher explains the difference between mutual justification and the mere aim to reach agreement:

When I realize that my position on some issue of consequence disagrees with yours, I am well advised to inquire into how it is that you have rendered a conclusion different from mine-and presumably then to change my view if the grounds for yours appear to be stronger. But I am not well advised to worry about the bare fact that your beliefs differ from mine in ways that are detached from the issues that relate to grounds and reasons. It makes good sense to revise beliefs to accommodate them to other evidence, but it makes no rational sense to revise them to accommodate other people. (Rescher, 1993, p. 17)

What Rescher makes clear is that consensus should not be a goal in itself, in order to conform to the beliefs of others. Of course, defenders of a consensus orientation such as Habermas do not argue that agreement should be reached "in ways that are detached from the issues that relate to grounds and reasons." On the contrary, they insist that a consensus is only valuable if it is reasonable or rationally motivated (e.g. Habermas, 1996). At the same time, Habermas and others insist on the importance of the connection between reasonableness and an orientation towards consensus. We hold that this connection does not have to be strong. What is important is that participants within a dialogue are willing to make themselves intelligible, to give an account of their views and beliefs. In order for a dialogue to count as reasonable in this sense, an orientation towards consensus is not necessary. ${ }^{12}$

\footnotetext{
${ }^{12}$ Of course, it is very difficult to have such a reasonable attitude if you know or suspect that others will not be listening nor willing to be reasonable either. These requirements only 'work' when all participants of a dialogue commit themselves to them, and when there is the trust among every participant that others have the same attitude. When stakeholder dialogue entirely lacks any of these deliberative elements, the interaction will be purely based on
} 
There is one significant complication in relation to the willingness to reconsider one's own view: most often, stakeholders within a dialogue do not participate on their own behalf, but represent a group or an organization. That means that, as part of their role, they have a responsibility to represent a specific view within a dialogue. They cannot simply change their mind during the dialogue if they become convinced of some alternative view, because they have to give an account of their input to the group or organization they represent. Moreover, they could only change their view if they have a mandate to do so, or after a round of feedback within their own group or organization. Stakeholder representatives play, so to say, a 'two-level game,' both within their group or organization and within the dialogue (cf. Warren \& Mansbridge, 2013, p. 96). Although this complicates the matters, it would be even more complicating for a consensus-oriented dialogue. In that case, a dialogue between actors, who-as part of their role-have no room to change their position, does not seem to make sense. Since agonistic deliberation allows for different outcomes, it can also better account for this complication. For example, a compromise allows for agreement on concrete goals or actions, while at the same time leaving room to maintain one's originals views and ideals.

\section{The scope of agonistic deliberation}

Until now, we have argued rather broadly that companies and NGOs engaging in dialogue about societal issues should not avoid conflict and should incorporate issues of self-interest. At the same time, we have left open the possibility that a consensus orientation can also be fruitful and appropriate in certain cases. However, we have not specified under which conditions the participants in a dialogue should resort to communicative action or to agonistic deliberation. Although it is beyond the scope of this chapter to elaborate extensively on this question, we want to give some remarks on the conditions when agonistic deliberation applies.

First, as we have argued before, agonistic deliberation is most suitable in cases when the core activities of companies are in conflict with the societal values that NGOs defend. Especially in those cases, NGOs play an important role in voicing social criticism, mobilizing the public, and stimulating social change. Although we have argued that it is still valuable that NGOs and companies engage in dialogue in such cases, a consensus orientation is not necessary and might even undermine the critical role of NGOs.

strategic action. This would be problematic, not because the pursuit of private interests is as such problematic, but because a conflict about ethical and societal issues should not be reduced to a conflict between private interests (cf. Benjamin, 1990, pp. 15-20). 
Second, agonistic deliberation will be more appropriate in cases of power differences between companies and NGOs (cf. Dawkins, 2015). The bigger the power differences are, the more difficult it will be to reach a genuine and unforced consensus. In such cases, it will be better to allow for more conflict and to acknowledge differences, so that actors with less power are also able to articulate their positions. Furthermore, in cases where there are big power differences, it is likely that the interests of minority groups are not taken into account (cf. Sanders, 1997). For that reason, agonistic deliberation might be desirable, because it aims to give room for the articulation of self-interest.

Third, agonistic deliberation does not have to apply to all the aspects of a dialogue about a societal issue. For example, it could be that participants can quite easily agree on the causes of a problem, but not on who is responsible for the solution. Agonistic deliberation is better suited for the latter, while communicative action might be appropriate to discuss the former. We can expect that the biggest conflicts between companies and NGOs will be about the division of responsibilities for addressing a social problem, which are conflicts that relate to action. It is our intuition that agonistic deliberation is most appropriate to discuss issues of action: what has to be done and who has to do what.

Fourth, when the debated topics are highly contested, and the differences in views between actors are large, agonistic deliberation can also be more suitable. This contrasts the claim made by Patzer et al. (2018, p. 341), who argue that "the newer the issue, the greater the disagreements about it, the likelier the conflicts between different stakeholder interests, and the greater the range of values it concerns . . . the more it will require communicative action" instead of strategic action. Probably the authors are right to prefer communicative action over pure strategic action in such cases, because the latter will come down to a mere power struggle. However, our argument would be that a form of communication that leaves more room for conflict, self-interest, and persistent differences than communicative action would be both more realistic and more desirable in the case of contested issues.

Fifth and last, it might be asked whether agonistic deliberation applies in different institutional contexts. For example, it has been argued within political CSR that deliberation between companies and societal actors becomes more important under conditions of globalization or when nation states are weak (Patzer et al., 2018; Scherer \& Palazzo, 2007, 2011; Scherer et al., 2016). Does the same hold for agonistic deliberation? The short answer is that agonistic deliberation does (of course) not equally apply in all institutional contexts. The long answer we have to suspend. Our approach is restricted to the question: Given that companies and NGOs engage in dialogue about societal issues, what kind of communicative norms should 
or should not be adopted by them? Specifying the institutional contexts in which agonistic deliberation is more or less needed is beyond the scope of this chapter.

\subsection{Conclusion}

In this chapter, we have been discussing the question of what a suitable regulative ideal is for stakeholder dialogue in the case of companies and NGOs. Our point has been that, when companies and NGOs engage in dialogue about a societal issue, it will often be better to allow for conflict and to incorporate strategic considerations, instead of striving for consensus. Agonistic deliberation is a conceptualization of an alternative to communicative action, one we think of as more realistic and more adapted to the context in which companies and NGOs operate. Our main arguments are that an orientation towards consensus is in tension with the function of NGOs to voice social criticism, and that the expectation to set aside strategic considerations is in tension with the idea of a competitive market in which companies are allowed to exhibit a certain partiality towards their own (commercial) interests. At the same time, agonistic deliberation upholds the importance of mutual justification, which requires that participants in a dialogue are willing to give a reasonable account of their position.

Our approach to stakeholder dialogue provides a third option between the ideal of communicative action on the one hand, and a purely conflictual or strategic understanding of the interaction between companies and NGOs on the other hand. Conflict and self-interest will always be present in stakeholder dialogues, and both can have a legitimate and constructive role. By taking this into account, agonistic deliberation has the potential to change the way in which stakeholder dialogue is understood and performed in practice. 



\section{CHAPTER 4}

\section{TENSIONS IN STAKEHOLDER INTERACTION: BALANCING SOCIO-ETHICAL AND COMMERCIAL OBJECTIVES}

Submitted to Business and Society Review

Co-author: Vincent Blok 


\section{CHAPTER 4 TENSIONS IN STAKEHOLDER INTERACTION: BALANCING SOCIO-ETHICAL AND COMMERCIAL OBJECTIVES}

\subsection{Introduction}

Companies can have different reasons for engaging in corporate social responsibility (CSR). A rough distinction can be made between socio-ethical and commercial reasons. Socio-ethical reasons for CSR relate to acting out of a sense of duty or responsibility, in order to contribute to the well-being of stakeholders and society as a whole. Commercial reasons relate to the private benefits that companies can obtain or costs that they can avoid by performing CSR activities. Although these two different kinds of considerations do not necessarily exclude each other (it is possible to have both socio-ethical and commercial reasons for doing CSR), there can be tensions between them (Margolis \& Walsh, 2003).

In this chapter, we investigate how tensions between socio-ethical and commercial objectives in CSR activities affect the dialogue between companies and their stakeholders. We do so by analysing the dialogue between stakeholders related to a specific form of CSR, namely industry self-regulation (ISR). Even though achieving social goals is most often presented as the main goal of ISR, companies can also have strategic interests in joining ISR schemes. ISR provides a clear example of the tension between socio-ethical and commercial reasons for doing CSR activities, since having a positive social impact and the realization of private benefits on the part of the participants in ISR schemes do not always smoothly go together (Bowen, 2019).

We can expect that the tensions between socio-ethical and commercial considerations for CSR in general and ISR schemes specifically, will affect the deliberative interaction between companies and their stakeholders. For example, participants will never be able to set their private interests completely aside. Furthermore, it is possible that actors package strategic considerations in moral terms, or they may be suspected by others to do so. As shown by several authors, companies sometimes use dialogue with stakeholders to co-opt critics and to silence criticism (Baur \& Schmitz, 2012; Burchell \& Cook, 2013a). This implies that stakeholder engagement in itself is not a sign of corporate responsibility, but can be conducted in more or less ethical ways (Greenwood, 2007). For that reason, a distinction has been made between 'genuine' and 'instrumental' approaches to stakeholder dialogue (Crane \& Livesey, 2003). Where a genuine approach to dialogue implies openness and responsiveness to the views and concerns of stakeholders, an instrumental approach means that those views and concerns are 
taken seriously only if a company can benefit from doing so. Following Crane and Livesey (2003), we hold that in reality there will be no purely instrumental or genuine stakeholder dialogues. Hence, in actual examples of stakeholder dialogue, the reasons and motivations will be mixed. Given these mixed forms of dialogue, it becomes interesting to study how companies and stakeholders deal with tensions between socio-ethical and commercial objectives. However, there is little empirical research about this on the level of dialogue.

We conduct a case-study of stakeholder dialogue organized by an ISR scheme in The Netherlands concerning a front-of-pack health label. Our aim to understand how representatives of the ISR scheme respond to tensions between socio-ethical and commercial objectives in their interaction with stakeholders. In order to answer this question, we analyse first whether the stakeholders that participate in the dialogue recognize this tension and how they perceive it. After that, we analyse the responses of ISR representatives on the basis of the stakeholder interaction. For our analysis, we make use of the paradox approach to corporate sustainability (Hahn et al., 2018). The central contention of the paradox approach is that, in order to address all the aspects of corporate sustainability properly, it is important to take the tensions between them seriously and confront them actively.

We find that all external stakeholders recognize tensions between socio-ethical and commercial objectives in relation to the ISR scheme (the label). In many cases, they consider this as a basis for criticism, because they have the impression that companies compromise on the social goal of the ISR scheme (informing consumers about health and stimulating healthy product innovation) in order to protect their commercial interests. Throughout the stakeholder interaction, we find that the representatives of the ISR scheme respond in three different ways to this criticism. First, the critics are framed as not constructive. For that purpose, the representatives employ an opposition between pragmatism and idealism, and denote the critics as idealistic while they perceive themselves as pragmatic. Second, representatives of the ISR scheme stress their motivations for the social objectives, but do not communicate about the possible tensions between socio-ethical and commercial objectives. Third, the interaction leads to a call for more government intervention, implying a certain form of splitting of economic objectives and social responsibility between respectively companies (as organized in the ISR scheme) and the government. We show that these three responses can be characterized as defensive responses to the tension between socio-ethical and commercial objectives.

The contribution of this chapter is twofold. First an empirical one: until now, there is little empirical research about the tensions in stakeholder engagement on the level of dialogue itself. The empirical insights we obtain can be useful for conducting stakeholder dialogues. This chapter indicates that stakeholder interaction 
can easily lead to defensive responses. Second, this chapter has a theoretical contribution. We combine literature on stakeholder engagement with the paradox approach to corporate sustainability. The latter provides a very useful lens to study organizational tensions. However, until now, most research about on organizational paradoxes has focused on the question how actors within organizations deal with and respond to organizational tensions. We show that organizational responses to tensions (such as between ethics and strategy) are not merely an internal organizational matter, but that those responses are constructed in relation to external stakeholders.

\subsection{Theoretical framework}

\section{Tensions in industry self-regulation}

Industry self-regulation is defined as “a regulatory process whereby an industry-level (...) organization (...) sets and enforces rules and standards relating to the conduct of firms in the industry" (Gupta \& Lad, 1983, p. 417). Recent well-known examples are the Responsible Care Program of the chemical industry (Gamper-Rabindran \& Finger, 2013; Niskanen, 2012) and the ISO 14001 which concerns environmental certification standards (Boiral, 2007). Despite its broad adoption as an alternative to governmental regulation, research shows that the effectiveness of ISR in improving the social performance of companies is mixed, and sometimes even negative (Christmann \& Taylor, 2006; Vogel, 2010; Lynch-Wood et al., 2009).

Bowen (2019) shows that companies can have different strategic (in contrast to socio-ethical) reasons for participation in ISR. First, they can achieve strategic control about a social issue, in order to deal with it on their own terms. Second, they can obtain reputational benefits from entering ISR schemes. Third, there are network benefits that result from participation, for example to show a credible signal of social performance. Fourth and last, companies can learn from each other within an ISR scheme how to respond to social issues. All these reasons relate to what Suchman calls pragmatic legitimacy, which "rests on the self-interested calculations of an organization's most immediate audiences" (Suchman, 1995, p. 578). The important contribution of Bowen (2019) is to show that there can be tensions between-in his terms - the moral and pragmatic legitimacy of ISR. For example, there is such a tension when companies join an ISR scheme in order to build a good reputation of their social performance, while the actual contribution of the ISR scheme in enhancing the social performance of companies is very limited. Societal criticism on ISR schemes often relate to this tension: companies are suspected to join for strategic reasons, while the social objectives are not well-served 
within those schemes, or so the criticism goes. In this chapter, we are interested in this kind of tensions, and especially on how participants of an ISR scheme respond to criticism that relate to those tensions.

\section{Tensions in stakeholder dialogue}

Suchman (1995) has noted that companies can build moral legitimacy by engaging in public discussion about the issue under concern. Palazzo and Scherer (2006) argue that with regard to the social issues that companies are involved in, deliberation is the key source of moral legitimacy. For this purpose, they build on the theory of deliberative democracy (Patzer et al., 2018; Scherer et al., 2013; see also Scherer \& Palazzo, 2007, 2011; Smith, 2004). The ideal of deliberative democracy can be characterized by the following elements: (1) it is talk-centred instead of vote-centred, (2) it is consensus-oriented instead of based on majorityrule, and (3) it aims at participation instead of representation of those affected by policies. ${ }^{1}$ When this ideal is translated to the business context, it means that companies have to engage in dialogue with those affected by their social activities, in order to build moral legitimacy for those activities (Kaptein \& Van Tulder, 2003; Pedersen, 2006).

Palazzo and Scherer (2006, p. 82) argue that " $[t]$ he challenge of communicative access to legitimacy is to engage in true dialogue, to convince others of the validity of one's arguments but not to persuade or manipulate by means of strategic instrumentalization”. In other words, dialogue can be used for socio-ethical purposes, but also for self-interested strategic purposes (cf. Crane \& Livesey, 2003). While the former is put forward as the normatively preferable mode, the second is problematized. Hence, there is a tension between these two approaches to dialogue.

Empirical literature shows that it is not easy to realize a stakeholder dialogue in which actors do not treat each other strategically, or in which self-interested objectives are absent (Burchell \& Cook, 2007; Golob \& Podnar, 2014). There remain tensions between the social and the commercial position of companies within dialogue (Høvring et al., 2018). Furthermore, companies can use dialogue as a means to co-opt critics (Burchell \& Cook, 2013a). Co-optation is "the ability (...) to bring the interests of a challenging group into alignment with (...) [someone's] own goal” ( Trumpy, 2008, p. 480; see also Baur \& Schmitz, 2012). Moog et al. (2015) have shown in a case-study of the Forest Stewardship Council-which is supposed to be a democratic and deliberative arena-that this multi-stakeholder initiative

\footnotetext{
${ }^{1}$ Although none of these elements is uncontested, they can be found, in varying degrees, in the major works on deliberative democracy (e.g. Cohen, 1997; Dryzek, 2002; Gutmann \& Thompson, 1997; Habermas, 1998). 
actually provided very limited space for deliberation, due to broader market forces and resource imbalances between the participating stakeholders (especially between corporations and NGOs). Together, this literature indicates that one can expect tensions between ethics and strategy to persist within stakeholder dialogue. For this reason, different authors have tried to provide alternative ways to conceptualize stakeholder dialogue, in order to account for issues of power, conflicts, tensions, and self-interest (Greenwood, 2007; Dawkins, 2015; Burchell \& Cook, 2013a). The question is therefore not so much how to eliminate tensions from stakeholder dialogue, but how to deal with them. In order to address this question, we make use of the paradox approach to organizational tensions, to which we now turn.

\section{The paradox approach to organizational tensions}

Margolis and Walsh (2003) have argued that organizational scholarship should not seek to reconcile, but embrace the tension between the economic and broader social objectives of companies. The paradox approach to corporate sustainability is one of the most recent examples that explicitly follows this suggestion (e.g. Hahn et al., 2018; Iivonen, 2018). Corporate sustainability entails the idea that in order to contribute to a sustainable society, companies should not only pursue economic, but also social and environmental objectives (Hahn et al., 2015; Wilson, 2003). The paradox approach to corporate sustainability builds on theories on organizational paradoxes (Lewis, 2000; Poole \& van de Ven, 1989; Smith \& Lewis, 2011). Smith and Lewis define organizational paradoxes as "contradictory yet interrelated elements that exist simultaneously and persist over time" (Smith \& Lewis, 2011, p. 382). They identify four different kinds of organizational paradoxes: (1) learning paradoxes, (2) belonging paradoxes, (3) organizing paradoxes, and (4) performing paradoxes. Underlying those paradoxes are certain tensions. To take the third paradox as an example, good organizing requires a certain amount of control and flexibility. These two elements are in tension with each other, and sometimes require contradicting measures. The central contention of the paradox approach is that the underlying tensions can never be entirely resolved, and hence the question is how to deal with the different elements of the tensions simultaneously.

The tensions in corporate sustainability have most in common with performing paradoxes, as these paradoxes relate to the tensions between different organizational objectives (Hahn et al., 2018). The same holds for the tension between socio-ethical and commercial objectives in ISR: most central to ISR is the extent to which it contributes to solving societal problems, which stands in a potentially conflictual relation with the extent to which companies can obtain private benefits from participating in ISR schemes. Hence, we interpret the tensions between socio-ethical and commercial objectives in ISR as a performing paradox. 
According to Smith and Lewis (2011), performing paradoxes stem from the plurality of stakeholder demands. The idea is that stakeholders have different expectations of the goals that an organization should pursue, and that these different expectations can be in conflict with each other. In relation to ISR, we can also expect that different stakeholders have different demands. To external stakeholders such as governments, NGOs, and citizens, the social objectives of ISR are likely to matter most. This is because they have an interest in the public benefits of ISR, while the private benefits are mainly relevant for the companies that participate. For companies that participate, however, both socio-ethical and commercial objectives are relevant. Depending on their motivations to participate, the different considerations will receive different weight.

\section{Active and defensive responses to organizational tensions}

In the literature on organizational paradoxes, different classifications of responses to organizational tensions have been developed. Most authors distinguish between two kinds of responses (although under different headers): active responses that take the tensions serious and defensive responses that are characterized by avoiding the difficulties posed by tensions (an exception is Poole \& van de Ven, 1989). Both active and defensive responses can become visible in basically two different ways: in how people talk (linguistic) and in the way they act (behavioural) (cf. Basu \& Palazzo, 2008). ${ }^{2}$ Since this chapter focuses on the level of dialogue, our analysis is restricted to the linguistic dimension of responses to organizational tensions. To the best of our knowledge, the literature on organizational paradoxes does not explicitly distinguish between linguistic and behavioural responses. Yet, we can expect that the two are heavily intertwined: how people talk influences and is influenced by how they act. Moreover, given that organizational tensions can be perceived by different actors in very different ways, responses to those tensions in actual behaviour will be strongly influenced by the way in which they are perceived.

Since much of the literature is focused on the question how paradoxes can be managed, most attention is paid to active responses. According to Lewis and Smith, those responses "seek to embrace, cope with, and thrive through tensions" (Lewis \& Smith, 2014, p. 135). Lewis (2000) discusses three strategies that aim to tap the positive potential of paradoxes: acceptance, confrontation, and transcendence. An acceptance strategy entails that an actor learns to live with a tension, without trying

\footnotetext{
${ }^{2}$ Basu and Palazzo (2008) distinguish the cognitive, linguistic, and conative (or behavioural) dimensions of corporate social responsibility. We left out the cognitive in describing how responses to tensions become visible, because how people think (cognitive) becomes visible to others in how they talk and act. 
to erase it. In the second strategy, a tension is confronted more actively in order to accommodate or mitigate its negative effects. Transcendence implies that actors reflectively construct a new understanding of a tension, which could lead to see its elements as complementary. Smith and Lewis (2011) distinguish between two kinds of active responses: acceptance and resolution. With regard to resolution strategies, they discuss spatial separation, temporal separation, and synthesis (see also Hahn et al., 2015; this classification is obtained from Poole \& van de Ven, 1989). Spatial and temporal separation imply that the different elements of a tension are located at different levels, places or at different moments in time. An example of spatial separation is to locate the responsibility for economic objectives and societal issues within different organizational units, such as sales departments and CSR departments respectively. Temporal separation could imply that attention to the different elements of a tension are spread throughout different periods. Synthesis is a "a way to make sense of two opposing elements through an overarching or mediating logic" (Hahn et al., 2015, p. 301). It should be noted that employing these resolution strategies do not imply that a tension is eliminated. It means that it is tried to address both sides of the tensions simultaneously (Smith \& Lewis, 2011).

Compared to active responses, there seems to be relatively little scholarly attention to defensive responses to organizational tensions. Lewis (2000) shortly describes a lists of six different defensive responses: splitting, projection, repression of the tension, regression, reaction formation, and ambivalence. Lewis and Smith (2014) mention some more defensive responses, such as avoiding risk and a drive towards consistency and simplicity. Smith and Lewis (2011) refer to defensive responses as vicious cycles, because they would lead to negative dynamics. Although these articles shortly discuss defensive responses, they do not give it a central place in the analysis. An important exception is the empirical study by Iivonen (2018). She discusses the response of Coca-Cola to the social issue of obesity. In her view, "sustainability tensions can be particularly challenging when a company's core business is perceived to be negatively correlated with a specific social goal" (Iivonen, 2018, p. 309). She finds that Coca-Cola's response is clearly defensive, especially in the form of repression and projection. Although Coca-Cola acknowledges that obesity is a problem that has to be addressed, it does not acknowledge that there is a tension between its core business and obesity, and thus represses the tension. Furthermore, Iivonen shows that the tension is projected outside the organization in several ways, among others by transferring the responsibility for addressing the problem of obesity to individuals and to society in general. Another thorough empirical study is conducted by Ashforth and Reingen (2014), who studied the duality of pragmatism (representing economic objectives) and idealism (representing values and social responsibility) within a food 
cooperative. Among others, they found a combination of splitting and projection. The response of splitting in this case entails that the members of the cooperative were split into two groups: pragmatists and idealists. The response of projection meant that negative aspects were projected on the other groups. Even though these are defensive responses, which are often assumed to lead to negative dynamics (e.g. Lewis, 2000), Ashforth and Reingen (2014) show that they-through mechanisms such as rituals of tolerance and forgiveness-did enable the organization to sustain itself.

\subsection{Method}

\section{Research approach}

We conduct a single case study to answer our question how representatives of an ISR scheme respond to tensions between socio-ethical and commercial objectives. The unit of analysis is the interaction between companies and their stakeholders, especially in the form of stakeholder dialogue, but also via the media. The level of analysis is the linguistic level (as compared to the behavioural level). Our aim is to understand how participating stakeholders in the interaction with the ISR scheme perceive the tension between socio-ethical and commercial objectives, and consequently how representatives of the ISR scheme respond to criticism related to this tension. Since our analysis focuses on the dynamics of stakeholder interaction, we did not examine the extent to which the arguments that participants used were valid.

We understand a case study in the broad sense as "an intensive study of a single unit for the purpose of understanding a larger class of (similar) units" (Gerring, 2004, p. 342). There are different rationales for conducting case-studies. Our case is closest to a representative or typical case, combined with elements of a revelatory case (Flyvbjerg, 2006; Yin, 2003). This is because our case could be considered as a typical example of multi-stakeholder interaction (even though the results are influenced by a lot of contextual factors), and our study might be revelatory in the sense that it tries to discover things that have - to the best of our knowledge- not been researched before. At least, our case does not seem rare or extreme: stakeholder dialogue takes place are various places in various ways, and it is not clear how our case would radically differ from other cases discussed in the literature (although a public debate does not seem to take place often). Our approach is mainly deductive, in that we used the active and defensive responses as identified in the literature on organizational paradoxes as our framework to analyse our data. 


\section{Case description}

We analyse the interaction between stakeholders in a case concerning a discussion about a front-of-pack health label in The Netherlands. This health label was initiated in 2006 by a group of food companies, including retailers, manufacturers, and foodservice companies. Together, the companies raised the foundation 'Ik Kies Bewust' (which translates literally as: 'I make a conscious choice'). The goal of the label, as the organizers put it, was twofold: assisting consumers in making a healthier choice and stimulating healthy product innovation. Although the label was a private sector initiative and received no government funding, it was approved by the government as the only health label that companies are allowed to use. This approval was related to the fact that in some policy areas, self-regulation and coregulation is a rather popular way of policy-making in the Netherlands, sometimes called corporatism (Hendriks, 2011).

If companies wanted their products to bear the label, they had to become a member of the foundation. The foundation had a wide range of members, from multinational corporations like Ahold Delhaize and Unilever to small and medium sized enterprises. Since most of the retailers in The Netherlands were a member of the foundation, many private label products carried the label as well. The board of the foundation consisted of representatives of member companies and was chaired by someone without a direct link to the food industry. Apart from the board, there was an independent scientific committee that determined the nutritional criteria on the basis of which the decision was made whether food products can bear the label or not (Roodenburg et al., 2011).

In 2015, the foundation decided to start a major evaluation of the label. As part of this evaluation, a public debate and three round table meetings with a broad range of stakeholders (food companies, NGOs, dieticians, scientists, government officials, et cetera) were organized in spring 2016. Around 120 persons participated in the public debate, while the round table meetings were visited by among 25 stakeholders. On the basis of their internal evaluation and the interaction with external stakeholders, the board drafted an advice to the minister of Health on how to proceed with the label. However, the minister of Health decided in the autumn of 2016 that the label had to be abandoned entirely.

\section{Data and analysis}

The focus in this chapter is on the interaction between stakeholders during the evaluation process of the label. We were able to analyse the public debate and the three round table meetings (which took place in the spring of 2016), since these 
meetings were recorded. ${ }^{3}$ The foundation agreed that these recordings could be used for research purposes. In order to strengthen the validity of the data, we also gathered several media items in which the label was discussed (newspaper articles, blogs, and a radio-item) and conducted interviews with participants. With regard to the media items: only those articles were gathered within a range of a year, from a half year before to a half year after the public debate. The criterion for including the articles was that it should include statements in which people express their opinion about the label or the evaluation process (purely factual news articles were left out). With regard to the interviews: we interviewed 15 persons who participated in one or more of the meetings (whether in the public debate or in the round table meetings). The interviewees represented different stakeholder groups: three representatives of companies of which two participated in the board of the foundation, two other representatives of the foundation ${ }^{4}$, three representatives from different NGOs, three (representatives of) dieticians, one government official, and two other stakeholders with strong links with the food industry, but not directly involved in the label. One interview took place in April 2016 and the other interviews between April and June 2017. They lasted between 30 and 90 minutes. Although we prepared the interviews with an interview guide, we used it loosely and focused on discussing the interviewees' views on and involvement in the label, and how they looked back to the meetings they participated in. We used probes to get deeper into the topic of the perceptions of tensions between moral and strategic goals of the label.

The recordings of the interviews, the public debate, and the radio items were transcribed in verbatim. The transcribed recordings and other media items were uploaded and coded in Atlas.ti. The round table meetings were analysed by making notes. We coded the data twice: first by open coding and second by combining related codes and coding the data again with these codes. Examples of codes are "government versus self-regulation" (when participants discussed the merits of selfregulation and government regulation in relation to healthy food), or "motivations ISR representatives" (which referred to instances in which the representatives of the label stated their intentions or motivations to be involved). Through the coding process, we gathered responses of representatives of the ISR scheme to tensions between socio-ethical and commercial objectives. We decided that specific instances indicating a certain response did not suffice for including them in the results. As a

\footnotetext{
${ }^{3}$ There were some other stakeholder meetings organized by the foundation, but during these meetings no researchers were present. We could also not be present during board meetings of the foundation.

${ }^{4}$ One representative of the foundation was interviewed twice, once before and once afterwards the meetings.
} 
criterion for including a response in the results, there needed to be a recurring pattern of a certain kind of response in all the different forms of interaction we have studied (public debate, round table meetings, and news media). In that way, we were able to single out responses that did not depend on the contribution of a particular person or a particular moment during the interaction.

\subsection{Results}

\section{Perceptions of the tension}

Although many organizations and consumers were quite positive about the label (or at least not explicitly negative), there was also criticism that grew throughout the years. Although this criticism was of various kinds, a common denominator was a certain distrust related to the fact that the label was a private initiative. This was perceived as problematic, since food companies would have conflicting interests when it comes to communicating about health. In an interview, a representative of the foundation said:

\footnotetext{
"In the current context, (...) there is a clear distrust to multinationals, who, in the eyes of the public, are only concerned with making profit. And they [the multinationals] are not believed if they say they are also concerned with something else [health]."
}

A central element of the criticism, then, is related to the tension between socioethical and commercial objectives: critics have the impression that the label is designed in such a way as to compromise on health objectives with a view to make profit. This criticism was often mentioned by representatives of NGOs. The NGO representatives we interviewed and those who participated in the meetings tended to stress the tensions between pursuing health goals and pursuing profit quite strongly. Moreover, in their view, companies often-if not always-subordinate the goal of pursuing health objectives to making a profit. For example, an NGO representative said: "In the end the industry wants to make a profit, and only within this aim they will consider how to do it well [with regard to health]". This is what they also saw happening in the label. On their website, an NGO wrote the following:

"The food industry is directly involved in the development and the administration of the label. According to many consumers, this is unacceptable. It is, of course, not surprising that companies love this system, in which potato chips, cookies, and sauces are designated as 'conscious choices'." 
In an opinion piece published in a well-known Dutch newspaper, a group of health professionals, journalists, and food activists made a similar, probably even stronger statement: "[the label is] good business, but bad information. Only the food industry has an interest in these vague checkmarks". Critics like these often mentioned that, in their view, the label was designed to give unhealthy food products a healthy image. Some stakeholders held the view that the label was nothing more than a marketing instrument. At the same time, not everyone shared this view. Several stakeholders (NGOs, health professionals, and other stakeholders) mentioned in the interviews that food companies could be genuinely motivated for public health, and participated in the label for that reason. Yet, even those stakeholders with this moderate view recognized that there can be tensions between the strategic interests of the participating companies and the health goals of the label. For example, a health professional said that "[this tension] doesn't hold only for the industry, I mean, I also have to make a living”, implying that everyone has to deal with similar tensions in one's job. Interestingly, also representatives of participating companies recognized this in the interviews. One company representative said:

"Of course, we experience a tension. I mean, we sell cigarettes, we sell wine, and we sell bacon. (...) Do you know how much fat and salt that [the bacon] contains? We have shelves full of cookies and sweets. If we would only focus on pure health, we would go bankrupt."

Companies said that they were strongly motivated to inform consumers about health and to make their product portfolio healthier. That there is (sometimes) a tension between taking responsibility for public health and the financial objectives of their companies was for them not a reason to wait and see. One company representative said: "I can do more than I thought. Of course, it [making food products healthier] requires the will to discover how to improve. So, it is about the willingness to improve continuously and being prepared to learn by trial and error."

It becomes clear that many stakeholders recognize a tension between socioethical and commercial objectives. At the same time, their perception is rather different. For some stakeholders, there is a complete conflict between taking genuine responsibility for public health and having commercial interests. For them, this is a reason to reject the entire idea of industry self-regulation with regard to health. Others still see the possible advantages of ISR, even though they recognize the tensions that come with it. It should be noted, however, that although companies also acknowledged the tension between socio-ethical and commercial objectives, this was only in the interviews. We could not find instances in which companies explicitly acknowledged this tension in the actual interaction with other stakeholders. 


\section{Framing the critics}

How do the companies that participated in the ISR scheme respond to the criticism they received? Throughout the interaction, a pattern of responding to criticism became visible: the adherents of the label created an opposition between idealists and pragmatists. This opposition was adopted as a frame, used to denote the critics as not constructive. We call this the pragmatist-idealist frame. When employing this frame, those who saw themselves as pragmatic referred to others as being (too) idealistic. The 'idealists' are mainly denoted in negative terms, namely as not pragmatic or constructive. The work that this frame seems to be doing for those who call themselves pragmatists is to denote the others as mere critics, who are shouting loudly how things should be done, but are not willing to cooperate constructively for improvement.

An opinion piece, published on the website of the label a day before the public debate and signed by the chair of the board, illustrates how the frame was used: "On April 21, the Choices label organizes a broad societal debate, with the central question: do we want a healthier society or are we fighting for food convictions?" Likewise, a representative of the foundation said during a radio-discussion: "Let's not fight about systems, let's care about overweight of a lot of youth in The Netherlands." Here we see the frame at work: the implicit message is that pragmatists (the companies participating in the ISR scheme) really take responsibility for a healthier society, while idealists only fight for food convictions. Apart from that, the employment of this frame also entails an invitation by the foundation to be pragmatic and constructive. During the debate, a company representative said:

"I think we have arrived at the heart of the dialogue here. (...). This is about creating a healthier situation for a lot of consumers in The Netherlands. Taking small steps for a lot of people instead of trying to take very big steps for very few people. (...) It is about, with all its shortcomings, try to take small steps for a whole lot of people in the direction of positive behavioural change."

Here again, the representatives of the ISR scheme depict themselves as people who take practical steps for improving the nutritional quality of food products. In an article on a website for food and nutrition professionals, in which the public debate was evaluated, the pragmatist mind-set was also adopted:

"The criticism about the label is partially right, as recognized by the board of the foundation, but could have been more constructive. What are the concrete alternatives for a better system? Perhaps the critics should look more beyond 
the borders of own views and think about which concrete possibilities exist to achieve a healthier product range."

As we said, the distinction between pragmatists and idealists is a frame employed by those who see themselves as pragmatic. The supposed idealists do not see themselves that way. For example, a representative of the foundation accused an NGO that campaigned against the label to be not constructive. This NGO started a campaign against the label, because they held the view that it was causing confusion among consumers. A representative of this NGO said: "we have been constructive and we have criticized the label for years before we decided that it would better disappear." They explained their critical stance towards the label as a response to the lack of openness of the foundation to criticism.

\title{
Stressing personal motivations for public health
}

When the companies that participated in the ISR scheme took part in the discussion, they often started with stressing how motivated they are to take responsibility for health issues. During the public debate, a board member said: "I think it is very important to discuss why we do this [issuing the label]. And why I do personally do it, is because I am committed to realizing a healthier lifestyle for many people." During one of the round table meetings, another board member said: "It's about the intrinsic motivation to make sure that everyone takes his own responsibility, to see to it what to do in order to contribute [to a healthier society].” During this same meeting, another board member introduced herself as follows:

\begin{abstract}
“In my personal life (...) I am concerned with health a lot (...). The reason I wanted to work for [company name] was because I wanted to contribute to making food healthier. (...) So, from this personal drive I take part in the board of the foundation on behalf of [company name]. I am absolutely enthusiastic about that, and that's what I also see with other board members. That's what I wanted to share with you, because we often see that there are a lot of companies behind the label, but behind those companies are also people putting a lot of time in it out of a personal drive. And I do feel that drive."
\end{abstract}

By letting the board members introduce themselves in this way, the foundation gave the communication a human face. Communicating one's personal motivations and drives in this way seems to be a response to the distrust concerning the intentions of companies. This topic was explicitly discussed during one of the round table meetings. Various people remarked that the label is seen as a marketing tool, maybe as a consequence of a lack of good communication. On this topic, the following conversation took place: 
"Stakeholder: I think it is important that companies take part in decreasing the amount of salt, sugar, and fat [in food products]. But that should not be with the intention of making as much money as possible. They should really be concerned with making people healthier. That should be the starting point.

Moderator: when do you believe them [the companies]?

Stakeholder: well, I think (...) that [name of board member] should tell who she is $(\ldots)$, and that she also wants her children to grow up healthy (...). Of course, a company need to survive, but give it [the communication] a personal face.

Board member: would that be enough?

Stakeholder: well, (...) I think it is important to communicate with consumers. (...) People should know who the companies are, what their intentions are. And that [the intentions of companies] should not be making as much money as possible."

In this conversation, personal and honest communication about the good intentions of companies is seen as a potential solution to the distrust in companies. The distrust is related to the perception of consumers that companies are only or at least mainly concerned with making money, thus paying too little or even no genuine attention to socio-ethical goals. This conversation suggests that companies should show in their communication that they are genuinely motivated for social goals. Furthermore, several stakeholders suggested that the trustworthiness of this kind of communication would be enhanced if it has a human face.

\section{Transferring responsibility to the state}

As we noted before, even though the label was endorsed by the government, the ISR scheme was governed a foundation whose members were only commercial companies. During the meetings, the limits of this construction were often discussed. Many stakeholders, but also most of the companies involved in the label agreed that a more active role of the government would be desirable. In a radio discussion between a critic of the label and a board member of the foundation, the role of the government came across several times. The critic accused the foundation of greenwashing. He argued that the label was devised to defer strict legislation concerning healthy food, and to make consumers think that the food industry is doing a good job with regard to consumer health. In this, he referred to the conflict between having commercial interests in selling your products and pursuing 
consumer health through the label. Because of this conflict, he argued, companies should not be given responsibility for a public good like health:

"Look, the health label has been given away to producers and traders who have a different interest. I understand that, and I grant everyone his business. But I think that businesses should do business, and let the government or independent people determine the borders within which they can do that."

A similar argument was used by a group of health professionals, journalists, and food activists who published an opinion piece in a newspaper on the day of the public debate. They wrote the following:

\begin{abstract}
"Members of parliament must finally realize that the public interest clashes very strongly with business interests in this case. (...) Health is our greatest good. This good is not safe in the hands of a sophisticated corporate lobby, which aims to maximize profits."
\end{abstract}

Since the authors of this opinion piece seem to understand the relation between having commercial interests and taking responsibility for societal values as mutually exclusive, they consider government regulation the only viable road for enhancing public health. Quite consistent with this view, the opinion piece did not even address food companies, but requested the government to abandon the label.

During the discussion on the radio, the board member of the foundation responded to the criticism on the label we described above. Among others, it was acknowledged that a bigger role for the government would be desirable:

\footnotetext{
"We also think the label would be more neutral if it would be part of the public domain. Yesterday [during the public debate] all the participants, the critics and the industry, have called upon the government and the minister: take a more active role and take the lead to make sure that the confusion among consumers will be resolved."
}

Although this board member also wanted more government action regarding the label, the arguments were different. Where the critics above provided a quite principled reason for government intervention (because of the perceived conflict between commercial interests and public health), the arguments of the board member can be considered instrumental: they are related to the effectiveness of the label. It was argued that the label would be more effective if the government made it obligatory so that everyone participates, and also because the government's independence from the food industry would make the label seem more trustworthy 
and neutral. During an interview, a board member complained about the accusation that the label was governed by a group of companies:

"It is possible to blame us for the fact that [the label] is owned by the industry, but the government leaves us alone. They don't want to take part. We have pleaded over and over again: government, take your responsibility (...). But they don't. So, we do it ourselves, because otherwise nothing happens. And now we get the criticism that we do it by ourselves. That's really weird."

It is true that the government did not want to take a very active role in the label. A government official explained in an interview that the ministry of health sees it as a private initiative. Moreover, it was pointed out that the role of the government is also limited: "The government is only the government. Businesses should take up social challenges. The government stimulates, pushes, monitors, and publishes. (...) [But] companies also have a public responsibility." Despite the fact that during the meetings the government did not show to be willing to take a more active role in the label, many stakeholders favoured a more active role of the government concerning food labels particularly and stimulating healthy nutrition generally.

\subsection{Discussion}

The main question of this chapter was: how do representatives of an ISR scheme respond to tensions between socio-ethical and commercial objectives in their interaction with stakeholders? In our theoretical framework, we discussed the responses to organizational tensions that have been identified in the literature. The question is what kind of responses stakeholder interaction fosters, at least for our case study. First, does it foster active or defensive responses? And second, what kind of active or defensive responses can be identified?

\section{The pragmatist-idealist frame: splitting and projection}

The first response we found was the creation of an opposition by adherents of the label (mainly companies), together with a framing of the critics. Critics accused companies of paying too much or even merely attention to their commercial interests, and of making consumer health instrumental to that goal. As a response, companies and representatives of the foundation framed this criticism as not constructive, and the critics as idealists who do not accomplish anything at all. In this frame, the pragmatists present themselves as willing to make compromises or trade-offs between social and strategic goals, in order to achieve some practical 
improvement. The critics are depicted as not willing to compromise, and are said thereby to achieve no practical improvement.

These two groups of stakeholders - the 'pragmatists' and 'idealists'-are struggling with each other about what a proper response to the social issue of health would be. Both are accusing the other of responding in the wrong way: the critics accused companies of compromising health goals for financial reasons, and the companies accused the critics of doing nothing at all. In a way, therefore, both groups are externalizing the problem by pointing at the other group. So, by creating an opposition, this framing leads in the first place to a kind of splitting between two groups: those who are constructive and those who are not. ${ }^{5}$ In the second place, the framing can be interpreted as an example of projection, whereby a negative aspect in attributed to someone else (Lewis, 2000). At the same time, a positive aspect is projection onto oneself. This is what Westenholz (1993) calls a 'self-referential frame of reference': the 'others' are framed as lacking a characteristicpragmatism - which the users of the frame themselves possess (see also Ashforth \& Reingen, 2014). By denoting themselves as pragmatic, the representatives of the foundation highlighted the positive side of the willingness to find a balance between socio-ethical and commercial objectives. The opposition between pragmatists and idealists was supposed to provide a more favourable picture of the efforts of companies. We could therefore conclude that conflict in stakeholder interaction could result in splitting and projection by way of framing.

\section{Stressing personal motivations for the social goal: reaction formation}

The second response we found was that companies that participated in the ISR scheme stressed how strongly they were motivated for the social goal, namely improving consumer health. Just like in the framing response we analysed above, the underlying problem seems to be that consumers and other stakeholders perceive companies as paying too much attention to their financial goals. The response of stressing personal motivations aims to change the perception of consumers through communication. In an effort to counter the perception that companies give too much weight to strategic considerations, they emphasize the other side of the coin, namely the extent to which companies are genuinely concerned with social objectives.

Through personal communication, the companies emphasize one side of the tension: that they are motivated to do what is in the best interest of society. Thereby,

\footnotetext{
${ }^{5}$ This group divide is not necessarily between companies and external stakeholders. There were also external stakeholders, who, in the eyes of the companies, were constructive in their criticism and willing to improve the label.
} 
their aim is to counter the image that companies only or mainly take commercial objectives into account. This is exactly the defensive response that Lewis called reaction formation: "excessively manifesting the feeling or practice opposite to the threatening one" (Lewis, 2000, p. 763). This is a defensive response, because, even though the socio-ethical objective itself is accepted besides the commercial objective, the tension between them is not explicitly mentioned nor acknowledged. According to the literature on organizational paradoxes, an active response would at least require that the tension is acknowledged. This defensive response during the stakeholder interaction is noticeable, especially given the fact that companies did acknowledge the tension in the interviews. Seemingly, it is more difficult to acknowledge tensions in actual interaction with stakeholders compared to an anonymous face-to-face situation.

\section{The call for an active role of the government: weak and strong splitting}

As third and last result, the interaction leads to a call on the government to take a more active role in the label, both from the part of the representatives of the foundation and from critical stakeholders. This could be interpreted as a form of splitting, whereby responsibility for the social objective is transferred to the government, and companies focus on their economic responsibility. This form of splitting conflicts with the very idea of ISR, which aims to combine the two.

There was a contrast between those who perceived a strong conflict between having commercial interests and pursuing socio-ethical objectives and those who do not. ${ }^{6}$ These different groups also advanced different arguments for government intervention. The participating companies seem to support government assistance mainly for instrumental reasons. In their view, the ISR scheme would be more effective and appear more independent when the government took a more active role. So, they still support the idea of self-regulation, but recognize that with government assistance its legitimacy in the eyes of the public might be improved. Hence, the companies support a weak form of splitting between socio-ethical and commercial objectives.

On the part of several fierce critics, a strong form of splitting occurred. Interestingly, those stakeholders sometimes used rather 'Friedmanite' arguments to defend their position: they employed the idea of a strict division of moral labour between markets and the state, in which businesses pursue profits and the government acts as arbiter and takes responsibility for public goods (Friedman, 1970). In their view, companies cannot be trusted in their efforts to enhance public

\footnotetext{
${ }^{6}$ It should be noted that whether stakeholders favour the one or the other view was not a matter of either/or, but a matter of degree.
} 
health because of their economic interests, and thus should not be given any responsibility for public health. This provides them with a principled reason for an active role of the government in issues about healthy food. These stakeholders propose to resolve the tension between the socio-ethical and commercial objectives of ISR by disfavouring the whole idea of ISR.

\section{Understanding defensive responses in stakeholder interaction}

As with every case-study, our findings depend highly on contextual factors such as the influence of moderators on the discussion, the participants, the structure of the interaction, and the stakes involved. The defensive responses in this case might well have to do with such contextual factors. For example, some stakeholders felt that the stakeholder consultation came quite late, because they voiced their criticism already for quite some time. This might have increased the fierceness of their criticism. Furthermore, the defensive responses might be aroused because the criticism on the label could also be framed in a certain way, for which stakeholders like NGOs can also have their own strategic reasons. When critics highlight only specific features of the label, or even present a distorted view of it, a defensive response on the part of companies is more understandable. A limitation of this study is that we did not investigate the reasons why some stakeholders were critical, nor whether the arguments they presented were valid. Another condition that might have influenced the responses is that a significant part of the interaction was public. In a public setting compared to interaction behind closed doors, polarization is more likely to occur. A public debate induces people to present their view in a catchy way, so as to win the audience for their views. Such a setting makes it difficult to admit mistakes and present dilemmas. A related limitation of this study is that we did not analyse how companies deal with the tension in their actual behaviour. It could be the case that, although defensive responses were prominent during the interaction, people did respond actively within their organization. Hence it might be that stakeholder interaction leads to active behavioural responses in the end, despite initial defensive linguistic responses.

In our view, the difficulty of active responses to the tension between socioethical and commercial objectives in stakeholder interaction is also related to its moralized character. To respond actively to it implies being honest about the ethical dilemmas one is involved in and about the compromises that sometimes have to be drawn. Furthermore, communicating such dilemmas and compromises to an external audience makes one vulnerable to criticism. The response of framing criticism as not constructive does precisely the opposite: it tries shield oneself against the imposed criticism. Furthermore, the response of stressing one's personal 
motivations for the socio-ethical objective does not communicate anything about the difficulties and dilemmas of being involved in pursuing those objectives together with commercial objectives.

A question that deserves more consideration is whether and why active responses to tensions are always desirable in stakeholder interaction. The normative presupposition in the literature is that active responses to tensions are preferable to defensive responses. For example, Lewis (2000) argues that defensive responses lead to a vicious cycle that reinforces and exacerbates the tension. The question why this is so, is often not addressed in depth. An exception is the article by Ashforth and Reingen, in which this normative presupposition is questioned by showing that " $[\mathrm{w}]$ hen groups embody different sides of a duality, organizational functionality may be attained at the price of apparent dysfunctionality at the group level" (Ashforth \& Reingen, 2014, p. 511). A similar pattern can be discerned on the level of interaction between companies and NGOs. One may argue that, from the perspective of NGOs, when companies pay attention merely to their commercial interests, NGOs are justified in representing the societal perspective in order to restore the balance. In that way, NGOs can voice social criticism and challenge companies to change their behaviour. It could be that behavioural change occurs despite defensive responses during stakeholder interaction.

\subsection{Conclusion}

In this case study, we found three patterns of responses to the tension between socio-ethical and commercial objectives within stakeholder interaction: (1) splitting by creating an opposition between pragmatists and idealists, which is used as a frame to project a negative aspect onto others and positive aspects to the users of the frame, (2) reaction formation by stressing personal motivations for the social objective of the ISR scheme (consumer health), and (3) a weak and strong form of splitting of commercial objectives and responsibility for societal values between respectively companies and the government. Hence, we find that stakeholder interaction leads to defensive responses to the tension between socio-ethical and commercial objectives. A question for further research is how stakeholder dialogues could be so organized and moderated that it fosters more active responses.

In general, our study shows that responses to the tension between socio-ethical and commercial objectives are constructed in relation to external stakeholders. Hence, this tension cannot be reduced to an internal organizational matter. In the construction of responses to this tension, companies have to deal with different and often contradicting perceptions of stakeholders. The response by a company will be different in the case that external stakeholders perceive the relation between socio- 
ethical and commercial objectives as conflictual, compared to a situation in which they perceive it as harmonious. Furthermore, we have shown that theoretical approaches that take organizational tensions seriously, provide a fruitful lens for studying stakeholder interaction. Our case study contributes to a growing literature that applies this lens to various aspects of corporate social responsibility. Besides its theoretical relevance, it also could provide the tools for practically relevant advice to companies which have to respond to tensions between socio-ethical and commercial objectives in their communications with stakeholders. 



\section{CHAPTER 5}

\section{COMMODITY OF FOCAL THING: \\ REFLECTIONS ON RESPONSIBLE INNOVATION AND THE GOOD LIFE}

A slightly different version of this chapter is submitted to Food Ethics 


\section{CHAPTER 5 COMMODITY OR FOCAL THING? REFLECTIONS ON RESPONSIBLE FOOD INNOVATION AND THE GOOD LIFE}

\subsection{Introduction}

In today's world, research institutes, universities, and companies spend a lot of time and resources on innovation. The goals which they try to achieve with this, can be very different. New technologies and products are developed to solve specific problems, and also to meet (or create) consumer demand. Innovation, however, is not ethically neutral. It may enhance certain values, but suppress others. It may have unexpected consequences, both desirable and undesirable. It influences the way people make choices. For this reason, reflection on what counts as responsible innovation is an important endeavour. Under this header, an entirely new research field has developed over the last years (de Saille, 2015; Timmermans, 2017). A very rough distinction can be made between approaches that focus on the innovation process and on the innovation product (Koops, 2015). The first asks the question how an innovation process can be carried out in a responsible way, while the second asks what a responsible product might look like.

In this chapter, I want to focus on the product-side of responsible innovation with regard to a specific context, namely the context of food. My aim is to provide relevant considerations for responsible food innovation, by asking the question how food innovation could contribute to the good life. I will do this by discussing some preliminary and fundamental questions about the role of food in our lives.

The reason for taking this detour is the following. I could take a specific approach to responsible innovation and apply it to food innovation. For example, Van den Hoven (2013) has developed Value-Sensitive Design, an approach with the aim of integrating values in the design of products. This approach can be directly applied to food, for example by showing the importance of integrating values related to health, the environment, or animal welfare in food products, and how that can be accomplished (see for this kind of approach Garst, Blok, Branzei, Jansen, \& Omta, 2019; Garst et al., 2017). Yet, before we can answer the question how certain values can be integrated in food product design, we need to have some idea about which values are relevant and why. This latter question, in my view, requires a conception of the place of food in a life well-lived. Such a conception provides a good starting point for a discussion about the ethical questions surrounding food innovation. Furthermore, by analysing the way we relate to food, and the place of food in the good life, different aspects will come into view compared a focus on the 
single ends that can be pursued with food innovation (like health, taste, or animal welfare).

Throughout this chapter, I take the philosophy of Albert Borgmann as a guide. In his work, Borgmann analyses the way in which modern technology affects and structures our life. I hope to make clear that his work can be fruitfully applied to food and food innovation. The setup of this chapter is as follows. First, I analyse Borgmann's understanding of modern technology and consequently apply this understanding to food. Borgmann argues that modern technology is characterized by the 'device paradigm'. This paradigm entails that modern technological devices procure the availability of commodities in an instantaneous, ubiquitous, safe, and easy way. I shortly discuss the downsides of the device paradigm, and how these downsides become manifested in the domain of food. The next step is to discuss the alternative to the device paradigm that Borgmann defends, namely focal things and practices. This discussion is followed by a short exploration of what it would mean to engage with food as a focal thing and a discussion of different reasons why food should be considered a focal thing. Since Borgmann's approach to technology is not uncontested, I go on with an examination of different objections that can be raised against this approach, and also formulate a reply to these objections. I close the chapter with drawing some implications for responsible food innovation.

\subsection{The device paradigm}

Over the years, Albert Borgmann has developed an original approach to the philosophy of technology (Borgmann, 1988, 1993). In his view, modern technology is characterized by a specific pattern, which he calls the 'device paradigm' (Borgmann, 1988). This pattern comprises making available commodities in an instantaneous, ubiquitous, safe, and easy way through technological devices. Typical examples of such devices are central heaters, television sets, and microwaves. These devices have specific functions. To take the microwave as an example: its single function is to heat food. Hence, it makes warmed food available instantaneously, safely, and easily. A further feature of the device paradigm is a split between means and ends, which has two dimensions. First, while the end of a device is stable, there is a "radical variability of means" (Borgmann, 1988, p. 43). This means that, when new or better technologies become available, the mechanism that procures the end can change, while the end remains the same (although it is likely to be realized even more safely, easily, and so on). For example, the change from cassette tapes to compact discs is a significant change in the means, while the end to procure sound remains the same. The second dimension of the split between ends and means involves that the means are concealed and that they are the domain 
of the technical expert, while the end is prominent and directly available. For example, the way a microwave works is not accessible to the consumer. It is made to be used conveniently, without the need for expert knowledge or certain skills. When it suffers from malfunction, a technician is needed to do the repairing (if the device is not simply replaced by a new one).

Borgmann acknowledges that there are great benefits in modern technology. At the same time, he notices that there is an 'irony' in relation to the promise of technology. The promise of technology is "connected with the aim of liberating humanity from disease, hunger, and toil, and of enriching life with learning, art, and athletics." (Borgmann, 1988, p. 36). The irony, according to Borgmann, is that the disburdenment that modern technological devices offer, also comes with a loss of engagement. An example that Borgmann often uses to make this clear is the central heating system as modern technological device versus the traditional hearth (Borgmann, 1988, pp. 41-42). With a central heating system, warmth becomes a commodity that is readily available. By a commodity, Borgmann means a good with a single purpose that can be easily available for consumption, without the need for engagement or the exertion of effort. The only thing we have to do in order to heat a room is to push some buttons on the thermostat. The hearth, on the contrary, requires wood to be chopped, stored, and dried. Furthermore, it needs to be set on fire carefully. To warm one's house with a hearth, therefore, requires bodily engagement with the world, and likely also engagement with others (to divide the tasks). Moreover, the hearth is not only something that heats the house. It occupies a focal place: a place to gather around to experience ease and togetherness. One could therefore say that the hearth not only requires, but also offers engagement. Not so the central heating system. For all the comfort that it offers, one could neither say that it requires nor offers engagement. The irony of modern technology, therefore, is that despite its promise to enrich human life (which it certainly does), it also invites a shallow consumerist way of dealing with the world, which demands the immediate availability of commodities without burdensome involvement.

Borgmann characterizes modern technology in terms of the device paradigm as a way to describe the typical role technology plays in the modern world. His choice for the word paradigm is related to his rejection of what he calls a substantive view of technology. According to Borgmann, the 'classic' philosophers of technology such as Jacques Ellul and Martin Heidegger employed a substantive view of technology, making technology an autonomous and deterministic force (Ellul, 2011; Heidegger, 2013). By calling the device paradigm the pattern of modern technology, Borgmann's view allows for exceptions and counterforces, thereby avoiding the deterministic trap. Hence, Borgmann's view leaves open the possibility of the reform of technology. 


\subsection{The device paradigm and food}

Could we say that the way people relate to food in technologically advanced countries is characterized by the device paradigm? This paradigm entails that commodities are made available (through all kinds of technological devices) ubiquitously, instantaneously, easily, and safely. It not difficult to relate those elements to developments in food. First, in our days, food is ubiquitously available. In supermarkets, people can buy everything they want. Furthermore, there are a lot of restaurants almost everywhere. The ubiquity of food is especially visible in the public spaces like stations and city centres, which are covered with snack shops, fast food restaurants, and cafés. Public health scholars even talk about 'obesogenic environments' to underscore how the current environment (physical, but also sociocultural, economic, and political) influences people's chance to become obese (Kirk, Penney, \& McHugh, 2010). Second, the availability of food is also more and more instantaneous. Supermarkets do their best to disburden the consumer. Not only do they offer sliced potatoes, onions, and fruits, but also ready-made meals which only have to be heated in microwaves. Third, closely related to this is the fact that access to and preparation of food is made more and more easy. A new trend is that supermarkets offer home delivery. Convenience is the key here. As put in an article from The Guardian: "screaming toddlers, long queues and heavy shopping bags just a few of the reasons to avoid setting foot in a supermarket aisle and do the weekly shop online." (Ferguson, 2015). Lastly, food is also offered in a safe way. In many countries, standards for food safety are pretty high, in the sense that little direct risk of food-borne illnesses.

Apart from these four elements, it is possible to recognize a split between means and ends in the way in which food production is organized. The end becomes to provide food on the table (or on the lap) that is tasty and has nutritional value. Consumers are however less and less involved in the process of growing and preparing food. Hence, the means become the domain of the food professional. Although farmers have been specialized in food production for a long time, the distance between farmers and consumers has grown strongly over the last century (Korthals, 2018). One of the main causes of this growing distance between food production and consumption is specialization. In an economy that is more and more specialized, production becomes more complex, which makes it more difficult to obtain knowledge about how production processes are organized. Of course, this does not only hold for food production, but also for other, especially high-tech, sectors. Beyond specialization, the globalization of food production also contributes to the distance between production and consumption. Many food products contain ingredients that are produced in countries all over the world. For individual 
consumers, it is nearly if not completely impossible to trace the sources of the products they consume. These economic developments contribute to what Borgmann calls the split between means and ends: the way in which food is made available is the domain of experts, and this domain is largely disconnected from consumption.

The gap between the food expert who prepares food and the lay person who consumes it, is nicely illustrated by what Michael Pollan has called the 'cooking paradox' (Pollan, 2014). He notices that, one the one hand, the time spend in American households on cooking has declined strongly since the mid-sixties. On the other hand, people talk more and more about food and cooking, illustrated by the popularity of cooking programmes on television. This paradox also illustrates the device paradigm: even though we apparently like to see people engaged with food at a professional level, we avoid the concrete and tangible engagement with food ourselves, but, in a way, consume the engagement of others.

\subsection{Problems of treating food as commodity}

There are basically two problems or downsides that Borgmann ascribes to the device paradigm. First, the ends that technology procures become understood in a more narrow and shallow way: the end becomes a commodity. Second, technological devices lead to less engagement, which in turn lead to a loss of skill and of meaningful connections with things. With regard to the first downsides, remember the example of the hearth versus the central heating system. Where the hearth does not only provide warmth, but also a place to repose and to gather around, the end of the central heating system is reduced to one thing: heating. It is possible to see something similar in relation to food? According to Borgmann, this is the case:

The technological view of a meal reveals an aggregate of tastes, textures, and nutritive features. They alone retain stable significance. How they come to be constituted and placed on the table is determined by the requirements of instantaneity, ubiquity, safety, and ease. (Borgmann, 1988, p. 192)

This quote indicates that, when food is understood purely as a commodity, its end is reduced to providing nutrition along with a nice taste and a pleasurable texture. From this perspective, the process of production, cooking, and sharing food is no more understood as constitutive for the quality of food. Hence, food as commodity entails a reduction of food to a few functions, like providing energy and nutrition. The richness of the meaning of food and food practices, which also have cultural and social aspects, is therefore put at risk. At the same time, the availability of food as commodity does affect the way it is produced and consumed. Borgmann notes 
that "[ $\mathrm{t}]$ echnology shows its force most disturbingly as it dissolves the tradition of cooking and the celebration of family meals, both ferial and festal" (Borgmann, 1988 , p. 59). In other words, when food is offered as a commodity that can be consumed with little effort, the practices of eating and sharing meals also change.

The second downside of the device paradigm is very much related to the first one. According to Borgmann, the richness and value of things can only be experienced through engagement. Through engagement, people develop skills, and the development and exercise of skills provide the door to the experience of meaning. For example, a music piece can be appreciated much better by people who play music themselves, or by those who know its complexities and subtleties. Likewise, people who have their own garden and know the difficulties that come with gardening, will be better able to appreciate a beautiful garden compared to those who do not have any knowledge of flowers or gardening. The problem of many modern technologies that offer disburdenment is that they diminish engagement, the development and exercise of skills, and consequently also the experience of meaning, or so Borgmann argues. The same would hold for treating food as a commodity. Only through engagement, people can learn the skills necessary for cooking and appreciating high quality food. When food is always readily available to us, we do not have to put effort in selecting ingredients or preparing meals. It is therefore also questionable whether we can have a meaningful relation to food if we treat it as a commodity.

\subsection{Focal things and practices}

The way in which Borgmann characterizes modern technology can be considered as quite pessimistic. As the above analysis of the application of the device paradigm to food shows, the overall evaluation of "technological eating" from the perspective of his philosophy seems to be rather negative (Borgmann, 1988, p. 204). At the same time, technology has made food available in a way that has reduced scarcity and hunger to a large extent. It also has given ordinary consumers access to all kinds of different foods and food cultures. Borgmann would not deny these benefits, but he points especially at the other side of the coin: standardization of food, the decline of cooking and sharing meals, in short, the decreasing direct engagement of people with food. To these we might add: the worldwide increase in obesity and the negative impact of monocultures on the environment and biodiversity. The question rises what alternatives there are to the device paradigm, specifically for our dealings with food. In this paragraph, I will describe what Borgmann considers to be the alternative to the device paradigm. 
Borgmann's critical analysis of the device paradigm presupposes a certain 'measuring rod', against which modern technological devices and the corresponding consumerist lifestyle are contrasted. He finds such a measuring rod in what he calls 'focal things and practices'. According to Borgmann, focal things and practices are constitutive for a good life, and they stand in a critical relation to the device paradigm. Now what do those things and practices look like? At first, it is helpful to clarify the relation between things and practices. Focal practices are those activities that are centred around and focused on the engagement with focal things. In addition, focal things can only be sustained in focal practices. In order for human activities to count as being part of focal practices, they have to be habit-like sustained activities that occupy a central place in a person's life. So, when I take my running boots only occasionally, running is not a focal practice in my life, while it is for a person who is dedicated to it and runs on a regular basis. Focal practices can be described as having the following four characteristics. First, their exercise requires engagement and skill. This is why watching cooking programmes cannot count as a focal practice, while baking one's own bread could. Second, focal practices engage us with concrete, tangible things in the world, and most often also with other people. The focal thing when baking bread is the bread itself, and the ingredients of which it is made. Borgmann writes that " $[\mathrm{t}] \mathrm{o}$ make the technological universe hospitable to focal things turns out to be the heart of the reform of technology." (Borgmann, 1988, p. 211). Focal things can be very different in kind: for the practice of hiking, the focal thing is the wilderness, while for the practice of cooking, it is the meal. ${ }^{1}$ Unlike commodities, focal things cannot simply be procured in a controllable way. A meal is different every time, like a hiking trip. Sometimes it is a success, sometimes it fails. Third, in exercising skill, and in engaging with focal things, people can experience meaning. The element of meaningfulness is a crucial element. According to Borgmann, focal practices are constitutive of the good life. In other words, a good life is a life in which focal practices have a central place. This, however, does not mean that all human activities should have the character of focal practices. This would be too demanding. Borgmann himself warns against this: "in one or another area of one's life one should gratefully accept the disburdenment from daily and time-consuming chores

\footnotetext{
${ }^{1}$ There is some ambiguity in the relation between focal things and practices. Borgmann sees engagement in politics also as a focal practice. The related focal thing would then be the community or the public sphere. These things, however, are less (or at least differently) concrete and tangible compared to a meal or a piece of furniture. Moreover, Haworth (2000) has noted that focal practices need not be associated with only one focal thing, and different practitioners might also experience the things which they consider to be focal in their practices differently.
} 
and allow celebration and world citizenship [or other focal practices, TB] to prosper in the time that has been gained." (Borgmann, 1988, p. 222). A single person could be dedicated only to a limited amount of focal practices. Beyond that, Borgmann does not mean that everyone should value the same focal practices. Where some people dedicate themselves to gardening, others are devoted to cooking or to sports. Yet, Borgmann does make the claim that focal practices are central to living a good life. "The good life, then, is one of engagement," he writes boldly (Borgmann, 1988 , p. 214). Fourth, focal practices are not necessarily non-technological or antitechnological. Borgmann notes that running shoes or hiking boots can be very much high-tech. The role of technology, however, is different in focal practices compared to the procurement of commodities. In focal practices, technology is instrumental to the engagement with focal things. For this reason, Borgmann calls technologies that are used in this way 'instruments' instead of 'devices.' Where devices have a disengaging and disburdening effect, instruments support the engagement with focal things.

\subsection{Engaging with food as focal practice}

We will now consider what it means to treat food as a focal thing and to engage with it in focal practices. In his work, Borgmann often uses food to illustrate both the device paradigm and focal things and practices. When it comes to dealing with food in a focal practice, he often talks about the 'culture of the table', which he describes as follows:

The great meal of the day, be it at noon or in the evening, is a focal event par excellence. It gathers the scattered family around the table. And on the table it gathers the most delectable things nature has brought forth. But it also recollects and presents a tradition, the immemorial experiences of the race in identifying and cultivating edible plants, in domesticating and butchering animals; it brings into focus closer relations of national or regional customs, and more intimate traditions still of family recipes and dishes. (Borgmann, 1988 , p. 204)

In this eminent description, it becomes clear how Borgmann envisages the engaging power of cooking and sharing a meal. It engages with the food itself, and through that with the practice of agriculture and with the culinary traditions of a region or country. At the same time, it brings people together. The meal is probably the only moment throughout the day when a family comes together in its entirety. Furthermore, sharing a meal together with guests is in many cultures an expression of hospitality and generosity. 
Of course, cooking and sharing meals is not the only way in which people engage with food, although these are probably the most significant ones. Another way is growing one's own food in a vegetable garden. Note that from the perspective of Borgmann's philosophy, the goal of doing so is not to be selfsufficient or independent from the food industry. The goal of growing one's own food is rather to be aware of the richness of food and its complexity, and to develop skills through the exercise of which people can experience meaning. It is also possible to be engaged with food without growing it yourself. Careful and knowledgeable buying is also a way to deal seriously with food. Consumes could ask themselves questions like: where does the food come from? How is it grown? Who benefits within a food chain and who does not? In considering these aspects of food production, we do not only take seriously the food itself, but also the effects of food production on the environment, animal welfare, and on people involved in food production.

What reasons do we have for treating food as a focal thing instead of a commodity? I shortly discuss three reasons. The first reason is that food is so basic to our existence. Hence, caring for our food is a way of caring for ourselves. Eating fast food or pre-packaged meals conflicts with such a caring relation to our food and consequently to ourselves. Such foods induce a form of 'mindless eating' (cf. Wansink, 2010), which draws the attention away from the food itself, and also from the impact it has on our body. We have already finished eating or emptied our can of soda, before our body gives any sign of saturation. Of course, this does not mean that we should always refrain from eating fast food. On occasion, we can have good reasons for not paying much attention to food and eating, for example when we are in a hurry. Moreover, we sometimes simply want to forget about health and indulge ourselves in the 'hyperpalatability' that fast food can offer. It is however problematic as a pattern of eating, and not only because that would be harmful for our health, but also because this pattern is in tension with an attentive and caring relationship to food and to ourselves.

Second, engagement with food supports relations to other people. As said before, the daily shared meal provides a time and a place where the members of a household meet. Beyond this, there are many festive occasions such as birthdays or (religious) holidays for which sharing a meal connects us to others. We might recognize experiences when cooking and eating together with friends invited good and memorable conversations that probably would not have taken place without the food. At the same time, it should be acknowledged that engaging with food is no guarantee for good social relations, just as treating food as commodity does not forbid them. But, like with the first point, the question is what kind of practices different ways of dealing with food typically or characteristically invite us to. In my 
view, readily available foods (like deep-frozen pizza's) invite to eat fast, alone, at a time that fits best for an individual, while engaging with food gives more room to relate in meaningful ways to other people.

The third reason to engage with food in focal practices is that it makes us aware of our dependence on the earth and its resources. It is characteristic for the device paradigm that the means are concealed. It therefore also hides from view the production process and the resources this process requires. Treating food as device or commodity does not help to realize that, for example, every nicely packaged piece of meat once was part of a living animal that was born, nourished, lived for a certain amount of years (likely not very long), and was slaughtered before its meat was cut in pieces and placed on the shells of a supermarket. A counterforce (if only a small one) to this lack of awareness induced by the device paradigm and the consequent distance between producer and consumer, can be found in different forms of direct engagement with food and its origins. Visiting local farms, buying local products, growing one's own vegetables, or planting some fruit trees are examples of engagement. It is very unlikely (and probably also undesirable) that these activities become a substitute for mass-produced industrial food. But they might increase the willingness of consumers to pay a higher price for high-quality agricultural products; products that better take into account the effects of its production on animal welfare and the environment. With regard to this point, Wendell Berry has rightly remarked that eating is an agricultural act: with the kind of foods we buy or grow, we together create the kind of agriculture and landscape that the production of those foods requires (Berry, 2010).

\subsection{Objections and responses}

There are different kinds of objections that can be raised against Borgmann's proposal that the good life is a life characterized by engagement with focal things in focal practices. I distinguish four such objections, and focus especially on possible criticism on the idea that food should be treated as a thing of focal importance in a life well-lived. The first objection entails that Borgmann's call for engagement is too demanding, and can be considered elitist: only people with enough free time and money can afford to engage with food as a focal thing. The second objection is that Borgmann's view is nostalgic, in that it relies on a romanticized view of the past, in which our relation to food was more engaging and less corrupted by modern technology. The third objection is more fundamental: it holds that the question of what a good life consists in should be left open in a liberal society. Since Borgmann defends a definite conception of the good life, his account is problematic from a liberal point of view. The fourth and last objections entails that, even if we accept 
that engagement is central to the good life, we cannot give engagement with food a special place among the plurality of focal practices. In what follows, I discuss these four objections, and formulate a reply to them.

\section{The elitist objection}

The ideal of treating food as a thing of focal importance seems to be too demanding. It implies that people should cook their own meals as much as possible, grow their own vegetables, share meals, or at least inform themselves about the origins food they buy. These activities seem to require a significant amount of free time, and some financial resources would also help to carry them out. Having one's own property for a vegetable garden is, after all, not for free. The question is how we can expect people to engage in this kind of activities, if they do not have the time and resources to do so. The problem of the corresponding account of the good life, one might argue, is not simply that it can be demanding in terms of time and resources, but also that time and resources are very unequally divided among the members of society. This would imply that people with little leisure and little money do not have as much access to living a good life compared to the well-off, and hence that Borgmann's conception of the good life is elitist.

There are two different ways to answer this objection. The first is to downplay the importance of having much time and money to engage in the kind of activities that treating food as a focal thing requires. Home-cooking and sharing meals with the family does not seem to be a privilege of the elite. For having one's own vegetable garden, it is indeed necessary to have some space for it, but this will more often be a problem for people living in cities (rich and poor) compared to those living in the countryside. Moreover, it can be considered a luxury, but not a necessary requirement for people who want to engage with their food. The second way to answer the objection is that to the extent that there is indeed inequality in distribution of time and resources in such a way that it strongly diminishes the ability of the least well-off to engage with food, this is a problem of social justice but not so much of Borgmann's conception of the good life. In some neighbourhoods, there is indeed little access to fresh food, and there are places where fast food or highly processed food is cheaper compared to fresh fruits and vegetables (Tempels, 2019). The availability of the latter type of food is important for engaging with it as a focal thing. From the perspective of Borgmann's philosophy, there are good reasons to consider this as problematic. This objection, however, does not disprove the value of engagement with food as such. 


\section{The nostalgia objection}

Since Borgmann's description of the device paradigm emphasizes the things that have been lost through modern technology, it seems to rely on a romanticized picture of the past. When applied to food, it seems to imply that we should long back to the time before the industrialization of food production, when many people grew their own food, or bought it on local markets, and when disengaging devices such as microwaves were not available. Laudan (2001) has argued that the SlowFood movement also relies on such a romanticized picture of the past. Furthermore, she has convincingly shown that the real picture is very different: the times before the industrialization of food was marked by seasons of hunger, unbalanced diets, toil in food preparation, and very high inequality in access to diverse and healthy food between the rich and the poor.

Borgmann's philosophy can be accused of nostalgia, especially because he underlines the importance of engagement. For that reason, he seems to be more supportive of traditional technologies that require more effort compared to modern devices, which becomes clear in the opposition he draws between the hearth and the central heating system and also between the home-cooked dinner and the microwave-dinner.

In a discussion of Borgmann's philosophy, Verbeek (2005) has argued that there are two different elements in engagement, namely exertion of effort and meaningfulness. It seems that Borgmann makes a necessary connection between the two, implying that exertion of effort goes together with the experience of meaning, and consequently that disburdenment is accompanied by a loss of meaning. Verbeek is right to note that this connection is not necessary. A lot of devices offer disburdenment, but not of the kind that most people experience as going together with a loss of meaning. Just consider some basic household activities: cleaning and doing the laundry. In the past, these activities were rather toilsome. Modern devices like washing machines, vacuum cleaners, and dishwashers have made these activities much easier. Most, if not all people would consider these devices a blessing. One could even argue that modern technology enhances the possibility to experience certain activities as meaningful, because they change from being a necessity to something optional, which we freely choose to engage in. In the past, many activities surrounding the preparation of meals were not optional. Laudan writes: "Churning butter and skinning and cleaning hares, without the option of picking up the phone for a pizza if something goes wrong, is unremitting, unforgiving toil" (Laudan, 2001, p. 41). In the same vain, Michael Pollan has noted that "one of the most interesting things about cooking today-optional cooking-is how it confounds the rigid categories of work and leisure, of production and consumption" (Pollan, 2014, p. 131). 
In her short, but convincing enumeration of the downsides of pre-industrial food production, Laudan (2001) makes clear that nostalgia about food and food preparation in the past is misplaced. Furthermore, it is important to acknowledge that there is no necessary connection between the exertion of effort and the experience of meaning (Verbeek, 2005). Yet, although Borgmann makes the impression of nostalgia at different places in his work, his argument does not necessarily entail it. For example, as noted before, he argues that we should embrace the benefits of modern technology in certain domains of life, to make room for the focal things and practice practices we value and want to be engaged in. Nostalgia is not a necessary element of a view of the good life in which focal things and practices are central, nor is one who wants to treat food as a focal thing automatically committed to the belief that we should go back to pre-industrial food production. At the same time, treating food as a focal thing could have correcting power in relation to the current way of industrial food production.

\section{The non-liberal objection}

The idea that the good life is one of engagement with focal things, is a rather definite conception of the good life. Yet, in a pluralist society, people have different conceptions of what a good life is. It is possible that people disagree about the centrality of engagement in a good life, or they might conceive of what counts as engagement very differently. Accepting differences in conceptions of the good life is one of the main tenets of a liberal society. From this point of view, Borgmann's account is non-liberal, as it defends a specific view of a live well-lived. This would be especially problematic if there are drawn implications for public policy from this specific view. For a liberal, this is one step too far: in a plural society, public policies should be defended on the basis of reasons that can be acceptable to everyone, without presupposing a particular conception of the good life.

Borgmann is conscious that his approach is non-liberal. He argues that neutrality with regard to a view of the good life is impossible when it comes to how we shape public life. Indeed, the organization of public life inevitably influences the kind of life people can live. For example, rules and expectations with regard to working hours influence how people organize their working life. And the way in which agriculture and food production is organized in a country, has a lot of influence on the agricultural landscape and also on the kind of food that people are presented with in shops. An example that Borgmann himself gives is the building of a highway through a forest, which diminishes the forests' attractiveness as a hiking area. Hence, he writes with regard to the question of the good life that " $[\mathrm{w}] \mathrm{hat}$ remains open is not whether but how we will answer it" (Borgmann, 1988, p. 178). 
Even though the organization of public life cannot be neutral with regard to conceptions of the good life, it is quite another thing to take a particular conception of the good life as its basis. In that sense, the question of the good life should indeed be left open: it should be possible to discuss and contest prevailing conceptions of the good life and the way they influence public life. In this discussion, the voice of Borgmann contests the prevailing paradigm of technology, which invites to a consumerist lifestyle that conflicts with a lifestyle of attention to and engagement with meaningful things. It seems to me that there are no good reasons not to take this voice seriously, even though it is built upon a definite conception of the good life.

\section{The plurality objection}

The former objection was rather broad, criticizing the fact that Borgmann's argument depends on a specific conception of the good life. It is likely that his way of reasoning will only be convincing for people who come along with the idea that engagement is central to a life well-lived. Yet, even when we accept the importance of engagement, the question for this chapter is why food, cooking, and eating should be the object of engagement. There is a plurality of things and practices that require engagement and through which people experience meaning. Where one person finds this in gardening, other people find it in sports, literature, art, or in crafts of various kinds. People can be devoted only to limited set of focal practices, because they require exercise and skill. Furthermore, the kind of practices people perform depend on their personal preferences. Suppose that a person does recognize the value of engagement, and has dedicated herself to a specific focal practice, say woodworking. She might object as follows: "Why should I be engaged with food? For me, cooking, let alone growing my own food, is a burden that takes a lot of time. Time that I would like to invest in things that I do value, like woodworking. I therefore often buy pre-packaged meals or at least chopped vegetables. Indeed, I like food to be available in an easy and instantaneous way. What is wrong with that?" This raises the question whether food is a focal thing of a special kind that should also receive attention from runners, readers, artists, and craftsmen.

We cannot really find an answer to this question in Borgmann's own philosophy, since he acknowledges that "engagement is variously realized by various people" (Borgmann, 1988, p. 214). Although he uses food and the "culture of the table' as one of the central examples of focal practices throughout his work, he does not argue that everyone should be dedicated to this specific practice, just like not everyone has to be dedicated to hiking in the wilderness. Yet, there are reasons for giving engagement with food a special place among focal practices. These reasons 
relate to a rather basic fact: everyone has to eat in order to even survive. Consequently, everyone has to shape and develop eating practices. This makes food a focal thing of a special kind, since not everyone has to make music, hike, or garden in order to survive. Further reasons for giving food a special place relate to this basic fact. Each household, to start with, has to develop habits about the way they cook and eat: what and how to cook by whom, and whether and when to share the meal. Furthermore, engaging with food can teach us about the interconnectedness between our bodies and the earth. Treating food as a commodity does not undo this interconnectedness, but it conceals it. Food that is ubiquitously readily available, invites a way of consumption that is forgetful about its origins and the processes needed to make it available. When we grow our own vegetables, we may come to recognize that the health of our bodies depends on the health of the environment in which our food is grown. A careful way of buying products may teach us about the relation between the kind of food we want to be available in supermarkets and the agricultural landscape we have.

The basic fact that everyone has to eat, and hence to develop some practice of dealing with food, makes food of a special kind among other focal things. There is indeed a variety of focal practices, and not everyone has to engage with food to the same degree. Yet, there are some good reasons to engage with food at least to some extent, and to limit our demand for ubiquitously and instantaneously available food.

\subsection{Implications for responsible food innovation}

After this rather long detour about food as commodity or focal thing, the question we started with has to come back: how could food innovation contribute to the good life? I hope to have made clear the relevance of reflection on the place of food in the good life. The next step is to draw some implications of these reflections for food innovation. I draw two implications, formulated as questions. The first question is: does a specific food innovation contribute to a reductionistic or holistic understanding of food? The second question is: does a specific food innovation invite engagement or disengagement with food?

\section{Reductionistic or holistic?}

The first question relates to a downside of modern technology that Borgmann identifies in his work: that technological devices tend to reduce the function of things to single procurable ends. Or, in his terminology, it reduces focal things to commodities. I think that this can also be a problem of food innovation: when it focuses on specific ends, the function of food can be reduced to this end. 
Reductionistic understandings of food are food as mere energy, mere pleasure, or mere nutrition. Especially the last one is popular in these days, as made clear by Scrinis (2013), who talks about 'nutritionism' as the dominant food ideology. Nutritionism, he writes, is the "reductive focus on the nutrient composition of foods as the means for understanding their healthfulness, as well as by a reductive interpretation of the role of these nutrients in bodily health" (Scrinis, 2013, p. 2). Clear examples of food innovations within this nutritionist paradigm are found within the category of so-called 'functional foods': foods with added nutrients that are claimed to have health-enhancing benefits. To such products, fibres, omega-3 fats, or vitamins are added to improve the nutritional composition. Examples that Scrinis mentions are "[p]robiotic ice cream, heart-healthy chocolate chip muffins, satiety smoothies, calorie-burning green teas, fiber-rich snack bars, omega-3fortified baby foods for brain and eye development, and low-glycemic-index meal replacements" (Scrinis, 2013, p. 191). He also aptly notes that to this understanding of food as mere nutrients corresponds a conception of the body in functional terms, focused on "the internal workings and functioning of the body and their relation to specific nutrients and foods" (Scrinis, 2013, p. 165).

Over against the nutritionist paradigm, Scrinis (2013) has developed what he calls the 'food-quality paradigm'. This paradigm aims to evaluate the quality of food in a more holistic way. Besides nutrition, it takes into account the way in which food is processed, cultural-traditional knowledge about food and cuisines, and the sensual-practical experience of people. All these elements contribute to food quality. So, what counts as 'good food' is not only determined on the basis of its nutritional composition, but also by the way in which it is made. The food quality paradigm fits very well with the idea of food as a focal thing, full of richness, complexity, and as a potential source of meaning. The element of sensual-practical experience indicates that people do not always have to rely on expert knowledge about nutrients and their effects on the body to assess the quality of food, but that they can use their senses and their experience with food as a reliable and practical guide.

People who are responsible for food innovation are well-advised to consider the question whether the food products they develop contribute to a reductionist or holistic understanding of food. For example, they could ask themselves questions like: what kind of understanding of food does this product enhance? Does this product fit within, respect, or conflict with cultural-traditional knowledge about food? Does it enable people to develop practical-sensual knowledge about food or is it based on providing direct enjoyment? When these questions are taken seriously, food innovation might contribute to food quality beyond reductionism. 


\section{Disengaging or engaging?}

The second question relates to the second downside of modern technology that I noticed before: that technological devices disburden people in such a way that engagement, skill, and potentially meaningful experiences are lost. Theses downsides also apply to food innovation. Now of course, this is not a problem for every individual innovation, just like it is not for all forms of disburdenment through technology. However, it can be problematic when the overall pattern of dealing with food in a society is dominated by the device paradigm. For this reason, it would be interesting to reflect on the question to what extent food innovation invites engagement or disengagement.

It is not difficult to imagine the kind of innovations that mainly offer disengagement. Just think about those focused on convenience like ready-made meals. It is more difficult to imagine innovations that contribute to engagement. This is because most innovations relate to processed food, as there is less to innovate on whole foods compared to processed foods. Furthermore, processed food is in general less engaging than whole food, since the processing part is taken over by companies. Probably, innovations that contribute to engagement with food will be process innovations more often. For example, an internet platform that connects citizens to local farmers that sell food is certainly an innovation, but not at the product level.

It is important to acknowledge that not all forms of disburdenment are bad, and also that engagement comes in degrees. It is not possible nor desirable that everyone produces his or her own food, and even people who do will most certainly not produce all of it by themselves (who bakes bread from his own grain?). It is also possible that certain products offer both a form of disburdenment and invite to engage with food at the same time. For example, many supermarkets offer meal packages with fresh vegetables, herbs, and spices in order to cook a complete meal. One the one hand, these products release people from the burden to always think about what they are going to cook and search for recipes. On the other hand, they still encourage people to cook a meal by themselves with fresh ingredients. Although this example can be considered ambiguous as it is a mix of engagement and disengagement, it at least fits in a time where people are busy and still look for a form of engagement.

\subsection{Conclusion}

My aim in this chapter was to provide relevant considerations for answering the question how food innovation could contribute to the good life. Following the philosophy of Borgmann, I argued that there are some problems with treating food 
as commodity, that is, as a product that is made safely, ubiquitously, instantaneously, and easily available through modern technological devices. Treating food as such could lead to a reductionistic understanding of food, loss of skill, and consequently also to a loss of meaningful experiences. There is a clear risk that food innovation, with its current focus on convenience, contributes to treating food as commodity.

I have argued that responsible food innovation implies to focus not only on direct ends like improved nutritional composition, but also on the indirect consequences on the understanding of food (reductionistic or holistic) and the relation of people to food (engaging or disengaging). These indirect consequences would probably not have come into view if I did not ask the question about the place of food in a life well-lived.

The approach of this chapter might be relevant for broader discussions about responsible innovation. In my view, this approach raises more fundamental and critical questions about the role of technology and innovation in our lives compared to other existing approaches to responsible innovation. I admit that the view of the good life presupposed and to some extent defended in this chapter is not indisputable. Knock-down arguments when it comes to defending a certain view of the good life are simply not available. At the same time, it is possible give reasons for a certain view, and it is relevant to have an exchange about those reasons. Borgmann calls such a debate about the good life a 'deictic discourse', about which he writes:

\footnotetext{
"Speakers of deictic discourse never finally warrant the validity of what they tell but point away from themselves to what finally matters; they speak essentially as witnesses. Enthusiasm gives deictic discourse the force of testimony (...). Sympathy gives deictic discourse the force of appeal" (Borgmann, 1988, p. 178).
}

Hopefully, this chapter contributes to such a discourse about food innovation and the good life. 



\section{CHAPTER 6}

\section{CONCLUSIONS AND DISCUSSION}




\section{CHAPTER 6 CONCLUSIONS AND DISCUSSION}

What does this thesis altogether add up to? How do the findings relate to each other? And what do they imply? These questions will be addressed in this discussion chapter. I will start with a short overview of the research questions and findings per chapter. After that, I will provide a discussion 'between' and 'beyond' the theoretical contributions of the different chapters. This will be the main body of this chapter. In this discussion, three themes will be central: the tensions that come with deliberation in the business context, the limits of corporate social responsibility in relation to the competitive structure of the market, and the current 'cult of innovation' in relation to food and responsible innovation. After that, the limitations of this thesis and suggestions for future research will be shortly discussed. The chapter closes with some practical recommendations that follow from the findings of this thesis.

\subsection{Recap of the results}

\section{Responsible Innovation in business (chapter 2)}

The research question for chapter 2 was whether deliberative engagement is a proper mechanism for RI in the business context. My answer to this question was not a simple yes or no. I indicated that the demand of opening up innovation processes to a broad set of stakeholders and to the public will result in tensions. Although a certain degree of deliberative engagement with stakeholders and the public could be beneficial for companies, there will be a point at which the demand for engagement will conflict with their need to be competitive. The reason for this conflict has everything to do with the fact that processes of deliberation require quite some time and resources. Furthermore, to be innovative and to use innovations for achieving competitive advantage necessitates companies to make use of information asymmetries. And those very information asymmetries are under pressure when companies engage extensively in deliberation with third parties. Another problem I pointed at was the tension between corporate governance structures that give a central place to those with financial interest (owners, investors, and shareholders), and the ideal of RI to democratize the governance of research and innovation. Underlying these different tensions, there is a basic tension between voice (deliberation) and exit (competitive pressure), which, I argued, is inherent to the functioning of the market. 
Although many RI scholars recognize the existence of tensions resulting from deliberative engagement in the business context, it is often not made clear what these tensions imply for the conceptualization of RI. As I argued, RI scholars should develop a conception of deliberation adjusted to the context of the market. Or, they should consider changes in the governance of markets that make the application of deliberation more favourable, for example by developing ideas for the democratization of corporate governance.

\section{Stakeholder dialogue as agonistic deliberation (chapter 3)}

The aim of chapter 3 was to develop a conception of stakeholder dialogue tied to the business context, so as to take the role of conflict and self-interest into account. When I was studying the literature on stakeholder dialogue, I found it remarkable that there was a gap between, on the one hand, the empirical literature, and on the other hand, the conceptual literature which discusses the norms and ideals of stakeholder dialogue. In the empirical literature, it is recognized that there are always tensions and conflicts between stakeholders and between different interests. Yet, in the conceptual literature, a rather high ideal of dialogue is presented, with an emphasis on consensus building, harmony, and shared interests. In chapter 3, I address this gap by developing a normative view of stakeholder dialogue that does justice to its 'messy' empirical reality.

In this chapter, I restricted myself to the interaction between companies and NGOs, and to the role of conflicts between commercial interests and societal values in their interaction. I argued that both conflict and self-interest are inevitable and to some degree even desirable elements in a dialogue between these actors, especially in cases when the activities of a company are in a conflictual relation with societal values. The presence of self-interest has everything to do with the fact that the very functioning of the market entails the permission for companies to pursue profit (or generally commercial interests). This permission is legitimate and belongs to the heart of the existence of companies. For this reason, companies cannot be simply put their commercial interests between brackets when they enter a dialogue about a societal issue. At the same time, this permission comes with a risk, namely that the pursuit of profit comes at the expense of societal values. For this reason, the market needs correction. Activism by NGOs is one of the forms of correction with an important societal function, namely to raise awareness among the public and to push companies and governments to action. The societal role of NGOs, therefore, stands in a critical relation to the status quo, which often results in a conflictual relation to actors that defend the status quo, for example companies with vested interests. Henceforth, I argue that there is often an adversarial element in the relation 
between companies and NGOs. The alternative conceptualization of stakeholder dialogue called 'agonistic deliberation' recognizes both the legitimacy and desirability of self-interest and conflict in deliberation. Yet, it also upholds the norm of mutual justification, which entails that participants in deliberation should be willing to justify their views to each other on the basis of reasons.

\section{Tensions in stakeholder interaction (chapter 4)}

That deliberation between companies and their societal stakeholders comes with tensions and conflicts, raises the question how participants in a dialogue deal with this. The different dialogues organized by the Dutch Choices Foundation gave the opportunity to do some qualitative empirical research about tensions within stakeholder dialogue. One of the tensions that I expected to play a role within stakeholder dialogue was between the commercial interests of companies and public or societal interests. There were enough reasons to expect such a tension in the specific case I studied, given the heated debate about the relation between the food industry and societal issues regarding overweight, obesity, and related health problems. The question, however, was how this tension would play out in the actual interaction. I focused specifically on the responses of companies to this tension within the dialogue, using the paradox approach to organizational tensions as the theoretical lens.

The responses I found are, from the perspective of the paradox approach, defensive: framing opponents as idealistic and not constructive, stressing one's personal motivations for the public goal, while not addressing possible tensions between this goal and commercial interests, and a certain splitting of responsibilities by requesting the government to take more responsibility for the issue at stake. Even though these responses are very understandable (given the criticism on companies), it is striking that, seemingly, companies find it difficult to accept and communicate tensions between their commercial activities and public interests.

Theoretically, this chapter adds to the existing literature on organizational tensions by showing that responses to those tensions are not an internal organizational matter, but are also constructed as a response to external stakeholders. In relation to the literature on corporate social responsibility, we underline the importance of taking tensions between commercial and socio-ethical considerations into account.

\section{Commodity or focal thing? (chapter 5)}

As explained in the introduction, chapter 5 adopts a substantive approach to RI. Hence, this chapter puts the innovation process between brackets, and delves 
directly into the question what RI means for food products. Or, in terms of the chapter, it discusses how food innovation could contribute to the good life. The aim of this chapter is not to provide a clear-cut answer to this question, but to discuss the kind of considerations that are relevant in answering it. I argue that a relevant consideration has to do with the way people relate to food products. A question this chapter raises, is whether food innovation contributes to a relation of engagement or disengagement with food.

The notion of engagement is borrowed from the philosophy of Albert Borgmann, who argues that engagement with focal things in focal practices is a central element of a good life. In other words, practices that contribute to the good life are those that require bodily and social engagement, and hence the development and maintenance of skills. However, as Borgmann argues, those engaging practices are under pressure due to modern technologies, which offer goods and services that are directly consumable. The home-cooked meal versus the microwave meal are paradigm examples in this regard. While the former requires engagement, the latter does not.

Several objections have been raised against Borgmann's account of modern technology and its relation to the good life. For example, that it is nostalgic and does not take the benefits of modern technology properly into account. Although I see elements of truth in these objections, the importance and value of engaging practices still stands. I propose several reasons in the chapter why specifically food should be a thing to engage with in focal practices. For food innovation, this implies at least to take seriously the effects of new products on the way people engage with food.

\subsection{Theoretical contributions: a discussion}

\section{The inevitability of tensions between voice and exit}

This thesis underlines the inevitability of tensions that arise when companies take part in deliberative processes about societal issues, whether related to innovation or broader societal issues. These tensions are inevitable because of the competitive structure of the market. Although they have different faces, they all relate in some way to the tension between what Hirschman has called 'voice' and 'exit' (Hirschman, 1970). Voice is the political mechanism per excellence, and exit the market mechanism. Voice means that people can raise their concerns in terms of reasons, arguments, stories, or generally, in terms of language. Exit means that people, when confronted with something they do not appreciate, make a different choice. So, when I do not like the products of brand A, I most often will simply choose a different brand. This distinction does in no way mean that voice does not 
play a role in the market, nor that exit plays a role in politics. The point is that voice qualifies the political context, while exit qualifies the market context. ${ }^{1}$

In deliberation, companies are expected to respond to voice: to complaints and criticism, or to compliments and praise. And even though they might be willing to respond, they still cannot put between brackets the fact that they are mainly used to respond to exit, namely sales, turnover rates, or developments in consumer satisfaction. Moreover, it can clearly be shown that voice and exit do not always go in the same direction: even though people sometimes communicate that they want products to be sustainable, animal friendly, and healthy, what they actually choose is often different, giving more attention to things like price, convenience, and taste. This is a tension companies have to deal with. Their social responsibility pulls them in the direction of responding to voice, while their profit-orientation and competitive context demands responsiveness to exit. Despite sometimes successful efforts to get these two demands in line with each other, areas of tensions will be persistent.

The defensive responses found in chapter 3 can also be explained along these lines. The critics in the dialogues of the case-study argue that companies compromise too much on societal goals (healthy food) for the sake of profit. Companies, on the other hand, have the feeling that critics do not understand that they have to find a certain compromise between the societal goal of health and their position in a competitive market. It is difficult to deal with this kind of conflicting understandings of the role and responsibility of companies in deliberation. A defensive response is the easiest way to protect oneself against criticism. The alternative conceptualization of stakeholder dialogue as worked out in chapter 4 was developed to recognize the persistence of tensions between public and private interests, between voice and exit, and between different actors. For this reason, I argued that conflict and self-interest have a legitimate place within deliberation. Beyond that, I argued that conflict can also be made productive, as it could mobilize people for a certain cause, and urge actors to change their behaviour.

The competitive structure of the market and the limits of corporate social responsibility

The persistence of tensions between voice and exit points to a core problem for theories of business ethics: how to conceptualize the relation between a firm's economic objectives and its social responsibilities. In my view, many theories try to

\footnotetext{
${ }^{1}$ Hirschman (1970) also discusses the intermediating role of loyalty. For example, the more loyal people are to a brand or company, the more likely it is that they will use voice instead of exit to raise their concerns.
} 
explain the tension away. Consider two still prominent frameworks: shareholder and stakeholder theory. Shareholder theory holds that companies simply do not have any social responsibility, except a responsibility to maximize profits (Friedman, 1970). This theory holds that the market generally and characteristically maximizes efficiency and consequently supports prosperity when firms focus on shareholder value alone. Hence, it explains the tension away by arguing that there is no conflict between the focus on economic efficiency and important values like welfare and freedom. To the extent that shareholder theorists acknowledge that the market mechanism also creates its own problems, they argue that it is not the role of companies but of governments to solve these problems.

Stakeholder theory holds that firms should not only pay attention to shareholder value, but should also address the legitimate demands of others stakeholders (e.g. Freeman et al., 2010). Freeman and colleagues summarize the stakeholder mindset as follows:

serving all your stakeholders is the best way to produce long term results and create a growing, prosperous company ... Let me be very clear about this: there is no conflict between serving all your stakeholders and providing excellent returns for shareholders. (Freeman et al., 2010, p. 27; quoting George, 2003)

The claim that behaving ethically (by addressing stakeholder interests) is not in conflict with economic value creation, is a recurrent one in stakeholder theory (e.g. Noland \& Phillips, 2010). Those who cast doubt on it are said to commit the 'separation fallacy', that is, the fallacy of separating ethical considerations and business decisions (Freeman, 1994; Noland \& Phillips, 2010). Thus, stakeholder theorists are eager to emphasize the compatibility of economic and ethical or social goals. Thereby, they also downplay structural role of tensions between these different goals, or between the different interests of stakeholders.

I contend that economic and ethical or social goals are in tension with each other, although they are not incompatible (cf. Margolis \& Walsh, 2003). The persistence of tensions between economic objectives and social responsibilities has everything to do with the competitive structure of the market as coordination mechanism. In what follows, I argue why this is the case.

Most fundamentally, tensions between economic objectives and social responsibility originate in the fact that competition in the market works like a prisoner's dilemma (Heath, 2014). An example of how this prisoner's dilemma works is shown in Table 1. In this example, companies have the choice between maintaining or lowering their price levels. Regardless of what firm B does, it is in the interest of firm A to lower its price level. The same holds for firm B, so the 
equilibrium is that both lower their price level and obtain a profit of 20 . The alternative for making more profit is to make a price agreement. But, since making price agreements is forbidden in competitive markets, the only viable alternative in this example is that both companies lower their price level. Of course, lowering one's price level is not the only competitive strategy in the real world: lowering costs, improving quality, or attending to specific consumer wants are also possible. Yet, the idea is that all these different competitive strategies lead to higher efficiency and higher consumer welfare, just like lower prices do.

Table 1: competition as prisoners dilemma

\begin{tabular}{|c|c|c|}
\hline & Firm A maintains price level & Firm A lowers price level \\
\hline Firm B maintains price & Profit $\mathrm{A}=50$ & Profit $\mathrm{A}=\underline{80}$ \\
level & Profit $\mathrm{B}=50$ & Profit $\mathrm{B}=0$ \\
\hline \multirow{2}{*}{ Firm B lowers price level } & Profit $\mathrm{A}=0$ & Profit $\mathrm{A}=\underline{20}$ \\
& Profit $\mathrm{B}=\underline{\mathbf{8 0}}$ & Profit $\mathrm{B}=\underline{20}$ \\
\hline
\end{tabular}

To the extent that markets functions like the prisoner's dilemma, there is a certain race to the bottom: in the pursuit of profit, companies look for ways to lower their costs or increase value for customers. On a basic level, this is the very point of market competition, because it creates efficiency. However, due to the existence of market failures, companies might make profit or lower their costs by passing on costs to others (i.e. dumping waste or paying very low wages).

That the market generally works as a prisoner's dilemma, together with the existence of market failures, results in the possibility of conflicts between economic objectives and social responsibility. These conflicts exist to the extent that taking social responsibility results in higher prices or lower profits (which is often the case) without there being sufficient demand for those responsible products. Take for example the clothing industry. It is common knowledge that there are problems with wages and working conditions of people working in this industry in low wage countries like Bangladesh. Competition and the pursuit of profit led manufacturers to these places. To produce clothes in a fair and sustainable way would be more expensive. Although some manufacturers take their social responsibility and produce fair and sustainable clothes, there is (at the moment) quite little demand for those higher priced products. In other words, it is at the moment difficult to make a profit by selling fair and sustainable clothes on a large scale. So, in a way, the prisoner's dilemma keeps companies away from making their products more fair and sustainable. 
That the market works this way, sets limits on what companies can achieve on their own (cf. van de Ven \& Jeurissen, 2005). Of course, a company can try to change its policies radically, but if there is no demand for their products, their fate will be decline and others will take their place. The point is that whether companies can combine being successful in the market with acting in a responsible way, does not only depend on their creativity, but also on a set of institutional and social conditions (Paine, 2000). For example, are there NGOs that campaign against problematic company behaviour? Are there critical citizens or not? Is there freedom of press? Is there a culture of transparency or a culture to cover-up bad behaviour? To what extent do companies have their own internal mechanisms of compliance and accountability? Conditions like these can support or undermine responsible behaviour.

This analysis underlines that the market is a nonideal and "fragile system", in which "the private and public good often do not converge" (Dubbink, 2004, p. 37). At least, it is a system in which it cannot be taken for granted that private and public good converge. The extent to which these converge depends not only on the good will of companies, but also on a complex set of social and institutional conditions. In my view, theories of business ethics need to take into account that tensions between economic objectives and social responsibility, or between private and public goods, are inherent to the imperfect structure of competitive markets. Furthermore, these theories should focus not only on what companies should do or refrain from, but also on how the surrounding social and institutional conditions can be supportive of responsible behaviour by companies (Dubbink, 2004).

That the competitive structure of the market limits what companies can do (on their own), should also be reflected in a conception of RI in business. In chapter 2, this led me to argue that the current ideal of deliberative engagement as the main way to conduct RI, is somewhat overambitious. Deliberation is not the golden bullet, and there will always be trade-offs between deliberation and competitiveness. But also approaches to RI that do not focus so much on deliberation, will have to take into account the limits of what companies can achieve on their own in a competitive context. On the other hand, the market as nonideal system underlines the emphasis in RI on cooperation between multiple stakeholders. Cooperation can be an instrument in a structure that supports responsible corporate behaviour, despite the fact that it will also bring along its own challenges.

\section{Responsible innovation, the cult of innovation, and food}

I close this discussion of the theoretical contributions of this thesis with some notes on what Winner (2018) has called the current 'cult of innovation'. Much of today's 
problems are expected to be solved through innovation. This is also the case in the context of food and health: to stop the increase of diabetes and obesity, many experts point at the necessity of healthy food innovation. This appears paradoxical to me, since we know already what healthy food is (vegetables, fruits, and other whole foods), while much of what we call unhealthy foods are the result of technological innovation (especially highly processed foods), which are developed for reasons of convenience, taste, and to reduce production costs (cf. Monteiro, 2009). The problem is not so much that there is no healthy food, or that we need more innovation to develop it, but that there is a big unbalance in the availability of healthy and unhealthy food. Healthy food innovation can only be a very partial solution to the problems of obesity, diabetes type-II, and other nutrition related diseases. Other things we need are different ways of selling food products (smaller portions, more healthy food on streets), different ways of preparing food (more fresh foods), and different eating practices (more careful and attentive eating instead of 'mindless' eating in front of a TV). By starting a substantive discussion about the relation between food, technology, and the good life in chapter 5, it was part of my aim to circumvent the cult of innovation. The result was that we might have to look in a different direction for innovations that contribute to the good life, beyond commercialized technological innovation.

By using innovation as a central term, RI buys into a discourse in which innovation is often presupposed to be inherently good, defined in technological terms, and considered as panacea for 'the grand challenges of our time' (cf. von Schomberg \& Blok, 2018; Timmermans \& Blok, 2018). The big question for RI is whether it can escape this cult of innovation. Is it not telling that the term 'innovation' is needed for getting research programs funded about the social and ethical aspects of technology?

In an article that critically discusses the cult of innovation, philosopher of technology Langdon Winner shortly contemplates on the possible meaning of 'benign innovation', which he, interestingly, illustrates it with an example about food. He brings forward Alice Waters, as 'advocate of new ways of growing, cooking and eating foods':

Beginning 1970s with her restaurant Chez Panisse in Berkeley, Waters took aim at the prevailing culinary practices of the time - over cooking, too much gravy, too much grease, etc. - and introduced methods that emphasize fresh, locally grown, organic ingredients, carefully prepared in a direct, tasty manner, a way of cooking that came to be known as the California Cuisine. Eventually her "innovations" became a model for transformations in restaurant and home cooking that swept the country (and much of the world) during the decades that followed. (Winner, 2018, p. 65) 
To me, this example of benign innovation seems in line with Borgmann's notion of engagement. It implies that we need innovations in which "old traditions are not trashed, but modified, gracefully unfolding into something new." (Winner, 2018, p. 65). I think that research on RI could benefit from Winner's critical reflection on the cult of innovation, and from his conception of benign innovation.

\subsection{Limitations and future research}

Doing research implies limiting oneself. So, although this thesis covered a quite broad set of topics and theories, it necessarily has its limitations. In what follows, I list what I consider to be the most important limitations of this thesis, and connect them to suggestions for future research:

- Most of the research in this thesis about deliberation in the business context is conceptual (except for chapter 3). At the same time, many arguments in the different chapters rely on empirical claims about the role that strategic considerations play within companies and generally in the market, and about the persistence of conflict between companies and other societal stakeholders (especially NGOs). Empirical research is needed to gain more insight in the role that strategic considerations play in how companies deal with societal issues. Furthermore, conflict can have different forms and degrees. This requires empirical research, in order to better understand the what and the how of conflict between companies and their stakeholders.

- In Chapter 2, I argue (with regard to deliberative engagement as a way of conducting RI in the business context) that RI scholars should modify the ideal of deliberative engagement, or reflect more critically on changes that are required in the market in order to make deliberative engagement possible. I followed the first road by developing an alternative conceptualization of stakeholder dialogue in chapter 4. In this alternative of agonistic deliberation, I take the competitive structure of the market as given. I argue that from this competitive structure follows the permission on the part of companies to pursue their particular interests (profit). However, the second road also requires attention, as it is the very competitive structure and the pursuit of profit which makes RI and deliberative engagement with stakeholders so complex. Hence, it might be that we need different governance structures within the market and different regulation of the market. One of the suggestions I shortly mentioned in chapter 2 was the inclusion of different stakeholders in corporate governance structures, in order to break the dominance of shareholder interests. This suggestion, in 
my view, requires more attention within research on RI, because it might enable deliberative engagement of stakeholders in a structural way.

- Chapter 4 discusses the role of conflict and self-interest in the interaction between companies and NGOs. In this chapter, I abstract from the different strategies of both companies and NGOs in the way they approach societal issues, in order to get a better view of the essential elements of their relation. A risk of this approach is that it conceptualizes the relation between companies and NGOs as too homogeneous. I recognize that there are many different types of NGOs, with different strategies in how they deal with companies. Although I shortly discuss the differences between radical and reformative NGOs, more refinement is needed. This also holds for the way in which companies approach societal issues. Some companies are very active in trying to address societal problems, while others have a more passive and defensive approach. I did, for example, not discuss literature on social and sustainable entrepreneurship, which focuses on companies that actively try to solve societal problems. It is imaginable that there is little conflict between very active companies and reformative NGOs, while there is outright conflict between passive companies and radical NGOs. Further research (both conceptual and empirical) could address how the different strategies of both companies and NGOs influence the role of conflict and self-interest in their interaction.

- When it comes to the topic of the place of food in our lives, it would be relevant to do empirical research about the extent to which people experience engagement as an important or meaningful element of the way in which they treat food. In chapter 5, inspired by the philosophy of Albert Borgmann, I give different reasons why it would be important to engage with food, instead of treating it merely as commodity. If engagement with food contributes to the good life, we could expect that people recognize this at least to a certain degree. Furthermore, it would be very interesting to study what factors influence the choice for convenience (such as buying pre-cooked or pre-packaged meals) versus engagement (such as growing and cooking one's own food).

- As chapter 5 provides a critical reflection on the relation between technology and the good life, it could give rise to the image that the best way of treating our food is as low-tech and pre-industrial as possible, since small scale local farming and home-cooking require high levels of engagement. I discussed this image shortly in the chapter by raising the question whether or not Borgmann's philosophy is characterized by nostalgia. Although I rejected the idea that Borgmann's approach necessarily 
implies a longing back to pre-industrial times, one could argue that his philosophy is characterized by the idea that technology alienates humans from reality (Verbeek, 2002). In contrast to this view, other philosophers of technology have emphasized the interconnectedness of humans and technology, stressing the fact that technology mediates the relation between humans and reality in different ways (Ihde, 1979; Verbeek, 2005). Although philosophers defending this approach do not deny that technology can be disengaging, they argue that this is but one of the ways in which technology mediates the relation between people and reality. They argue that technology can also engage us (Verbeek, 2005). A possibility for further research is to explore the implications of this approach to the philosophy of technology for the relation between humans and food.

\subsection{Practical implications}

The findings of this thesis have practical implications. In the list of implications below, I try to show the relevance of my research for different groups of people:

- Moderators of stakeholder dialogues might give more room for diversity in the interaction between companies and their stakeholders. If my argument in this thesis is correct, their goal should not so much (or at least not only) be to create a common vision. The exploration of differences and sources of conflict and is just as important. The challenge for moderators, of course, will be to ensure that differences can be expressed and explored in a way that leads to mutual understanding between participants. In other words, the challenge is to create active responses of participants to the tensions and conflicts within the dialogue. That means that participants recognize the tensions between different actors and within their own position, and confront them instead of repress or deny them. In order to achieve this, it is, in my view, important that moderators can clearly set the terms and rules of the interaction. It would be helpful if moderators explicitly name differences, that those differences provide by themselves a good reason to engage in dialogue, since people can learn from each other thanks to differences, and hence that a dialogue is not in vain even if no consensus is achieved.

- Companies that participate in stakeholder dialogues about societal issues should have the courage to acknowledge their commercial interests. To emphasize one's motivation to be socially responsible is one thing, but it is another to do this while being completely silent about one's commercial 
interest. In my view, the latter will only raise the suspicion that there are strategic reasons behind the emphasis of companies on their motivation to be socially responsible. I think that a dialogue would lead to more mutual understanding if companies acknowledge that taking social responsibility sometimes conflicts with their commercial goals, or generally with the fact that they operate in a competitive context. It is a misunderstanding that people just want to hear a nice story from companies. Critical stakeholders will sooner or later find out when companies are mainly interested in keeping up appearances.

- Those responsible for food innovation in companies should critically reflect on the impact of food innovation. Direct goals of food innovation can be taste, texture, convenience, health, sustainability, and many more. But beyond these goals, there are also good reasons to reflect on the impact food innovation has on the way people engage with food. Even though not every individual innovation has to aim at engagement, it is certainly a good thing to reflect on what conception of the good life, and the place of food within it, a company enhances with its innovation and marketing strategy as a whole. Is this a life of passive consumption, in which consumers are depicted as just wanting ease, direct availability of food, and convenience? Or is it a richer picture in which people are also (although not always) active, and in which engagement of humans with food and through food with their environment, animals, and other people is an important and meaningful part?

- Lastly, we as ordinary consumers could reflect on the question to what extent we eat with attention. Attention can lead to a sense of wonder about the availability of food that is beautiful, tasteful, and nutritious. Wonder can motivate us to take care. Care implies to consider the effects of our choices on ourselves and our environment, and take responsibility for those effects. Do our meals provide us with moments to interact with others? Do our food choices reflect the values we deem important, such as sustainability and care for animals? Attention, wonder, and care together can make us prepared to pay a higher price for products of higher quality (if we can afford it), or to put more effort in acquiring those products. If we consider this way of treating food as part of a life well-lived, we are not discouraged too much by the fact that the effects of our choices are very small. 


\subsection{Concluding remarks}

The aim of this thesis was to reflect from a normative-ethical perspective on the meaning and challenges of RI in the context of business generally, and the food industry specifically. This led me to debate the notion of deliberative engagement with stakeholders, which is so central in the debate on RI. I have argued that the challenges of RI in business are related to the tensions between the ideal of deliberation and the competitive structure of the market. Since these tensions are persistent, I have argued that we need a different conception of deliberation, which takes conflict and self-interest into account. When it comes to the meaning of RI in the context of food, I have argued that we need to reflect on the place of food (innovation) in the good life. This reflection could help to broaden our ideas of what innovation should be aimed at, and it also helps to recognize the limits of what can be achieved through innovation. Especially this last element might be needed in a time that extols innovation more than ever. 


\section{REFERENCES}

Achterhuis, H. (Ed.). (2001). American philosophy of technology: The empirical turn. Bloomington: Indiana University Press.

Aghion, P., Bloom, N., Blundell, R., Griffith, R., \& Howitt, P. (2005). Competition and Innovation: An Inverted-U Relationship. The Quarterly Journal of Economics, 120(2), 701-728. https://doi.org/10.1093/qje/120.2.701

Applbaum, A. I. (1999). Ethics for adversaries: The morality of roles in public and professional life. Princeton, N.J: Princeton University Press.

Arenas, D., Lozano, J. M., \& Albareda, L. (2009). The Role of NGOs in CSR: Mutual Perceptions Among Stakeholders. Journal of Business Ethics, 88(1), 175-197. https://doi.org/10.1007/s10551-009-0109-x

Ashforth, B. E., \& Reingen, P. H. (2014). Functions of Dysfunction: Managing the Dynamics of an Organizational Duality in a Natural Food Cooperative. Administrative Science Quarterly, 59(3), 474-516. https://doi.org/10.1177/0001839214537811

Auer, A., \& Jarmai, K. (2018). Implementing Responsible Research and Innovation Practices in SMEs: Insights into Drivers and Barriers from the Austrian Medical Device Sector. Sustainability, 10(1), 17. https://doi.org/10.3390/su10010017

Barbaroux, P. (2014). From market failures to market opportunities: Managing innovation under asymmetric information. Journal of Innovation and Entrepreneurship, 3(1), 5. https://doi.org/10.1186/2192-5372-3-5

Basu, K., \& Palazzo, G. (2008). Corporate Social Responsibility: A Process Model of Sensemaking. Academy of Management Review, 33(1), 122-136. https://doi.org/10.5465/amr.2008.27745504

Baur, D., \& Palazzo, G. (2011). The Moral Legitimacy of NGOs as Partners of Corporations. Business Ethics Quarterly, 21(04), 579-604. https://doi.org/10.5840/beq201121437

Baur, D., \& Schmitz, H. P. (2012). Corporations and NGOs: When Accountability Leads to Co-optation. Journal of Business Ethics, 106(1), 9-21. https://doi.org/10.1007/s10551-011-1057-9

Bendell, J. (2003). Talking for change? Reflections on effective stakeholder dialogue. In J. Andriof, S. Waddock, B. Husted, \& S. Sutherland Rahman (Eds.), Unfolding stakeholder thinking 2: Relationships, communication, reporting and performance (pp. 53-69). Sheffield, UK: Greenleaf.

Benjamin, M. (1990). Splitting the difference: Compromise and integrity in ethics and politics. Lawrence, Kan: University Press of Kansas. 
Berman, S. L., Wicks, A. C., Kotha, S., \& Jones, T. M. (1999). Does Stakeholder Orientation Matter? The Relationship Between Stakeholder Management Models and Firm Financial Performance. Academy of Management Journal, 42(5), 488-506. https://doi.org/10.5465/256972

Berry, W. (2010). The Pleasures of Eating. In What Are People For? (pp. 145-152). Berkeley, CA: Counterpoint.

Blok, V. (2014a). Look who's talking: Responsible innovation, the paradox of dialogue and the voice of the other in communication and negotiation processes. Journal of Responsible Innovation, 1(2), 171-190.

https://doi.org/10.1080/23299460.2014.924239

Blok, V. (2014b). The Metaphysics of Collaboration: Identity, Unity and Difference in Cross-sector Partnerships for Sustainable Development: Philosophy of Management, 13(2), 53-74. https://doi.org/10.5840/pom201413211

Blok, V. (2019). From participation to interruption: Toward an ethics of stakeholder engagement, Participation and Partnership in CSR and Responsible Innovation. In R. von Schomberg \& J. Hankins, International Handbook on Responsible Innovation (pp. 243-257). Edward Elgar Publishing. https://doi.org/10.4337/9781784718862.00024

Blok, V., Hoffmans, L., \& Wubben, E. F. M. (2015). Stakeholder engagement for responsible innovation in the private sector: Critical issues and management practices. Journal on Chain and Network Science, 15(2), 147-164. https://doi.org/10.3920/JCNS2015.x003

Blok, V., \& Lemmens, P. (2015). The Emerging Concept of Responsible Innovation. Three Reasons Why It Is Questionable and Calls for a Radical Transformation of the Concept of Innovation. In B.-J. Koops, I. Oosterlaken, H. Romijn, T. Swierstra, \& J. van den Hoven (Eds.), Responsible Innovation 2 (pp. 19-35). Retrieved from http://link.springer.com/10.1007/978-3-319-17308-5_2 Boatright, J. R. (2006). What's Wrong-And What's Right-With Stakeholder Management. The Journal of Private Enterprise, 22(2), 106-130.

Bogers, M. (2011). The open innovation paradox: Knowledge sharing and protection in R\&D collaborations. European Journal of Innovation Management, 14(1), 93-117. https://doi.org/10.1108/14601061111104715

Boiral, O. (2007). Corporate Greening Through ISO 14001: A Rational Myth? Organization Science, 18(1), 127-146. https://doi.org/10.1287/orsc. 1060.0224

Borgmann, A. (1988). Technology and the character of contemporary life: A philosophical inquiry (Paperback ed., 3. pr). Chicago: Univ. of Chicago Press. 
Borgmann, A. (1993). Crossing the postmodern divide. Chicago: Univ. of Chicago Press.

Bowen, F. (2019). Marking Their Own Homework: The Pragmatic and Moral Legitimacy of Industry Self-Regulation. Journal of Business Ethics, 156(1), 257-272. https://doi.org/10.1007/s10551-017-3635-y

Brand, T., \& Blok, V. (2019). Responsible innovation in business: A critical reflection on deliberative engagement as a central governance mechanism. Journal of Responsible Innovation, 6(1), 4-24. https://doi.org/10.1080/23299460.2019.1575681

Brittan, G. G. (2000). Technology and Nostalgia. In E. Higgs, A. Light, \& D. Strong (Eds.), Technology and the Good Life? (pp. 70-88). Chicago: University of Chicago Press.

Brown, J., \& Dillard, J. (2013). Critical accounting and communicative action: On the limits of consensual deliberation. Critical Perspectives on Accounting, 24(3), 176-190. https://doi.org/10.1016/j.cpa.2012.06.003

Burchell, J., \& Cook, J. (2006). Assessing the impact of stakeholder dialogue: Changing relationships between NGOs and companies. Journal of Public Affairs, 6(3-4), 210-227. https://doi.org/10.1002/pa.229

Burchell, J., \& Cook, J. (2007). Stakeholder dialogue and organisational learning: Changing relationships between companies and NGOs. Business Ethics: A European Review, 17(1), 35-46. https://doi.org/10.1111/j.14678608.2008.00518.x

Burchell, J., \& Cook, J. (2013a). CSR, Co-optation and Resistance: The Emergence of New Agonistic Relations Between Business and Civil Society. Journal of Business Ethics, 115(4), 741-754. https://doi.org/10.1007/s10551-0131830-z

Burchell, J., \& Cook, J. (2013b). Sleeping with the Enemy? Strategic Transformations in Business-NGO Relationships Through Stakeholder Dialogue. Journal of Business Ethics, 113(3), 505-518. https://doi.org/10.1007/s10551-0121319-1

Burget, M., Bardone, E., \& Pedaste, M. (2017). Definitions and Conceptual Dimensions of Responsible Research and Innovation: A Literature Review. Science and Engineering Ethics, 23(1), 1-19. https://doi.org/10.1007/s11948-016-9782-1

Chesbrough, H. W. (2003). The Era of Open Innovation. MIT Sloan Management Review, 44(3), 35-41.

Choi, J., \& Wang, H. (2009). Stakeholder relations and the persistence of corporate financial performance. Strategic Management Journal, 30(8), 895-907. https://doi.org/10.1002/smj.759 
Christmann, P., \& Taylor, G. (2006). Firm self-regulation through international certifiable standards: Determinants of symbolic versus substantive implementation. Journal of International Business Studies, 37(6), 863-878. https://doi.org/10.1057/palgrave.jibs. 8400231

Ciepley, D. (2013). Beyond Public and Private: Toward a Political Theory of the Corporation. American Political Science Review, 107(1), 139-158. https://doi.org/10.1017/S0003055412000536

Cohen, B., \& Winn, M. I. (2007). Market imperfections, opportunity and sustainable entrepreneurship. Journal of Business Venturing, 22(1), 29-49. https://doi.org/10.1016/j.jbusvent.2004.12.001

Cohen, J. (1997). Deliberation and Democratic Legitimacy. In J. Bohman \& W. Rehg (Series Ed.), Deliberative Democracy: Essays on Reason and Politics (pp. 6791). Cambridge MA: MIT Press.

Cohen, W. M., \& Levinthal, D. A. (1990). Absorptive Capacity: A New Perspective on Learning and Innovation. Administrative Science Quarterly, 35(1), 128 152. https://doi.org/10.2307/2393553

Crane, A., \& Livesey, S. (2003). Are you talking to me? Stakeholder communication and the risks and rewards of dialogue. In J. Andriof, S. Waddock, B. Husted, \& S. Sutherland Rahman (Eds.), Unfolding stakeholder thinking 2:

Relationships, communication, reporting and performance (pp. 39-52). Sheffield, UK: Greenleaf.

Crouch, C. (2011). The strange non-death of neoliberalism. Cambridge: Polity Press. Davis, L. N. (2001). R\&D Investments, Information and Strategy. Technology Analysis \& Strategic Management, 13(3), 325-342. https://doi.org/10.1080/09537320120088165

Dawkins, C. (2015). Agonistic Pluralism and Stakeholder Engagement. Business Ethics Quarterly, 25(1), 1-28. https://doi.org/10.1017/beq.2015.2

de Saille, S. (2015). Innovating innovation policy: The emergence of 'Responsible Research and Innovation.' Journal of Responsible Innovation, 2(2), 152-168. https://doi.org/10.1080/23299460.2015.1045280

Dean, T. J., \& McMullen, J. S. (2007). Toward a theory of sustainable entrepreneurship: Reducing environmental degradation through entrepreneurial action. Journal of Business Venturing, 22(1), 50-76. https://doi.org/10.1016/j.jbusvent.2005.09.003

den Hond, F., \& de Bakker, F. G. A. (2007). Ideologically motivated activism: How activist groups influence corporate social change activities. Academy of Management Review, 32(3), 901-924. https://doi.org/10.5465/AMR.2007.25275682 
Dryzek, J. S. (2001). Legitimacy and Economy in Deliberative Democracy. Political Theory, 29(5), 651-669. https://doi.org/10.1177/0090591701029005003

Dryzek, J. S. (2002). Deliberative democracy and beyond: Liberals, critics, contestations. Oxford: Oxford University Press.

Dubbink, W. (2004). The Fragile Structure of Free-Market Society: The Radical Implications of Corporate Social Responsibility. Business Ethics Quarterly, 14(1), 23-46. https://doi.org/10.5840/beq20041412

Dubbink, W., \& van de Ven, B. (2012). On the Duties of Commission in Commercial Life. A Kantian Criticism of Moral Institutionalism. Ethical Theory and Moral Practice, 15(2), 221-238. https://doi.org/10.1007/s10677-0119283-x

Dubbink, W., \& Van Liedekerke, L. (2014). Grounding Positive Duties in Commercial Life. Journal of Business Ethics, 120(4), 527-539. https://doi.org/10.1007/s10551-013-2003-9

Ellul, J. (2011). The technological society. New York, NY: Vintage books.

Elster, J. (2000). Arguing and Bargaining in Two Constituent Assemblies. Journal of Constitutional Law, 2(2), 345-421.

Erman, E. (2009). What is wrong with agonistic pluralism?: Reflections on conflict in democratic theory. Philosophy \& Social Criticism, 35(9), 1039-1062. https://doi.org/10.1177/0191453709343385

Ferguson, D. (2015, February 5). Online shopping: Which supermarket really delivers? The Guardian. Retrieved from https://www.theguardian.com/money/2015/may/02/online-shoppingsupermarkets-home-delivery (viewed 10 January 2020)

Flyvbjerg, B. (2006). Five Misunderstandings About Case-Study Research. Qualitative Inquiry, 12(2), 219-245. https://doi.org/10.1177/1077800405284363

Foster, D., \& Jonker, J. (2005). Stakeholder relationships: The dialogue of engagement. Corporate Governance: The International Journal of Business in Society, 5(5), 51-57. https://doi.org/10.1108/14720700510630059

Freeman, R. E. (1994). The Politics of Stakeholder Theory: Some Future Directions. Business Ethics Quarterly, 4(04), 409-421. https://doi.org/10.2307/3857340

Freeman, R. E. (2002). Stakeholder theory of the modern corporation. In T. Donaldson, P. H. Werhane, \& M. Cording (Eds.), Ethical issues in business: A philosophical approach (7th ed, pp. 38-48). Upper Saddle River, N.J: Prentice Hall. 
Freeman, R. E., Harrison, J. S., Wicks, A. C., Parmar, B., \& de Colle, S. (2010). Stakeholder theory: The state of the art. Cambridge; New York: Cambridge University Press.

Friedman, M. (1970, September 13). The social responsibility of business is to increase its profits. New York Times Magazine.

Fung, A. (2003). Recipes for Public Spheres: Eight Institutional Design Choices and Their Consequences. Journal of Political Philosophy, 11(3), 338-367. https://doi.org/10.1111/1467-9760.00181

Gamper-Rabindran, S., \& Finger, S. R. (2013). Does industry self-regulation reduce pollution? Responsible Care in the chemical industry. Journal of Regulatory Economics, 43(1), 1-30. https://doi.org/10.1007/s11149-012-9197-0

García-Marzá, D. (2005). Trust and Dialogue: Theoretical Approaches to Ethics Auditing. Journal of Business Ethics, 57(3), 209-219. https://doi.org/10.1007/s10551-004-8202-7

Garst, J., Blok, V., Branzei, O., Jansen, L., \& Omta, O. S. W. F. (2019). Toward a Value-Sensitive Absorptive Capacity Framework: Navigating Intervalue and Intravalue Conflicts to Answer the Societal Call for Health. Business \& Society. https://doi.org/10.1177/0007650319876108

Garst, J., Blok, V., Jansen, L., \& Omta, O. (2017). Responsibility versus Profit: The Motives of Food Firms for Healthy Product Innovation. Sustainability, 9(12), 2286. https://doi.org/10.3390/su9122286

George, B. (2003). Authentic leadership: Rediscovering the secrets to creating lasting value (1st ed). San Francisco: Jossey-Bass.

Gerring, J. (2004). What Is a Case Study and What Is It Good for? American Political Science Review, 98(02), 341-354. https://doi.org/10.1017/S0003055404001182

Gilbert, D. U., \& Rasche, A. (2007). Discourse Ethics and Social Accountability: The Ethics of SA 8000. Business Ethics Quarterly, 17(02), 187-216. https://doi.org/10.5840/beq200717230

Godin, B. (2015). Innovation contested: The idea of innovation over the centuries. New York, NY: Routledge.

Golob, U., \& Podnar, K. (2014). Critical points of CSR-related stakeholder dialogue in practice. Business Ethics: A European Review, 23(3), 248-257. https://doi.org/10.1111/beer.12049

Greenwood, M. (2007). Stakeholder Engagement: Beyond the Myth of Corporate Responsibility. Journal of Business Ethics, 74(4), 315-327. https://doi.org/10.1007/s10551-007-9509-y

Grinbaum, A., \& Groves, C. (2013). What Is "Responsible" about Responsible Innovation? Understanding the Ethical Issues. In R. Owen, J. Bessant, \& M. 
Heintz (Eds.), Responsible Innovation (pp. 119-142). Retrieved from http://doi.wiley.com/10.1002/9781118551424.ch7

Gupta, A. K., \& Lad, L. J. (1983). Industry Self-Regulation: An Economic,

Organizational, and Political Analysis. Academy of Management Review, 8(3), 416-425. https://doi.org/10.5465/amr.1983.4284383

Gutmann, A., \& Thompson, D. F. (1997). Democracy and disagreement (2nd ed.). Cambridge, Mass.: Belknap Press of Harvard University Press.

Habermas, J. (1985). The Theory of Communicative Action, Volume 1: Reason and the Rationalization of Society (T. MacCarthy, Trans.). Boston: Beacon.

Habermas, J. (1987). The Theory of Communicative Action, Volume 2: Lifeworld and System: A Critique of Functionalist Reason (T. MacCarthy, Trans.). Boston: Beacon.

Habermas, J. (1990). Moral Consciousness and Communicative Action. Cambridge, Mass: MIT Press.

Habermas, J. (1996). Between facts and norms: Contributions to a discourse theory of law and democracy. Cambridge, Mass: MIT Press.

Habermas, J. (1998). Three Normative Models of Democracy. In The Inclusion of the Other: Studies in Political Theory (Reprint, pp. 239-252). Cambridge: Polity Press.

Hahn, T., Figge, F., Pinkse, J., \& Preuss, L. (2018). A Paradox Perspective on Corporate Sustainability: Descriptive, Instrumental, and Normative Aspects. Journal of Business Ethics, 148(2), 235-248. https://doi.org/10.1007/s10551-017-3587-2

Hahn, T., Pinkse, J., Preuss, L., \& Figge, F. (2015). Tensions in Corporate Sustainability: Towards an Integrative Framework. Journal of Business Ethics, 127(2), 297-316. https://doi.org/10.1007/s10551-014-2047-5

Hartley, S., Pearce, W., \& Taylor, A. (2017). Against the tide of depoliticisation: The politics of research governance. Policy \& Politics, 45(3), 361-377. https://doi.org/10.1332/030557316X14681503832036

Hasnas, J. (1998). The Normative Theories of Business Ethics: A Guide for the Perplexed. Business Ethics Quarterly, 8(1), 19-42.

https://doi.org/10.2307/3857520

Hasnas, J. (2013). Whither Stakeholder Theory? A Guide for the Perplexed Revisited. Journal of Business Ethics, 112(1), 47-57. https://doi.org/10.1007/s10551012-1231-8

Haworth, L. (2000). Focal Things and Focal Practices. In E. Higgs, A. Light, \& D. Strong (Eds.), Technology and the Good Life? (pp. 55-69). Chicago: University of Chicago Press. 
Heath, J. (2006). Business Ethics Without Stakeholders. Business Ethics Quarterly, 16(4), 533-557. https://doi.org/10.5840/beq200616448

Heath, J. (2007). An Adversarial Ethic for Business: Or When Sun-Tzu Met the Stakeholder. Journal of Business Ethics, 72(4), 359-374. https://doi.org/10.1007/s10551-006-9175-5

Heath, J. (2011). Business Ethics and the 'End of History' in Corporate Law. Journal of Business Ethics, 102(S1), 5-20. https://doi.org/10.1007/s10551-0111192-3

Heath, J. (2014). Morality, competition, and the firm: The market failures approach to business ethics. Oxford ; New York: Oxford University Press, USA.

Heath, J. (2019). The Moral Status of Profit. In M. D. White (Ed.), The Oxford Handbook of Ethics and Economics (pp. 336-357). https://doi.org/10.1093/oxfordhb/9780198793991.013.20

Heidegger, M. (2013). The question concerning technology and other essays (W. Lovitt, Trans.). New York; London Toronto: HarperCollins Publishers.

Hendriks, C. (2011). The story behind the Dutch model: The consensual politics of wage restraint. Oisterwijk: BOXPress.

Hirschman, A. O. (1970). Exit, voice, and loyalty: Responses to decline in firms, organizations, and states. Cambridge, Mass: Harvard University Press.

Hirschman, A. O. (1994). Social Conflicts as Pillars of Democratic Market Society. Political Theory, 22(2), 203-218. https://doi.org/10.1177/0090591794022002001

Høvring, C. M., Andersen, S. E., \& Nielsen, A. E. (2018). Discursive Tensions in CSR Multi-stakeholder Dialogue: A Foucauldian Perspective. Journal of Business Ethics, 152(3), 627-645. https://doi.org/10.1007/s10551-016-3330-4

Hussain, W., \& Moriarty, J. (2018). Accountable to Whom? Rethinking the Role of Corporations in Political CSR. Journal of Business Ethics, 149(3), 519-534. https://doi.org/10.1007/s10551-016-3027-8

Iatridis, K., \& Schroeder, D. (2016). Responsible Research and Innovation in Industry. https://doi.org/10.1007/978-3-319-21693-5

Ihde, D. (1979). Technics and Praxis: A Philosophy of Technology. Dordrecht: Reidel.

Iivonen, K. (2018). Defensive Responses to Strategic Sustainability Paradoxes: Have Your Coke and Drink It Too! Journal of Business Ethics, 148(2), 309-327. https://doi.org/10.1007/s10551-017-3580-9

Jensen, M. C., \& Meckling, W. H. (1976). Theory of the firm: Managerial behavior, agency costs and ownership structure. Journal of Financial Economics, 3(4), 305-360. https://doi.org/10.1016/0304-405X(76)90026-X 
Johnson, J. (1991). Habermas on Strategic and Communicative Action. Political Theory, 19(2), 181-201. https://doi.org/10.1177/0090591791019002003

Johnson-Cramer, M. E., Berman, S. L., \& Post, J. E. (2003). Re-examining the concept of "stakeholder management." In J. Andriof, S. Waddock, B. Husted, \& S. Sutherland Rahman (Eds.), Unfolding stakeholder thinking 2:

Relationships, communication, reporting and performance (pp. 145-161). Sheffield, UK: Greenleaf.

Jones, T. M. (1995). Instrumental Stakeholder Theory: A Synthesis of Ethics and Economics. Academy of Management Review, 20(2), 404-437. https://doi.org/10.5465/amr.1995.9507312924

Kaptein, M., \& Van Tulder, R. (2003). Toward Effective Stakeholder Dialogue. Business and Society Review, 108(2), 203-224. https://doi.org/10.1111/1467-8594.00161

Keulartz, J., Schermer, M., Korthals, M., \& Swierstra, T. (2004). Ethics in Technological Culture: A Programmatic Proposal for a Pragmatist Approach. Science, Technology, \& Human Values, 29(1), 3-29. https://doi.org/10.1177/0162243903259188

Kirk, S. F. L., Penney, T. L., \& McHugh, T.-L. F. (2010). Characterizing the obesogenic environment: The state of the evidence with directions for future research. Obesity Reviews, 11(2), 109-117. https://doi.org/10.1111/j.1467-789X.2009.00611.x

Kirzner, I. M. (1973). Competition and entrepreneurship. Chicago: University of Chicago Press.

Knops, A. (2007). Debate: Agonism as Deliberation ? On Mouffe's Theory of Democracy. Journal of Political Philosophy, 15(1), 115-126. https://doi.org/10.1111/j.1467-9760.2007.00267.x

Koops, B.-J. (2015). The Concepts, Approaches, and Applications of Responsible Innovation. In B.-J. Koops, I. Oosterlaken, H. Romijn, T. Swierstra, \& J. van den Hoven (Eds.), Responsible Innovation 2: Concepts, Approaches, and Applications (pp. 1-15). Retrieved from http://link.springer.com/10.1007/978-3-319-17308-5_1

Koops, B.-J., Oosterlaken, I., Romijn, H., Swierstra, T., \& van den Hoven, J. (Eds.). (2015). Responsible innovation 2: Concepts, Approaches, and Applications. Retrieved from http://link.springer.com/book/10.1007/978-3-319-173085

Korthals, M. (2018). Goed eten: Filosofie van voeding en landbouw (Eating well: Philosophy of food and agriculture). Nijmegen: Uitgeverij Vantilt. 
Laudan, R. (2001). A Plea for Culinary Modernism: Why We Should Love New, Fast, Processed Food. Gastronomica: The Journal of Critical Food Studies, 1(1), 36-44.

Lee, R. G., \& Petts, J. (2013). Adaptive Governance for Responsible Innovation. In R. Owen, J. Bessant, \& M. Heintz (Eds.), Responsible Innovation (pp. 143-164). Retrieved from http://doi.wiley.com/10.1002/9781118551424.ch8

Lewis, M. W. (2000). Exploring Paradox: Toward a More Comprehensive Guide. The Academy of Management Review, 25(4), 760-776. https://doi.org/10.2307/259204

Lewis, M. W., \& Smith, W. K. (2014). Paradox as a Metatheoretical Perspective: Sharpening the Focus and Widening the Scope. The Journal of Applied Behavioral Science, 50(2), 127-149.

https://doi.org/10.1177/0021886314522322

Long, T. B., \& Blok, V. (2017). Integrating the management of socio-ethical factors into industry innovation: Towards a concept of Open Innovation 2.0. International Food and Agribusiness Management Review, 21(4), 463-486. https://doi.org/10.22434/IFAMR2017.0040

Lubberink, R., Blok, V., van Ophem, J., \& Omta, O. (2017a). A Framework for Responsible Innovation in the Business Context: Lessons from Responsible-, Social- and Sustainable Innovation. In L. Asveld, R. van Dam-Mieras, T. Swierstra, S. Lavrijssen, K. Linse, \& J. van den Hoven (Eds.), Responsible Innovation 3 (pp. 181-207). https://doi.org/10.1007/978-3-319-648347_11

Lubberink, R., Blok, V., van Ophem, J., \& Omta, O. (2017b). Lessons for Responsible Innovation in the Business Context: A Systematic Literature Review of Responsible, Social and Sustainable Innovation Practices. Sustainability, 9(5), 721. https://doi.org/10.3390/su9050721

Lynch-Wood, G., Williamson, D., \& Jenkins, W. (2009). The over-reliance on selfregulation in CSR policy. Business Ethics: A European Review, 18(1), 52-65. https://doi.org/10.1111/j.1467-8608.2009.01548.x

Maitland, I. (1994). The Morality of the Corporation: An Empirical or Normative Disagreement? Business Ethics Quarterly, 4(4), 445-458. https://doi.org/10.2307/3857343

Mäkinen, J., \& Kasanen, E. (2016). Boundaries Between Business and Politics: A Study on the Division of Moral Labor. Journal of Business Ethics, 134(1), 103-116. https://doi.org/10.1007/s10551-014-2419-x

Mansbridge, J. (2006). Conflict and Self-Interest in Deliberation. In S. Besson \& J. L. Martí (Eds.), Deliberative Democracy and its Discontents (pp. 107-132). Aldershot, England; Burlington, USA: Ashgate. 
Mansbridge, J. (2009). Deliberative and Non-deliberative Negotiations. Retrieved from https://dash.harvard.edu/handle/1/4415943

Mansbridge, J., Bohman, J., Chambers, S., Estlund, D., Føllesdal, A., Fung, A., ... Martí, J. L. (2010). The Place of Self-Interest and the Role of Power in Deliberative Democracy. Journal of Political Philosophy, 18(1), 64-100. https://doi.org/10.1111/j.1467-9760.2009.00344.x

Margolis, J. D., \& Walsh, J. P. (2003). Misery Loves Companies: Rethinking Social Initiatives by Business. Administrative Science Quarterly, 48(2), 268-305. https://doi.org/10.2307/3556659

Markell, P. (1997). Contesting Consensus: Rereading Habermas on the Public Sphere. Constellations, 3(3), 377-400. https://doi.org/10.1111/j.14678675.1997.tb00066.x

Martens, K. (2002). Mission Impossible? Defining Nongovernmental Organizations. Voluntas: International Journal of Voluntary and Nonprofit Organizations, 13(3), 271-285. https://doi.org/10.1023/A:1020341526691

Matten, D., \& Crane, A. (2005). Corporate Citizenship: Toward an Extended Theoretical Conceptualization. Academy of Management Review, 30(1), 166179. https://doi.org/10.5465/AMR.2005.15281448

Mena, S., \& Palazzo, G. (2012). Input and Output Legitimacy of Multi-Stakeholder Initiatives. Business Ethics Quarterly, 22(03), 527-556. https://doi.org/10.5840/beq201222333

Mena, S., \& Waeger, D. (2014). Activism for Corporate Responsibility: Conceptualizing Private Regulation Opportunity Structures: Private Regulation Opportunity Structures. Journal of Management Studies, 51(7), 1091-1117. https://doi.org/10.1111/joms.12092

Mitchell, R. K., Agle, B. R., \& Wood, D. J. (1997). Toward a Theory of Stakeholder Identification and Salience: Defining the Principle of Who and What Really Counts. Academy of Management Review, 22(4), 853-886. https://doi.org/10.5465/AMR.1997.9711022105

Monteiro, C. A. (2009). Nutrition and health. The issue is not food, nor nutrients, so much as processing. Public Health Nutrition, 12(05), 729-731. https://doi.org/10.1017/S1368980009005291

Moog, S., Spicer, A., \& Böhm, S. (2015). The Politics of Multi-Stakeholder Initiatives: The Crisis of the Forest Stewardship Council. Journal of Business Ethics, 128(3), 469-493. https://doi.org/10.1007/s10551-013-2033-3

Moriarty, J. (2014). The Connection Between Stakeholder Theory and Stakeholder Democracy: An Excavation and Defense. Business \& Society, 53(6), 820-852. https://doi.org/10.1177/0007650312439296 
Mouffe, C. (1999). Deliberative Democracy or Agonistic Pluralism? Social Research, 66(3), 745-758.

Mouffe, C. (2000a). Deliberative Democracy or Agonistic Pluralism. IHS Political Science Series, (72). Retrieved from http://irihs.ihs.ac.at/1312/

Mouffe, C. (2000b). The democratic paradox. London; New York: Verso.

Mouffe, C. (2005). On the political. London; New York: Routledge.

Néron, P.-Y. (2010). Business and the Polis: What Does it Mean to See Corporations as Political Actors? Journal of Business Ethics, 94(3), 333-352. https://doi.org/10.1007/s10551-009-0266-y

Néron, P.-Y. (2016). Rethinking the Ethics of Corporate Political Activities in a PostCitizens United Era: Political Equality, Corporate Citizenship, and Market Failures. Journal of Business Ethics, 136(4), 715-728. https://doi.org/10.1007/s10551-015-2867-y

Niskanen, T. (2012). A Finnish study of self-regulation discourses in the chemical industry's Responsible Care programme. Business Ethics: A European Review, 21(1), 77-99. https://doi.org/10.1111/j.1467-8608.2011.01638.x

Noland, J., \& Phillips, R. A. (2010). Stakeholder Engagement, Discourse Ethics and Strategic Management. International Journal of Management Reviews, 12(1), 39-49. https://doi.org/10.1111/j.1468-2370.2009.00279.x

Noorman, M., Swierstra, T., \& Zandbergen, D. (2017). Questioning the Normative Core of RI: The Challenges Posed to Stakeholder Engagement in a Corporate Setting. In L. Asveld, R. van Dam-Mieras, T. Swierstra, S. Lavrijssen, K. Linse, \& J. van den Hoven (Eds.), Responsible Innovation 3 (pp. 231-249). https://doi.org/10.1007/978-3-319-64834-7_13

Norman, W. (2011). Business Ethics as Self-Regulation: Why Principles that Ground Regulations Should Be Used to Ground Beyond-Compliance Norms as Well. Journal of Business Ethics, 102(S1), 43-57. https://doi.org/10.1007/s10551-011-1193-2

Norman, W. (2013a). Business Ethics. In H. Lafollette (Ed.), International Encyclopedia of Ethics. https://doi.org/10.1002/9781444367072.wbiee7 19 Norman, W. (2013b). Stakeholder Theory. In H. Lafollette (Ed.), International Encyclopedia of Ethics. Retrieved from http://doi.wiley.com/10.1002/9781444367072.wbiee690

Norman, W. (2015). Rawls on Markets and Corporate Governance. Business Ethics Quarterly, 25(01), 29-64. https://doi.org/10.1017/beq.2015.16

Orts, E. W., \& Strudler, A. (2009). Putting a Stake in Stakeholder Theory. Journal of Business Ethics, 88(S4), 605-615. https://doi.org/10.1007/s10551-009$0310-y$ 
Owen, R. (2014). Responsible Research and Innovation: Options for Research and Innovation Policy in the $E U$ [Report for the European Research and Innovation Area Board (ERIAB)]. Retrieved from https://ec.europa.eu/research/innovation-union/pdf/expertgroups/Responsible_Research_and_Innovation.pdf

Owen, R., Bessant, J. R., \& Heintz, M. (Eds.). (2013). Responsible innovation: Managing the responsible emergence of science and innovation in society. Chichester, West Sussex: John Wiley \& Sons Inc.

Owen, R., Macnaghten, P., \& Stilgoe, J. (2012). Responsible research and innovation: From science in society to science for society, with society. Science and Public Policy, 39(6), 751-760. https://doi.org/10.1093/scipol/scs093

Owen, R., Stilgoe, J., Macnaghten, P., Gorman, M., Fisher, E., \& Guston, D. (2013). A Framework for Responsible Innovation. In R. Owen, J. Bessant, \& M. Heintz (Eds.), Responsible Innovation (pp. 27-50). Retrieved from http://doi.wiley.com/10.1002/9781118551424.ch2

Paine, L. S. (2000). Does Ethics Pay? Business Ethics Quarterly, 10(1), 319-330. https://doi.org/10.2307/3857716

Palazzo, G., \& Scherer, A. G. (2006). Corporate Legitimacy as Deliberation: A Communicative Framework. Journal of Business Ethics, 66(1), 71-88. https://doi.org/10.1007/s10551-006-9044-2

Patzer, M., Voegtlin, C., \& Scherer, A. G. (2018). The Normative Justification of Integrative Stakeholder Engagement: A Habermasian View on Responsible Leadership. Business Ethics Quarterly, 28(3), 325-354.

https://doi.org/10.1017/beq.2017.33

Payne, S. L., \& Calton, J. M. (2002). Towards a Managerial Practice of Stakeholder Engagement. Journal of Corporate Citizenship, 2002(6), 37-52. https://doi.org/10.9774/GLEAF.4700.2002.su.00006

Pedersen, E. R. (2006). Making Corporate Social Responsibility (CSR) Operable: How Companies Translate Stakeholder Dialogue into Practice. Business and Society Review, 111(2), 137-163. https://doi.org/10.1111/j.14678594.2006.00265.x

Pellé, S. (2016). Process, outcomes, virtues: The normative strategies of responsible research and innovation and the challenge of moral pluralism. Journal of Responsible Innovation, 3(3), 233-254. https://doi.org/10.1080/23299460.2016.1258945

Phillips, R. A. (1997). Stakeholder Theory and A Principle of Fairness. Business Ethics Quarterly, 7(1), 51-66. https://doi.org/10.2307/3857232 
Phillips, R. A. (2003a). Stakeholder Legitimacy. Business Ethics Quarterly, 13(1), 25-41. https://doi.org/10.5840/beq20031312

Phillips, R. A. (2003b). Stakeholder theory and organizational ethics (1st ed.). San Francisco, Calif: Berrett-Koehler.

Phillips, R. A., Freeman, R. E., \& Wicks, A. C. (2003). What Stakeholder Theory is Not. Business Ethics Quarterly, 13(4), 479-502.

https://doi.org/10.5840/beq200313434

Pollan, M. (2014). Cooked: A natural history of transformation. New York, NY: Penguin Books.

Poole, M. S., \& van de Ven, A. H. (1989). Using Paradox to Build Management and Organization Theories. Academy of Management Review, 14(4), 562-578. https://doi.org/10.5465/AMR.1989.4308389

Rasche, A., \& Esser, D. E. (2006). From Stakeholder Management to Stakeholder Accountability: Applying Habermasian Discourse Ethics to Accountability Research. Journal of Business Ethics, 65(3), 251-267. https://doi.org/10.1007/s10551-005-5355-y

Rawls, J. (1987). The Idea Of An Overlapping Consensus. Oxford Journal of Legal Studies, 7(1), 1-25. https://doi.org/10.1093/ojls/7.1.1

Rescher, N. (1993). Pluralism: Against the demand for consensus. Oxford: New York: Clarendon Press; Oxford University Press.

Reynolds, M., \& Yuthas, K. (2008). Moral Discourse and Corporate Social Responsibility Reporting. Journal of Business Ethics, 78(1-2), 47-64. https://doi.org/10.1007/s10551-006-9316-x

Ribeiro, B. E., Smith, R. D. J., \& Millar, K. (2017). A Mobilising Concept? Unpacking Academic Representations of Responsible Research and Innovation. Science and Engineering Ethics 23, 81-103. https://doi.org/10.1007/s11948-016-9761-6

Rip, A. (2014). The past and future of RRI. Life Sciences, Society and Policy, 10, 17. https://doi.org/10.1186/s40504-014-0017-4

Roloff, J. (2008). Learning from Multi-Stakeholder Networks: Issue-Focussed Stakeholder Management. Journal of Business Ethics, 82(1), 233-250. https://doi.org/10.1007/s10551-007-9573-3

Rondinelli, D. A., \& London, T. (2003). How corporations and environmental groups cooperate: Assessing cross-sector alliances and collaborations. Academy of Management Perspectives, 17(1), 61-76. https://doi.org/10.5465/ame.2003.9474812

Roodenburg, A. J. C., Popkin, B. M., \& Seidell, J. C. (2011). Development of international criteria for a front of package food labelling system: The 
International Choices Programme. European Journal of Clinical Nutrition, 65(11), 1190-1200. https://doi.org/10.1038/ejcn.2011.101

Ruggiu, D. (2015). Anchoring European Governance: Two Versions of Responsible Research and Innovation and EU Fundamental Rights as 'Normative Anchor Points.' NanoEthics, 9(3), 217-235. https://doi.org/10.1007/s11569-015$0240-3$

Rummens, S. (2009). Democracy as a Non-Hegemonic Struggle? Disambiguating Chantal Mouffe's Agonistic Model of Politics. Constellations, 16(3), 377-391. https://doi.org/10.1111/j.1467-8675.2009.00548.x

Rummens, S. (2012). Staging Deliberation: The Role of Representative Institutions in the Deliberative Democratic Process. Journal of Political Philosophy, 20(1), 23-44. https://doi.org/10.1111/j.1467-9760.2010.00384.x

Sabadoz, C., \& Singer, A. (2017). Talk Ain't Cheap: Political CSR and the Challenges of Corporate Deliberation. Business Ethics Quarterly, 27(02), 183-211. https://doi.org/10.1017/beq.2016.73

Sanders, L. M. (1997). Against Deliberation. Political Theory, 25(3), 347-376. https://doi.org/10.1177/0090591797025003002

Scherer, A. G., Baumann-Pauly, D., \& Schneider, A. (2013). Democratizing Corporate Governance: Compensating for the Democratic Deficit of Corporate Political Activity and Corporate Citizenship. Business \& Society, 52(3), 473514. https://doi.org/10.1177/0007650312446931

Scherer, A. G., \& Palazzo, G. (2007). Toward a Political Conception of Corporate Responsibility: Business and Society Seen from a Habermasian Perspective. Academy of Management Review, 32(4), 1096-1120. https://doi.org/10.5465/AMR.2007.26585837

Scherer, A. G., \& Palazzo, G. (2011). The New Political Role of Business in a Globalized World: A Review of a New Perspective on CSR and its Implications for the Firm, Governance, and Democracy. Journal of Management Studies, 48(4), 899-931. https://doi.org/10.1111/j.1467-6486.2010.00950.x

Scherer, A. G., Rasche, A., Palazzo, G., \& Spicer, A. (2016). Managing for Political Corporate Social Responsibility: New Challenges and Directions for PCSR 2.0. Journal of Management Studies, 53(3), 273-298.

https://doi.org/10.1111/joms.12203

Scrinis, G. (2013). Nutritionism: The science and politics of dietary advice. New York, NY: Columbia Univ. Press.

Seitanidi, M. M., \& Crane, A. (2009). Implementing CSR Through Partnerships: Understanding the Selection, Design and Institutionalisation of NonprofitBusiness Partnerships. Journal of Business Ethics, 85(S2), 413-429. https://doi.org/10.1007/s10551-008-9743-y 
Selsky, J. W., \& Parker, B. (2005). Cross-Sector Partnerships to Address Social Issues: Challenges to Theory and Practice. Journal of Management, 31(6), 849-873. https://doi.org/10.1177/0149206305279601

Shane, S., \& Venkataraman, S. (2000). The Promise of Entrepreneurship as a Field of Research. Academy of Management Review, 25(1), 217-226.

https://doi.org/10.5465/AMR.2000.2791611

Singer, A. (2018). Justice Failure: Efficiency and Equality in Business Ethics. Journal of Business Ethics, 149, 97-115. https://doi.org/10.1007/s10551-0163086-x

Smith, J. D. (2004). A precis of a communicative theory of the firm. Business Ethics: A European Review, 13(4), 317-331. https://doi.org/10.1111/j.14678608.2004.00373.x

Smith, W. K., \& Lewis, M. W. (2011). Toward a Theory of Paradox: A Dynamic equilibrium Model of Organizing. Academy of Management Review, 36(2), 381-403. https://doi.org/10.5465/amr.2009.0223

Steenbergen, M. R., Bächtiger, A., Spörndli, M., \& Steiner, J. (2003). Measuring Political Deliberation: A Discourse Quality Index. Comparative European Politics, 1(1), 21-48. https://doi.org/10.1057/palgrave.cep.6110002

Stilgoe, J., Owen, R., \& Macnaghten, P. (2013). Developing a framework for responsible innovation. Research Policy, 42(9), 1568-1580. https://doi.org/10.1016/j.respol.2013.05.008

Suchman, M. C. (1995). Managing Legitimacy: Strategic and Institutional Approaches. Academy of Management Review, 20(3), 571-610. https://doi.org/10.5465/AMR.1995.9508080331

Tempels, T. (2019). A Janus-faced food industry? Ethical reflections on corporate responsibility for health (Wageningen University). https://doi.org/10.18174/501690

Thompson, D. F. (2008). Deliberative Democratic Theory and Empirical Political Science. Annual Review of Political Science, 11(1), 497-520. https://doi.org/10.1146/annurev.polisci.11.081306.070555

Timmermans, J. (2017). Mapping the RRI Landscape: An Overview of Organisations, Projects, Persons, Areas and Topics. In L. Asveld, R. van DamMieras, T. Swierstra, S. Lavrijssen, K. Linse, \& J. van den Hoven (Eds.), Responsible Innovation 3 (pp. 21-47). https://doi.org/10.1007/978-3-31964834-7_3

Timmermans, J., \& Blok, V. (2018). A critical hermeneutic reflection on the paradigm-level assumptions underlying responsible innovation. Synthese. https://doi.org/10.1007/s11229-018-1839-z 
Trumpy, A. J. (2008). Subject to Negotiation: The Mechanisms Behind Co-Optation and Corporate Reform. Social Problems, 55(4), 480-500.

https://doi.org/10.1525/sp.2008.55.4.480

Unerman, J., \& Bennett, M. (2004). Increased stakeholder dialogue and the internet: Towards greater corporate accountability or reinforcing capitalist hegemony? Accounting, Organizations and Society, 29(7), 685-707.

https://doi.org/10.1016/j.aos.2003.10.009

van de Kerkhof, M. (2006). Making a difference: On the constraints of consensus building and the relevance of deliberation in stakeholder dialogues. Policy Sciences, 39(3), 279-299. https://doi.org/10.1007/s11077-006-9024-5 van de Poel, I., Asveld, L., Flipse, S., Klaassen, P., Scholten, V., \& Yaghmaei, E. (2017). Company Strategies for Responsible Research and Innovation (RRI): A Conceptual Model. Sustainability, 9(11), 2045. https://doi.org/10.3390/su9112045

van de Ven, B., \& Jeurissen, R. (2005). Competing Responsibly. Business Ethics Quarterly, 15(2), 299-317. https://doi.org/10.5840/beq200515216 van den Hoven, J. (2013). Value Sensitive Design and Responsible Innovation. In R. Owen, J. Bessant, \& M. Heintz (Eds.), Responsible Innovation (pp. 75-83). Retrieved from http://doi.wiley.com/10.1002/9781118551424.ch4 van Huijstee, M., \& Glasbergen, P. (2008). The practice of stakeholder dialogue between multinationals and NGOs. Corporate Social Responsibility and Environmental Management, 15(5), 298-310.

https://doi.org/10.1002/csr.171

van Lente, H., Swierstra, T., \& Joly, P.-B. (2017). Responsible innovation as a critique of technology assessment. Journal of Responsible Innovation, 4(2), 254-261. https://doi.org/10.1080/23299460.2017.1326261

van Oudheusden, M. (2014). Where are the politics in responsible innovation? European governance, technology assessments, and beyond. Journal of Responsible Innovation, 1(1), 67-86. https://doi.org/10.1080/23299460.2014.882097

Van Tulder, R., Seitanidi, M. M., Crane, A., \& Brammer, S. (2016). Enhancing the Impact of Cross-Sector Partnerships: Four Impact Loops for Channeling Partnership Studies. Journal of Business Ethics, 135(1), 1-17. https://doi.org/10.1007/s10551-015-2756-4

Verbeek, P.-P. (2002). Devices of Engagement: On Borgmann's Philosophy of Information and Technology. Techné: Research in Philosophy and Technology, 6(1), 48-63. https://doi.org/10.5840/techne20026113 
Verbeek, P.-P. (2005). What things do: Philosophical reflections on technology, agency, and design (2nd printing). University Park, Pa: Pennsylvania State Univ. Press.

Voegtlin, C., \& Scherer, A. G. (2015). Responsible Innovation and the Innovation of Responsibility: Governing Sustainable Development in a Globalized World. Journal of Business Ethics. https://doi.org/10.1007/s10551-015-2769-z

Vogel, D. (2010). The Private Regulation of Global Corporate Conduct: Achievements and Limitations. Business \& Society, 49(1), 68-87. https://doi.org/10.1177/0007650309343407

von Schomberg, L., \& Blok, V. (2018). The turbulent age of innovation. Synthese. https://doi.org/10.1007/s11229-018-01950-8

von Schomberg, R. (2013). A Vision of Responsible Research and Innovation. In R. Owen, J. Bessant, \& M. Heintz (Eds.), Responsible Innovation (pp. 51-74). Retrieved from http://doi.wiley.com/10.1002/9781118551424.ch3 Walzer, M. (1999). Deliberation, and What Else? In S. Macedo (Ed.), Deliberative politics: Essays on democracy and disagreement (pp. 58-69). New York: Oxford University Press.

Wansink, B. (2010). Mindless eating: Why we eat more than we think (Bantam Books mass market ed). New York, N.Y: Bantam Books.

Warren, M. E., \& Mansbridge, J. (2013). Deliberative Negotiation. In Negotiating Agreement in Politics (pp. 86-120). Washington, D.C: American Political Science Association.

Westenholz, A. (1993). Paradoxical Thinking and Change in the Frames of Reference. Organization Studies, 14(1), 37-58. https://doi.org/10.1177/017084069301400104

Whelan, G. (2012). The Political Perspective of Corporate Social Responsibility: A Critical Research Agenda. Business Ethics Quarterly, 22(04), 709-737. https://doi.org/10.5840/beq201222445

Wickson, F., \& Carew, A. L. (2014). Quality criteria and indicators for responsible research and innovation: Learning from transdisciplinarity. Journal of Responsible Innovation, 1(3), 254-273. https://doi.org/10.1080/23299460.2014.963004

Wilson, M. (2003). Corporate sustainability: What is it and where does it come from? Ivey Business Journal, (March/April 2003), 1-5.

Winner, L. (2018). The Cult of Innovation: Its Myths and Rituals. In E. Subrahmanian, T. Odumosu, \& J. Y. Tsao (Eds.), Engineering a Better Future (pp. 61-73). https://doi.org/10.1007/978-3-319-91134-2_8 
Wong, P.-H. (2016). Responsible innovation for decent nonliberal peoples: A dilemma? Journal of Responsible Innovation, 3(2), 154-168. https://doi.org/10.1080/23299460.2016.1216709

Yaziji, M., \& Doh, J. P. (2009). NGOs and corporations: Conflict and collaboration. Cambridge: Cambridge University Press.

Yin, R. K. (2003). Case study research: Design and methods (3rd ed). Thousand Oaks, Calif: Sage Publications.

Zakhem, A. (2008). Stakeholder Management Capability: A Discourse-Theoretical Approach. Journal of Business Ethics, 79(4), 395-405. https://doi.org/10.1007/s10551-007-9405-5 


\section{SUMMARY}

In our time, innovation is considered an important way to address societal problems. In order reduce or even end our dependence on fossil fuels, we expect a lot from new sustainable technologies. In order to make our societies safer, a lot of resources are spent on innovative security systems. And, in order to make people healthier, we aim to improve the nutritional composition of food through innovation. That we expect so much from innovation to solve the challenges of our time, makes the question what could count as 'responsible innovation' more pressing. And that is what this thesis will be about.

This thesis starts out in chapter 1 with a general overview of the research questions, and discusses the concepts and theories I use in order to answer these questions. As the subtitle says, the aim of this thesis is to offer philosophical reflections on responsible innovation in the business context. Since that is still a quite broad topic, the main title suggests its further focus: deliberation and food. The first focus originates from the idea in the academic literature on responsible innovation, that innovators should not just assess by themselves what 'responsible' is, but should invite others (experts and lay people) to think along with them about the social and ethical aspects of innovation. In short, to engage in responsible innovation implies to engage with others in deliberation. Chapter 2 to 4 zoom in on this aspect of responsible innovation. The second focus has to do with the specific context of application, namely food and the food industry. Chapter 4 and 5 relate the topic of responsible innovation to this context.

In the literature on responsible innovation, different reasons are provided for the importance of discussing the social and ethical aspects of innovation with a broad set of stakeholders and members of society. For example, although researchers are often technical experts, they have limited knowledge about the ethical aspects of their work. In order to know what relevant values and norms for their work are, they need to discuss those with others. Furthermore, new products affect the lives of its users. Does it not make sense to give those users a voice about what the products they use should look like? Or to take into account the values relevant for them? Another reason is that researchers often spend public money. By given ordinary citizens a voice about how this money is spent, innovation processes can be 'democratized'. For these reasons, deliberation and inclusion are presented as central ideals of responsible innovation.

The question I raise in chapter 2 is whether the ideal of inclusive deliberation is suitable for innovation processes in businesses. I argue that this is not so easy, and provide different reasons why companies might not be willing to involve societal 
stakeholders into their innovation processes. First, setting up mechanisms for such forms of engagement about the innovation strategy of a company requires time and resources. The requirement of deliberation can therefore be tension with the ability of companies to exploit their innovations commercially within a competitive market. Second, deliberation requires a certain degree of transparency about the innovation strategy of a company. Companies might not be willing to provide this transparency, because they fear knowledge leakage to other companies. Third, companies are controlled most often by people with a financial stake. Therefore, we can expect that financial considerations are decisive in the investment decisions of companies. This could conflict with the ideal of responsible innovation to 'democratize' innovation processes. In chapter 2, I also discuss the place of deliberation in different approaches to business ethics. I show that these different approaches do not resolve the tension between the demands of deliberation and the competitive context of the market. Altogether, the introduction of deliberation as a way to conduct responsible innovation in companies can be quite challenging. Hence, I suggest that scholars should modify the ideal of deliberation in order to make it suitable to the business context, or they should suggest changes in the governance and regulation of markets so as to make deliberation more workable.

Another question for responsible innovation in business is how to deal with conflicting views between participants, as not everyone will have the same ideas about the desirable direction of innovation. Chapter 3 discusses the place of conflict and self-interest in deliberation. It starts with a discussion of the literature on stakeholder dialogue. In this literature, the ideal dialogue is presumed to aim at consensus. This also implies that participants avoid conflict and set self-interested considerations aside. I argue that this ideal of dialogue is problematic, especially for a dialogue between companies and NGOs. I show that companies can never completely set aside their profit-orientation, and hence that this 'self-interest' always influences their input in a dialogue. Furthermore, conflict and criticism can be necessary to make clear that societal problems require more attention, whether from the general public or from companies. Since the market is an imperfect institution, we need critical citizens and stakeholders such as NGOs to assess the behavior of companies. A certain degree of conflict between companies and NGOs may therefore be more desirable than a focus on consensus. For these reasons, I develop an alternative approach to dialogue (which I call agonistic deliberation) in which conflict and self-interest have a legitimate place, and can even play a productive role.

In chapter 4, a case-study is conducted to better understand how participants in a dialogue deal with conflicts. In this case-study, I analyzed different dialogues organized by the foundation 'Ik Kies Bewust', which issued a front-of-pack health label (known as 'Het Vinkje'). In this way, the chapter connects the topics of 
deliberation, food, and, indirectly, innovation, because the goal of the label was to stimulate healthy food innovation. In my analysis, I investigate the conflict between, on the one hand, the value of public health and healthy food, and, on the other hand, the commercial interests of companies. More specifically, I studied how companies deal with this conflict. They could not ignore this topic, because critics argued that the label gave unhealthy food a healthy image, and hence that it compromised on health goals in order to make profit. In their response to this criticism, three patterns became visible. First, companies frame their critics as not constructive, because, in their view, they only criticize but do not help to improve the label. Second, they stressed that they are really and genuinely motivated to make food healthier or to make a healthy food choice easier. Thereby, they seemingly tried to counter the image that they are just motivated to make profit. Third, they called on the government to take more control over the label, because this would make the label more reliable and more broadly adopted. I qualify these responses as defensive, which means that the conflict between commercial considerations and public interests is suppressed or ignored. An active response would require to recognize and confront the conflicts and dilemmas that companies face. The casestudy makes clear how difficult it can be to engage in dialogue with critical stakeholders.

The chapters 2, 3, and 4 concentrated on deliberation as a part of a responsible innovation process. Chapter 5 puts the innovation process between brackets and takes a substantive approach to responsible innovation. In this chapter, I reflect on how food innovation can be responsible. In trying to answer this question, I take a certain detour, by starting a discussion about the place of food in a life well-lived. For this purpose, I use the philosophy of Albert Borgmann. He argues that modern technology is characterized by a device paradigm, which entails that many modern technological devices provide us with goods and services without requiring effort or engagement. Despite the clear benefits of modern technology, Borgmann points at a downside, namely the loss of engagement, and the consequent loss of meaning that can be experienced in engagement. Engaging practices offer the possibility for maintaining and increasing skills, bodily exercise, and social interaction. What does this mean for the way we deal with food? I argue that there are good reasons for engaging with food in active way, for example by growing your own vegetables and home-cooking, instead of consuming food merely passively. I also draw some implications for food innovation. In my view, people responsible for food innovation should critically assess whether new products or services enhance engagement or disengagement. Is it desirable, for example, to develop even more and better pre-packaged meals, or should we stimulate consumers to cook by themselves? I argue that it would be problematic if our overall pattern of dealing 
with food is characterized by disengagement and convenience, and hence that food innovation should not only go in this direction.

The thesis closes with a discussion of the results (chapter 6). On the basis of chapter 2, 3, and 4, I conclude that deliberation with companies and their stakeholders about societal issues inevitably comes with tensions between actors and between different views on societal problems and their possible solutions. This has everything to do with the fact that the market is a nonideal and imperfect institution. We cannot take for granted that commercial interests coincide with public values, even when companies engage in deliberative processes with their stakeholders. The competitive structure of the market sets limits on what companies can achieve on their own in addressing social problems through innovation. Beyond that, it is important to recognize the limits of innovation as such in addressing societal problems. With regard to food, this implies to recognize that health problems can only very partially be addressed through food innovation. Reflection on responsible innovation can be valuable for many different reasons, but it is valuable already if it helps us to recognize just that. 


\section{SAMENVATTING}

In onze tijd wordt innovatie gezien als een veelbelovende manier om maatschappelijke problemen aan te pakken. We verwachten veel van nieuwe duurzame technologieën om onze afhankelijkheid van fossiele brandstoffen te verminderen of zelfs te beëindigen. Er worden veel middelen gespendeerd aan innovatieve veiligheidssystemen om onze maatschappijen veiliger te maken. En we proberen door innovatie de voedingssamenstelling van ons voedsel te verbeteren, om zodoende mensen gezonder te laten eten. Dat we zoveel van innovatie verwachten om de uitdagingen van onze tijd op te lossen, maakt de vraag naar wat 'maatschappelijk verantwoord innoveren' is des te dringender. Dat is dan ook het onderwerp dat ik in dit proefschrift centraal stel.

Dit proefschrift begint in hoofdstuk 1 met een algemeen overzicht van de onderzoeksvragen, en bespreekt de concepten en theorieën die ik gebruik om die vragen te beantwoorden. Zoals de ondertitel aangeeft, is het doel van dit proefschrift om filosofische reflecties te bieden over maatschappelijk verantwoord innoveren in de bedrijfscontext. Aangezien dat nog steeds een breed onderwerp is, suggereert de hoofdtitel de verdere focus: dialoog en voedsel. De eerste focus vindt zijn oorsprong in de gedachte (die wordt verdedigd in de wetenschappelijke literatuur over maatschappelijk verantwoorde innovatie) dat mensen die bezig zijn met innovatie niet slechts bij zichzelf te rade moeten gaan over de vraag wat 'verantwoord' is, maar anderen (experts en leken) zouden moeten uitnodigen om met hen mee te denken over de sociale en ethische aspecten van innovatie. Kort gezegd, maatschappelijk verantwoorde innovatie impliceert het aangaan van de dialoog met anderen. De hoofdstukken 2 tot en met 4 zoomen in op dit aspect van maatschappelijk verantwoord innoveren. De tweede focus heeft te maken met het toepassingsgebied met het oog waarop dit proefschrift is geschreven, namelijk voedsel en de voedingsindustrie. Hoofdstuk 4 en 5 relateren maatschappelijk verantwoorde innovatie aan dit toepassingsgebied.

In de wetenschappelijke literatuur over maatschappelijk verantwoord innoveren worden verschillende argumenten naar voren gebracht voor het belang van het bespreken van de sociale en ethische aspecten van innovatie met een brede groep belanghebbenden en burgers. Een van de argumenten is dat onderzoekers, ondanks het feit dat ze vaak technische experts zijn, beperkte kennis hebben over de ethische aspecten van hun werk. Om te weten te komen wat de relevante waarden en normen voor hun werk zijn, dienen ze daarover in gesprek te gaan met anderen. Een ander argument is dat nieuwe producten het leven van gebruikers beïnvloedt. Zou dat geen reden zijn om gebruikers een stem te geven in de vormgeving van die producten of 
in ieder geval de waarden die zij belangrijk vinden in acht te nemen? Nog een ander argument is dat veel onderzoek wordt gedaan met publiek geld. Door het geven van een stem aan burgers hoe dit geld wordt besteedt, kunnen innovatieprocessen worden 'gedemocratiseerd'. Vanwege deze redenen worden dialoog en inclusie gepresenteerd als de centrale idealen voor maatschappelijk verantwoord innoveren.

In hoofdstuk 2 stel ik de vraag of het ideaal van een inclusieve dialoog wel geschikt is voor innovatieprocessen in bedrijven. Ik betoog dat dit ideaal niet zo makkelijk te bereiken is, en geef verschillende redenen waarom bedrijven misschien niet zo graag maatschappelijke belanghebbenden zouden willen betrekken bij hun innovatieprocessen. Als eerste kost het tijd en middelen om mensen mee te laten praten over de innovatiestrategie van een bedrijf. Het aangaan van de dialoog kan daarom op gespannen voet staan met het commercieel exploiteren van innovaties in een competitieve markt. Als tweede vereist dialoog een bepaalde mate van transparantie over de innovatiestrategie van een bedrijf. De kans bestaat dat bedrijven die transparantie niet willen bieden, omdat ze bang zijn voor een kennislek naar andere bedrijven. Ten derde worden bedrijven meestal bestuurd door mensen met een financieel belang. We kunnen daardoor verwachten dat financiële overwegingen doorslaggevend zijn in de investeringsbeslissingen van bedrijven. Dit kan conflicteren met het ideaal van maatschappelijk verantwoord innoveren om innovatieprocessen te democratiseren. In hoofdstuk 2 bespreek ik ook de plaats van dialoog in verschillende benaderingen van bedrijfsethiek. Ik laat zien dat deze verschillende benaderingen de spanning tussen de eisen van dialoog en de competitieve context van de markt niet oplossen. Het invoeren van maatschappelijk verantwoord innoveren met een sterke nadruk op dialoog in bedrijven kan dus vrij ingewikkeld zijn. Daarom werp ik de suggestie op dat het ideaal van dialoog aangepast moet worden, of dat er wijzigingen moeten komen in de manier waarop het bedrijfsleven wordt gereguleerd om dialoog beter mogelijk te maken.

Een andere uitdaging voor maatschappelijk verantwoord innoveren in bedrijven is het omgaan met conflicterende opvattingen tussen deelnemers aan de dialoog, aangezien niet iedereen dezelfde opvattingen zal hebben over de gewenste innovatiekoers. Hoofdstuk 3 behandelt de plaats van conflict en eigenbelang in een dialoog. Het hoofdstuk begint met een bespreking van de literatuur over 'stakeholder dialoog'. In deze literatuur wordt consensus gezien als het hoogste doel van een dialoog. De implicatie daarvan is dat deelnemers conflict uit de weg gaan en overwegingen die betrekking hebben op hun eigenbelang parkeren. Ik beargumenteer dat dit ideaal problematisch is, in het bijzonder voor een dialoog tussen bedrijven en maatschappelijke organisaties (zoals NGOs). Ik laat zien dat bedrijven hun winstoriëntatie nooit helemaal aan de kant kunnen zetten, en dat deze vorm van eigenbelang altijd hun inbreng in een dialoog beïnvloedt. Vervolgens, 
conflict en kritiek kunnen nodig zijn om duidelijk te maken dat bepaalde maatschappelijke problemen meer aandacht behoeven, hetzij van bedrijven, hetzij van de bevolking in het algemeen. Aangezien de markt een onvolmaakte institutie is, hebben we kritische burgers en instellingen zoals NGOs nodig om het handelen van bedrijven te beoordelen. Een bepaalde mate van conflict tussen bedrijven en NGOs zou daarom weleens wenselijker kunnen zijn dan een gerichtheid op consensus. Om deze redenen heb ik een alternatieve benadering van dialoog ontwikkeld (die ik agonistische deliberatie noem), waarin conflict en eigenbelang een legitieme plaats hebben en zelfs een productieve rol kunnen spelen.

Hoofdstuk 4 beschrijft een casestudy met als doel om beter te begrijpen hoe deelnemers in een dialoog omgaan met conflicten. Voor deze casestudy heb ik verschillende dialogen geanalyseerd die georganiseerd waren door Ik Kies Bewust, de stichting achter het voormalige voedselkeuzelogo Het Vinkje. Dit hoofdstuk verbindt de onderwerpen dialoog, voedsel, en indirect ook innovatie, omdat het doel van het logo onder andere het stimuleren van innovatie in gezonde voeding was. In mijn analyse heb ik mij gericht op de spanning tussen enerzijds de waarde van publieke gezondheid en gezonde voeding en anderzijds de commerciële belangen van bedrijven. Ik heb in het bijzonder gekeken naar de manier waarop bedrijven zelf omgaan met deze spanning. Ze konden dit onderwerp tijdens de dialoog niet vermijden, aangezien critici beargumenteerden dat het logo ongezond voedsel een gezond imago gaf, en daarmee compromitteerde op de waarde van gezondheid ten gunste van commerciële bedrijfsbelangen. In de reactie van bedrijven op deze kritiek kwamen drie patronen naar voren. Als eerste beschreven bedrijven hun critici als 'niet constructief', omdat ze in hun optiek alleen kritiek leverden maar niet bijdroegen aan het verbeteren van het logo. Als tweede benadrukten ze dat ze wel degelijk oprecht gemotiveerd waren om voedsel gezonder te maken en de gezonde voedselkeuze voor de consument makkelijker te maken. Ze probeerden daarbij schijnbaar hun imago als op winst gerichte actoren bij te stellen. Als derde deden ze een beroep op de overheid om meer regie te nemen met betrekking tot het logo, aangezien dat ervoor zou kunnen zorgen dat het logo betrouwbaarder overkwam en breder gebruikt zou worden. Ik typeer deze reacties als defensief, omdat in deze reacties het conflict tussen commerciële en publieke belangen wordt onderdrukt of genegeerd. Een actieve reactie zou vereisen dat conflicten expliciet worden erkend en de confrontatie ermee wordt aangegaan. De casestudy maakt duidelijk hoe ingewikkeld het kan zijn om in dialoog te gaan met kritische belanghebbenden.

De hoofdstukken 2, 3 en 4 concentreren op dialoog als onderdeel van het proces van maatschappelijk verantwoord innoveren. In hoofdstuk 5 zet ik het proces tussen haakjes, en richt ik me meer inhoudelijk op de vraag wat maatschappelijk 
verantwoorde innovatie is. In dit hoofdstuk reflecteer ik op de vraag hoe voedselinnovatie verantwoord kan zijn. In het beantwoorden van deze vraag maak ik een omweg, door de plaats van voedsel in 'het goede leven' te bediscussiëren. Voor dit doel maak ik gebruik van de filosofie van Albert Borgmann. Hij beargumenteert dat moderne technologie wordt gekarakteriseerd door een 'apparaat-paradigma'. Dit paradigma houdt in dat veel moderne technologische middelen goederen en diensten leveren zonder betrokkenheid of inspanning van de kant van de consument te vereisen. Ondanks de overduidelijke voordelen van moderne technologie, wijst Borgmann op een keerzijde, namelijk het verlies van betrokkenheid en dientengevolge het verlies van betekenis. Praktijken die betrokkenheid vereisen, bieden namelijk de mogelijkheid voor lichamelijke oefening, sociale interactie en het ontwikkelen van vaardigheden. Wat betekent dit voor de manier waarop we met voedsel omgaan? Ik beargumenteer dat er goede redenen zijn om op een actieve manier met ons eten bezig te zijn in plaats van voedsel alleen maar passief te consumeren, bijvoorbeeld door je eigen groenten te verbouwen en zelf te koken. Ik trek ook een aantal lijnen naar voedselinnovatie. Mijns inziens zouden mensen die verantwoordelijk zijn voor voedselinnovatie kritisch moeten beoordelen of nieuwe producten of diensten leiden tot meer betrokkenheid of juist tot een gebrek daaraan. Is het bijvoorbeeld wenselijk om in te zetten op nog meer en betere voorverpakte maaltijden, of zouden consumenten gestimuleerd moeten worden om zelf te koken? Het zou problematisch zijn als onze omgang met voedsel wordt gekenmerkt door een gebrek aan betrokkenheid en een pure gerichtheid op gemak. Voedselinnovatie moet dus niet alleen gericht zijn op het ontlasten van consumenten, maar ook (of misschien wel juist) op het betrekken van consumenten.

Dit proefschrift sluit af met een bespreking van de resultaten (hoofdstuk 6). Op basis van hoofdstuk 2, 3 en 4, concludeer ik dat de dialoog tussen bedrijven en belanghebbenden over maatschappelijke onderwerpen onvermijdelijk gepaard gaat met spanningen tussen actoren en tussen verschillende opvattingen over maatschappelijke problemen en hun mogelijke oplossingen. Dat heeft alles te maken met het feit dat de markt een onvolmaakte institutie is. We kunnen er niet van uitgaan dat commerciële belangen altijd samen opgaan met publieke waarden, ook niet als bedrijven actief de dialoog aangaan met belanghebbenden. De competitieve structuur van de markt beperkt wat bedrijven in hun eentje kunnen bereiken als het gaat om het aanpakken van maatschappelijke problemen door middel van innovatie. Bovendien is het belangrijk om de beperkingen van innovatie als zodanig te erkennen als manier om maatschappelijke problemen aan te pakken. Met betrekking tot voedsel betekent dit dat gezondheidsproblemen slechts voor een klein deel aangepakt kunnen worden door voedselinnovatie. Reflectie op maatschappelijk 
verantwoord innoveren kan waardevol zijn vanwege veel verschillende redenen, maar het is al waardevol als het ons helpt om juist dat te realiseren. 


\section{ACKNOWLEDGEMENTS}

Although doing a PhD may sometimes feel like one of the loneliest jobs on earth, it is also a job that cannot be completed without the help of others. Acknowledging this help is therefore the right way to close this thesis.

To start with, I want to thank my supervisors Vincent and Marcel. Vincent, I am thankful for the fact that you were always willing to make time for me. Even though you had quite a lot of PhDs during my stay in Wageningen, you made the time to discuss the direction of my research and to give feedback on texts. I also like that you stimulated me to read philosophical classics as part of my TSP. Despite the fact that this thesis does not have any reference to Aristotle, Descartes, or Kant, I will never regret that I read and summarized some of their major works during my $\mathrm{PhD}$. You also encouraged me to be involved in teaching and to present my research on conferences, through which I developed skills beyond those needed for writing scientific papers. Thank you!

Marcel, it was always a good experience to discuss texts with you. I was often insecure about what I produced, but you made me feel more confident. As I remember it, you always started a conversation with positive feedback, and gave concrete suggestions for improving the texts. You also pushed me to be precise and define the concepts I use in a clear way. Thanks a lot!

Working with Vincent also means being part of a 'team'. The weekly coffee meeting is probably the most significant institution of this team. We did not only talk about research, but also about politics, movies, holidays, and much more. It has been a pleasure to work with August, Tjidde, Lisa, Rob, Jilde, Mmapatla, Waliou, Daniel, Thomas, Lucien, Saskia, Edurne, Job, Peter, and Eugen. Besides the team I should not forget our smaller NWO-project team, of which (besides Vincent, Marcel, and Jilde) Léon was also a part. Thank you for constructively thinking along with my research.

I want to thank the people of both the BMO group and the Philosophy group for the good time we had. I look back to interesting colloquia and lunches with the 'philosophers', and to instructive 'brown bag seminars' and sociable $\mathrm{PhD}$ meetings at BMO. I want to mention some persons in particular. Tjidde, your research was close to mine, and I have very good memories of our coffee breaks in which we gave feedback on each other's work, but also shared frustrations, and discussed future plans. Annemarie, it was nice to recognize that we had similar interests (like 
gardening), combined with a shared ambivalent relation to our $\mathrm{PhD}$ ("do I really want to do this?"). My thanks also go to Ina, Linette, Liesbeth, and Marloes, not only for their practical assistance, but also for the daily talks we had around the coffee machine and in the secretariat office. I am also grateful to Inge, who supported me with the practicalities towards the defense.

I turn to Dutch for the remaining words of thanks. Allereerst mijn kamergenoot Jilde. Je doet je onderzoek met passie, en je zet je met veel energie in voor de groep. Je hecht er ook veel waarde aan dat je werk een bijdrage levert aan de maatschappij. Dat je zo betrokken bent, betekent ook dat je je flink kunt opwinden over van alles en nog wat. Daar heb ik weleens om moeten glimlachen. Als je je aan iets ergerde, was mijn reactie vaak 'ach ja, er gaat overal weleens iets mis', terwijl jij uitgebreide mails begon te typen met wat er mis was en hoe het beter kan. Het geeft in ieder geval aan dat je je met hart en ziel inzet in alles wat je doet, en daar heb ik respect voor. Bedankt voor de goede tijd die we hebben gehad!

Ik wil Geerten, Kees en Wilco bedanken voor hun vriendschap. Hoewel jullie als theologen wellicht weinig feeling hebben met de inhoud van dit proefschrift, weten jullie wat het is om onderzoek te doen en te schrijven. Wilco, jij in het bijzonder bedankt voor de vele goede gesprekken die we voerden via Skype en Facetime. Ik wil ook Aad bedanken voor de immer opbeurende telefoongesprekken die we regelmatig hadden tijdens onze middagwandeling.

Het meest dankbaar ben ik voor de plek die thuis heet. Als ik daar aankwam na een (voor mijn gevoel) onproductieve dag, waren Suze en Stef de zonnetjes die de dag licht maakten. Jullie hielpen mij altijd weer om mijn werk te relativeren en te genieten van wat we met elkaar hebben. Nienke, ik weet niet waar ik zou zijn zonder jou. In ieder geval niet in Oene op een prachtige woonboerderij met een lap grond, de plek waar het (in de zomer) nog altijd als vakantie voelt. Bedankt voor je ondernemingszin, je creativiteit, je nuchterheid en je vertrouwen in mij. Ik hou van je! 


\section{Teunis Brand}

Wageningen School of Social Sciences (WASS)

Completed Training and Supervision Plan

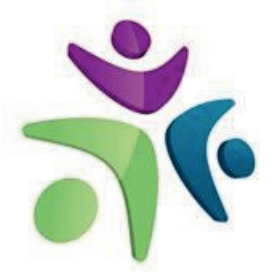

Wageningen School

of Social Sciences

Name of the learning activity

Department/Institute Year

ECTS*

\section{A) Project related competences}

Philosophy of Responsible Innovation

OZSW

2015

5

Philosophy and Ethics of Food Science and WGS

2016

1,5

Technology

Deliberative Democracy'

Writing research proposal
Radboud University

Nijmegen

WUR/BMO

2018

6

$2015-2016 \quad 6$

\section{B) General research related competences}

WASS Introduction Course

Reading of philosophical classics

'A Free Market for Responsible

Innovation?'

'Struggling for Moral Legitimacy'

'Communicative Action and Beyond'

'Responsibility versus Profit: Responsible Innovation in the Dutch Food Industry'

'Paradoxes in Stakeholder Dialogue'
WASS

WUR/PHI

Philosophy of

Management

Conference

Business \& Society

Conference

OZSW Annual

Conference

NOW-MVI Annual

2018

Conference

European Business

2018

Ethics Conference
2017

1

2015

2015-2017 6

2016

1

2017

1

1

\section{C) Career related competences/personal development}


Teaching CPT 38306

Efficient Writing Strategies

Brain-friendly Working and Writing

Total

WUR

2016-2018 4

WGS

2018

2018

WGS

0.3

36.1

*One credit according to ECTS is on average equivalent to 28 hours of study load 


\section{COLOPHON}

The research described in this thesis was funded by a grant of the Netherlands Organization for Scientific Research (NWO), partially supported by the Dutch Choices Foundation.

Financial support from Wageningen University for printing this thesis is gratefully acknowledged.

Cover design: Vera van Beek

Printed by: Digiforce / Proefschriftmaken

Contact: teunisbrand89@gmail.com

Copyright (C) 2020, Teunis Brand, Oene. 

